Universidade de SÃo PaUlo

Faculdade de Filosofia, Letras e Ciências Humanas

Departamento de Letras Clássicas e Vernáculas

Programa de Pós-GraduaÇão em Filologia e Língua Portuguesa

VAnessa Pinheiro de Araújo

Um Dicionário Principense-Português 


\author{
Universidade de SÃo Paulo \\ Faculdade de Filosofia, Letras e Ciências Humanas \\ Departamento de Letras Clássicas e Vernáculas \\ Programa de Pós-graduaÇão em Filologia e Língua Portuguesa
}

VAnessa Pinheiro de Araújo

\title{
Um Dicionário Principense-PortuguêS
}

\begin{abstract}
Dissertação apresentada ao Programa de Pós-graduação em Filologia e Língua Portuguesa do Departamento de Letras Clássicas e Vernáculas da Faculdade de Filosofia, Letras e Ciências Humanas da Universidade de São Paulo, como requisito parcial para a obtenção do título de Mestre em Filologia e Língua Portuguesa.
\end{abstract}

Orientador: Prof. Dr. Gabriel Antunes de Araújo 


\section{Sumário}

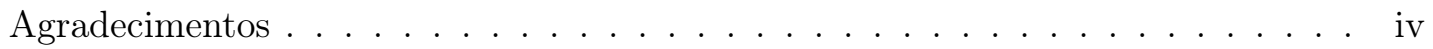

Resumo ................................ vi

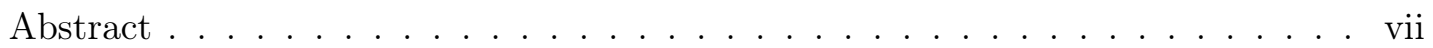

Lista de Abreviaturas . . . . . . . . . . . . . . . . . . viii

1 Introdução 1

1.1 Introdução . . . . . . . . . . . . . . . . . . . . . . . . . 1

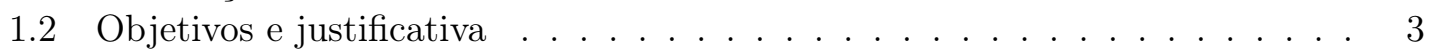

1.3 Historiografia e situação sociolinguística . . . . . . . . . . . . . . 6

1.4 Material, métodos e forma de análise dos resultados . . . . . . . . . . . . 9

1.5 Acesso à ilha do Príncipe . . . . . . . . . . . . . . . . . . . . . 11

1.6 Trabalho de campo . . . . . . . . . . . . . . . . . . . . . . . . 13

1.7 Linguística de contato e considerações iniciais . . . . . . . . . . . . . . . 14

1.7.1 Definição do termo crioulo . . . . . . . . . . . . . . . . . . 14

1.7.2 Hipóteses de formação dos crioulos . . . . . . . . . . . . . . . 17

1.7.3 Propostas para a formação dos crioulos do Golfo da Guiné . . . . . . 20

2 Principense 22

2.1 Introdução . . . . . . . . . . . . . . . . . . . . . . . . . . . 22

2.2 Breve descrição fonológica do principense . . . . . . . . . . . . . . . . . 22

2.2 .1 Sistema vocálico . . . . . . . . . . . . . . . . . . . . 22

2.2 .2 Sistema consonantal . . . . . . . . . . . . . . . . 23

2.2 .3 Sílaba . . . . . . . . . . . . . . . . . . . 25

2.2 .4 Tonologia . . . . . . . . . . . . . . . . . . 26

2.3 Grafia . . . . . . . . . . . . . . . . . . . . 27

3 Lexicografia 32

3.1 Introdução . . . . . . . . . . . . . . . . . . . . . . . . . . . 32

3.2 Definição de uma obra lexicográfica . . . . . . . . . . . . . . . . . . . 32

3.3 Dicionário bilíngue e sua proposta . . . . . . . . . . . . . . . 35

3.3.1 Funcionalidade, direcionalidade e reciprocidade . . . . . . . . . . 37

3.4 Dicionário principense . . . . . . . . . . . . . . . . . . 37

3.4 .1 Macro e microestrutura . . . . . . . . . . . . . . . 38

3.4.1.1 Macroestrutura. . . . . . . . . . . . . . 38

3.4.1.2 Microestrutura . . . . . . . . . . . . . . . 39

4 Considerações finais $\quad 42$

5 Referências bibliográficas $\quad 44$

A Dicionário Principense-Português 49 


\section{Agradecimentos}

Agradeço aqui a todos os que contribuíram direta ou indiretamente para a realização desse projeto:

- Em primeiro lugar gostaria de agradecer à minha família: meu pai, minha mãe e meus irmãos pelo companheirismo, dedicação, incentivo e carinho;

- Aos meus amigos Lisandra, Daniel, Wânia, Fernanda, Oliver, Renata e todos os outros agradeço pelo afeto, amizade e disponibilidade em ajudar nas mais diversas situações;

- Ao professor Dr. Gabriel Antunes de Araújo pela orientação, sempre atenciosa, e pela leitura cuidadosa das versões desse trabalho, que contribuiu de forma incalculável na discussão dos dados e na elaboração de toda a pesquisa;

- À Ana Lívia dos Santos Agostinho pela doçura infinita e pela disposição a não somente compartilhar os dados como também verificar todas as entradas (várias vezes) e discutir vários pontos da fonologia e da morfossintaxe da língua;

- Às professora Dra. Márcia Duarte dos Santos Oliveira e Dra. Mariângela Araújo pela leitura do trabalho e por valiosos comentários;

- Ao povo da Ilha do Príncipe e ao Presidente do Conselho Regional José Cassandra. Ao padre Fabiàn, Mimi, Diana, Carina e Papito pela amizade e toda a ajuda durante as minhas estadias no Príncipe;

- Aos informantes Salomé, Juju, Paz, Siel e esposa, Marcelo, Dinha;

- À Embaixada do Brasil por todo o apoio durante as visitas às ilhas e principalmente à Raquel e Naduska;

- Aos colegas de curso e membros da audiência em todos os lugares onde o trabalho foi apresentado;

- Ao CNPq, pela bolsa processo 490509/2008-8; 
- À FAPESP, pela bolsa concedida durante a iniciação científica (processo n. 2007/04462-8) e durante o mestrado (processo n. 2009/12980-4).

É importante salientar que todas as pessoas que ajudaram ou leram o meu trabalho não são, de forma alguma, responsáveis pelos eventuais erros que permanecerem. 


\section{Resumo}

O objetivo dessa dissertação é apresentar um dicionário bilíngue principense/português, bem como seu processo de produção. O dicionário foi elaborado a partir de dados coletados em trabalho de campo original obtidos em viagens à ilha do Príncipe e da compilação de dados retirados da literatura. No que diz respeito à microestrutura dos verbetes, o dicionário contém anotação (ortográfica, transcrição fonética, rubrica gramatical e equivalência em português. Neste trabalho, também apresento uma abordagem da problemática do acesso à língua, da coleta de dados e da formação desse tipo de lista. Todo o material foi anotado considerando a proposta ortográfica do ALUSTP (Alfabeto Unificado para a Escrita das Línguas Nativas de S. Tomé e Príncipe), aprovada em 2012 pelo Governo de São Tomé e Príncipe como grafia oficial das línguas nacionais. Em última análise, disponibilizamos um instrumento linguístico que poderá ser útil tanto para os habitantes da ilha do Príncipe como para a comunidade científica e, dessa forma, preencher uma lacuna em relação à inexistência de materiais paradidáticos bilíngues principense/português, que possa auxiliar no ensino da língua principense nas escolas.

Palavras-chave: Principense, português, dicionário, lexicografia, São Tomé e Príncipe. 


\section{Abstract}

The aim of this work is to present a bilingual dictionary Principense-Portuguese, as well as explain the proceedings taken in the compilation. The dictionary was compiled from data collected in original fieldwork obtained on trips to the island of Principe and compiling data from the literature. Regarding the microstructure of the lexical entries, the dictionary contains annotation (spelling, phonetic transcription, grammatical category and the equivalent in Portuguese. This paper also presents an approach to issues of access to language, data collection and formation of such list. All material was recorded considering the draft of Alfabeto Unificado das Línguas Nativas de São Tomé e Príncipe- ALUSTP (Unified Alphabet for the Writing of Native Languages of São Tomé and Príncipe), approved in 2012 by the Government of São Tome and Príncipe as an official orthography to the national languages. In conclusion, we provide a linguistic tool that can be useful both for the inhabitants of the island of Principe, as to the scientific community and thus fill a gap in relation to the lack of bilingual educational materials Principense-Portuguese, that can provide assistance in teaching principense language in schools.

Keywords: Principense, Portuguese, dictionary, lexicography, São Tomé and Principe. 


\section{Lista de Abreviaturas}

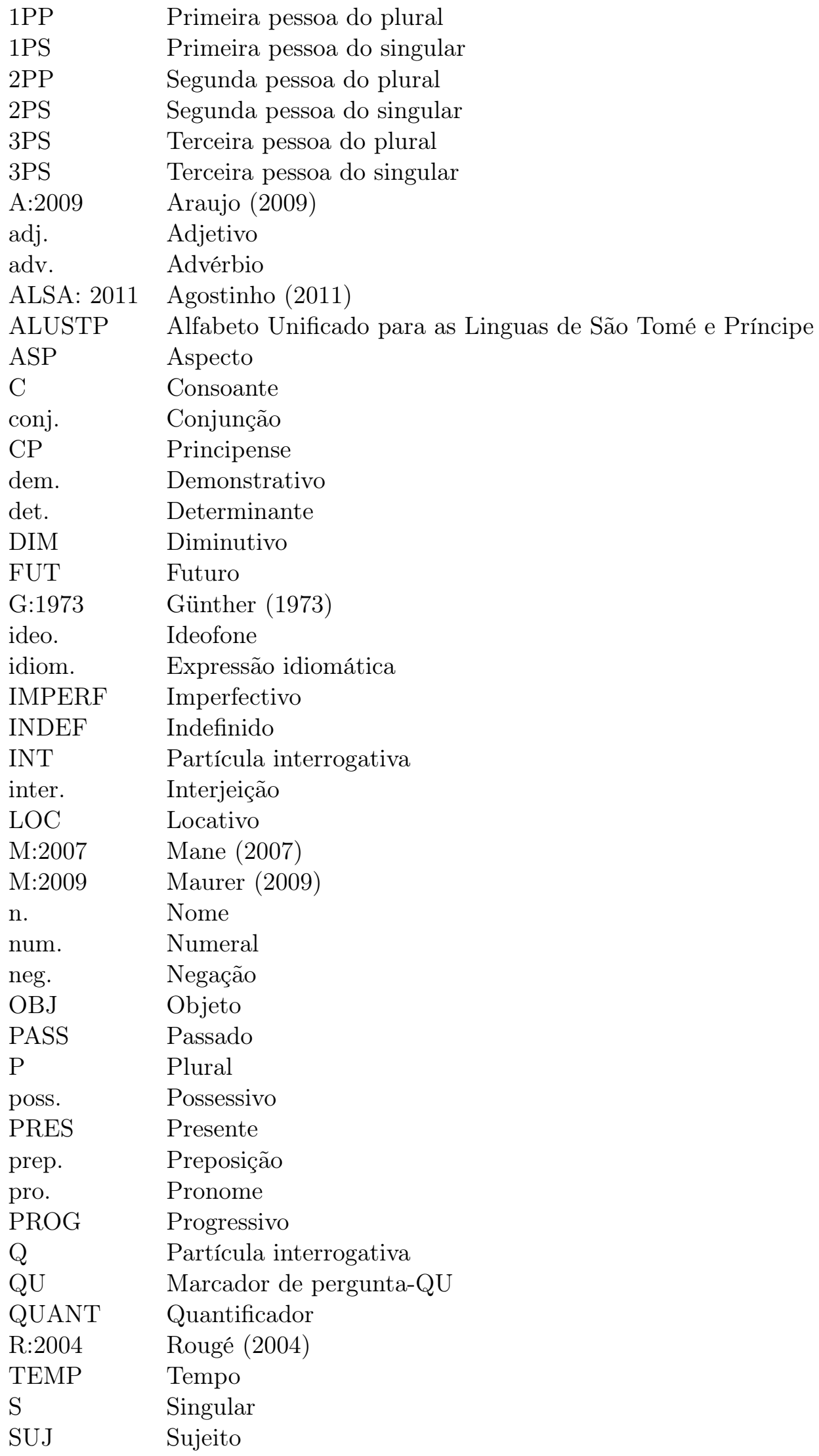




$\begin{array}{ll}\text { TAM } & \text { Tempo-aspecto-modo } \\ \text { top. } & \text { Topônimo } \\ \text { USP } & \text { Universidade de São Paulo } \\ \text { V } & \text { Vogal } \\ \text { v. } & \text { Verbo } \\ \text { VPA:2009 } & \text { Araújo (2009) } \\ \text { VPA:2011 } & \text { Araújo }(2011)\end{array}$




\section{Capítulo 1}

\section{Introdução}

\subsection{Introdução}

O objetivo deste trabalho é apresentar um Dicionário bilíngue Principense-Português, produzido a partir da coleta de dados in loco com falantes nativos e da reunião de dados provenientes de materiais publicados sobre a língua principense, dentre eles, Negreiros (1895), Valkhoff (1966), Günther (1973), Ferraz (1979), Rougé (2004), Mane (2007) e Maurer (2009). O dicionário encontra-se no capítulo ANEXO.

Os dados obtidos nos trabalhos de campo, bem como aqueles oriundos de material publicado foram formatados, inicialmente, no programa Toolbox seguindo o padrão gráfico do Alfabeto Unificado para a Escrita das Línguas Nativas de São Tomé e Príncipe (ALUSTP). As convenções do ALUSTP, bem como a metodologia utilizada será tratada adiante. Ao final do trabalho de edição, os dados do dicionário foram formatados com o programa TexWorks. Os verbetes do dicionário contêm notação gráfica, forma fonética, rubrica gramatical, tradução/equivalências em português, exemplos de sentenças em palavras funcionais e referências de uso de autoridade (quando aplicável).

O principense, uma língua ainda pouco estudada, é falada na Ilha do Príncipe, na República de São Tomé e Príncipe (STP). Há poucos trabalhos publicados sobre o principense, dos quais Rougé 2004 e Maurer 2009 são os mais conhecidos, porém não há um 
dicionário inteiramente dedicado a essa língua. No que diz respeito à lexicografia do principense, há pequenas listas de palavras, normalmente referentes ao léxico utilizado em textos específicos, como as de Ribeiro 1888 (apud Maurer 2009), Günther (1973), Rougé 2004 e Maurer 2009. Assim, o dicionário ora apresentado pretende ser o primeiro material dessa natureza cuja língua-veículo é o português, língua oficial e de escolarização do país, portanto, acessível também à população de STP.

A língua principense, localmente denominada lung'ie (literalmente 'língua da ilha') está em risco de extinção. A diminuição da população étnica, a escolarização em português, políticas de desvalorização das línguas nacionais de STP no período colonial e o acesso aos meios de comunicação fizeram com que o português alcançasse um prestígio crescente e o principense fosse relegado a um papel secundário no tabuleiro linguístico do pequeno país africano. Dessa forma, a situação de ameaça ao principense, associada à necessidade de produção de instrumentos linguísticos impressos que possam ajudar na manutenção e na preservação do idioma, foram as justificativas para esta pesquisa. Além disso, a imagem das línguas crioulas como 'imperfeitas' entre os habitantes da ilha do Príncipe, em particular, e de STP, em geral, a inexistência de letramento em língua principense e a precariedade do mundo da escrita em São Tomé e Príncipe são fatores que desestimularam os esforços para a preservação e manutenção das línguas crioulas santomenses. De um lado, o dicionário aqui apresentado ajudará a preencher parcialmente essa lacuna, além de servir como instrumento para a difusão da língua principense dentro e fora da comunidade. De outro lado, o dicionário poderá revelar um pouco da complexidade cultural e a herança linguística da ilha do Príncipe. Além de sua relevância para a comunidade científica, junto com a gramática pedagógica produzida por Ana Lívia dos Santos Agostinho (em preparação), são instrumentos linguísticos que podem atender a população da 
ilha, auxiliando no aprendizado da língua nas escolas, bem como servir de apoio a futuros projetos educacionais e de promoção da literatura em língua nativa.

Aragonés (2004) considera o dicionário não só uma obra linguística, mas também um instrumento cultural, pois inclui informação extra-linguística (enciclopédica, etnográfica, antropológica e ideológica) que transmite e difunde socialmente, confirmadas como norma de uso, palavras com informação sobre o mundo e sobre a cultura da comunidade de fala. Desta forma, o escopo do dicionário não é somente linguístico, constituindo-se também uma tentativa de preservação cultural.

O capítulo está organizado da seguinte forma: em 1.2 apresento os objetivos e justificativas para o projeto seguido da historiografia e situação sociolínguística do principense em 1.3, e da metodologia e forma de análise dos resultados em 1.4. Em 1.5 trato das questões pertinentes ao acesso à ilha e das dificuldades do trabalho de campo em 1.6. A seção 1.7 apresenta algumas considerações a respeito da linguística de contato e é dividida em três sub itens: tem-se em 1.7.1 a definição do termo crioulo, em 1.7.2 as hipóteses de formação e finalmente, em 1.7.3 as propostas para formação dos crioulos do Golfo da Guiné.

\subsection{Objetivos e justificativa}

A proposta inicial do trabalho consistia na elaboração de um dicionário que contivesse transcrições gráficas e fonéticas (ambas em principense) e o equivalente em português, com a respectiva tradução/equivalência em português do material coletado em fontes impressas (Negreiros 1895, Valkhoff 1966, Reis 1969, Günther 1973, Ferraz 1979, Rougé 2004, Mane 2007 e Maurer 2009). Nas entradas do dicionário, apenas a base lexical conteria as formas fonéticas. Haveria, ainda, a rubrica gramatical (verbo, nome, pronome, etc.) e, em seguida, a descrição semasiológica do verbete. Nos casos de palavras funcionais, seriam apresentados também alguns exemplos (retirados da literatura ou das fontes secundárias), seguidos da 
tradução em português. Assim, na fase inicial, parti dos trabalhos publicados sobre o principense para formar a primeira parte da lista cujo resultado seria o dicionário da língua principense. Contudo, a partir do segundo ano da pesquisa, o projeto foi ampliado para incluir dados coletados em trabalho de campo. Em março de 2009, estive na ilha do Príncipe (graças a um financiamento do Conselho Nacional de Desenvolvimento Científico e Tecnológico (CNPq), programa Pró-África, processo 490509/2008-8) e pude coletar meus próprios dados. Ao mesmo tempo, todo o material coletado da literatura foi verificado com falantes nativos e ampliado em outras viagens de trabalho de campo. Os trabalhos de campo posteriores a 2009 contaram com o apoio financeiro da Fundação de Amparo à Pesquisa do Estado de São Paulo (FAPESP), processo 2009/12980-4.

Como mencionado, não há um dicionário dedicado exclusivamente à língua principense. Rougé (2004) é um dicionário multilíngue, com dados das línguas crioulas de base portuguesa da Alta Guiné (cabo-verdiano, guineense, casamancês) e do Golfo da Guiné (santome, principense, angolar), no entanto, a parte dedicada ao principense é modesta (com menos de 400 verbetes). Além disso, a língua-veículo do dicionário de Rougé é o francês. Desta forma, não há glossários ou dicionários bilíngues publicados que contenham, ao mesmo tempo, dados das línguas principense e portuguesa. Assim, a situação de grave risco de extinção do principense, associada à necessidade de produção de instrumentos linguísticos impressos que possam ajudar na manutenção e preservação do idioma reforçam a necessidade de materiais linguísticos da língua principense.

Há duas gramáticas do principense: a tese de doutorado inédita Das portugiesische Kreolisch der llha do Príncipe, de Wilfried Günther (1973) e Principense (Lung'Ie) Grammar, Texts, and Vocabulary of the Afro-Portuguese Creole of the Island of Principe, Gulf of Guinea, publicado por Phillippe Maurer (2009). Na primeira, a língua-veículo do texto é o alemão e na segunda, o inglês. Desta forma, ambos os trabalhos são pouco ou nada 
acessíveis à população da Ilha do Príncipe. Todas as menções ao principense presentes em manuais de crioulística ou em livros-texto sobre línguas crioulas (cf. Couto 1994b, Holm 1988/9, Arends et al. 2000, entre outros) utilizam como base o trabalho de Günther (1973) e, mais recentemente, de Maurer (2009). Desse modo, qualquer trabalho sobre o principense publicado em português, além de poder servir à comunidade científica, também auxiliará a própria comunidade linguística do Príncipe, mostrando aos seus falantes que sua língua é objeto de interesse fora de seu país (Vaux, Cooper \& Tucker 2006: 4) e, ao mesmo tempo, será um instrumento de apoio a futuros projetos educacionais. Não obstante, Holm (2000: 64) sugere que o desafio básico para os crioulistas do século XXI é escrever descrições linguísticas e socioculturais de todas as línguas pidgins e crioulas conhecidas, bem como de seus dialetos. Ademais, o principense está em risco de extinção. Embora Mane (2007: 177, citando Grimes 1996) mencione que o principense conta com apenas 1558 falantes, sendo falado, sobretudo, pelas pessoas mais idosas da comunidade, a questão da ameaça à manutenção da língua é mais antiga, pois Valkhoff (1966: 85) já atestava a grande dificuldade em encontrar informantes em 1958 e mais premente, uma vez que, em seu trabalho, Günther (1973) sugere que o principense estaria em processo de extinção e que seria substituído pelo santome e pelo português em menos de 30 anos (a partir da década de 1970). A previsão de Günther não se concretizou por completo, no entanto, a escolarização e a mídia (televisão e rádio), fenômenos pós-independência ${ }^{1}$, deram ao português um prestígio que não pode ser rivalizado, mesmo pelo santome, outra língua crioula de São Tomé e Príncipe. Portanto, a previsão de Günther não se mostrou totalmente incorreta. Nosso trabalho de campo corrobora as previsões mais pessimistas, pois averiguamos que a língua é falada comumente por menos de uma centena de pessoas. Além disso, as crianças não utilizam mais o principense, fato este que coloca a língua em

${ }^{1}$ São Tomé e Príncipe se tornou independente em 1975. 
sério risco de extinção (cf. Crystal 2000: 21). Neste sentido, Crystal (2000) afirma que é crucial para os estudos linguísticos contar com descrições de línguas em extinção.

Assim, além de servir como base para estudos lexicográficos, o dicionário pode se tornar intrumento para o fortalecimento da literatura, ficcional e não-ficcional, em língua principense, tendo em vista a produção e promoção de material didático na própria língua e a necessidade de instrumentos linguísticos em geral.

\subsection{Historiografia e situação sociolinguística}

Formada por duas ilhas, a República de São Tomé e Príncipe é um estado insular localizado na região do Golfo da Guiné, costa ocidental da África. O país situa-se próximo às costas do Gabão, Guiné Equatorial, Camarões e Nigéria. Seu contingente populacional é de cerca de 170 mil habitantes, sendo que destes, menos de 10 mil vivem na ilha do Príncipe. O país é dividido em sete distritos, dos quais 6 são localizados na ilha de São Tomé e 1 na região autônoma do Príncipe.

As ilhas de São Tomé e Príncipe eram desabitadas até serem descobertas pelos portugueses João de Santarém e Pedro Escobar na segunda metade do século XV. Há indícios de que a ocupação tenha acontecido primeiro na ilha de São Tomé, em 1485, e mais tarde na ilha do Príncipe, em 1500 (Garfield 1992). No final do século XV, a cana-de-açúcar foi introduzida nas ilhas, mas sua cultura entra em declínio devido a forte concorrência brasileira e às constantes rebeliões locais. Com o declínio da cultura da cana no século XVI, as ilhas se tornam entrepostos de escravos. A agricultura local ganha novo incentivo no século XIX com o cultivo do café e do cacau. Em 12 de julho de 1975 é proclamada a independência e São Tomé e Príncipe se torna uma República Democrática. A atividade pesqueira e a aposta recente no turismo são as principais atividades econômicas do país.

No início do século XVI São Tomé era um entreposto de escravos onde teria se formado 
um primeiro crioulo de base portuguesa dessa área e este foi, então, transplantado para as ilhas de Príncipe e Ano Bom com o envio de escravos que serviram de mão-de-obra nas fazendas recém-implantadas (Garfield 1992). Segundo Hagemeijer (2009), o contato entre falantes do português e falantes das línguas africanas inicialmente deu origem a uma língua emergencial na ilha de São Tomé, que rapidamente teria se nativizado entre os descendentes da primeira geração de escravos. Para ele, o crioulo principense surgiu provavelmente de uma primeira variedade do proto-crioulo do Golfo da Guiné e isso explica o porquê desses crioulos, bem como os demais crioulos de base portuguesa do Golfo da Guiné, a saber, o santome, o angolar e o fa d'ambô, dividirem parte considerável do vocabulário e semelhanças gramaticais. Segundo Maurer, em sua amostra de 1650 itens lexicais do principense, $80 \%$ é de origem portuguesa, $14 \%$ de origem Edo e Benue-Congo, $1 \%$ do Kikongo e outros $5 \%$ não identificados.

Em São Tomé e Príncipe são faladas quatro línguas crioulas: na ilha de São Tomé são falados o santome e o angolar, na ilha do Príncipe, são falados o crioulo principense de base portuguesa e o caboverdiano é falado em ambas as ilhas. Os falantes do caboverdiano foram levados pelos colonos portugueses no século XIX para trabalharem nas plantações de café e cacau e vivem ainda hoje marginalizados, em situação de extrema pobreza no interior das roças. A importação dos caboverdianos para a ilha do Príncipe também está relacionada à epidemia da doença do sono que ocorreu por volta de 1900 e que dizimou grande parte da população étnica original e fez com que o governo português tivesse de importar trabalhadores de outras possessões coloniais, entre elas Angola, Moçambique, São Tomé e principalmente das ilhas de Cabo Verde (Günther 1973).

Günther (1973:17) sugeriu que seríamos capazes de assistir ao desaparecimento total do principense. Segundo ele, a língua principense estava em vias de extinção, sendo falada somente pelas pessoas mais idosas da comunidade. Günther estimava que já no ano 2000, 
não haveria mais vestígios do principense, pois estes seria substituído pelo caboverdiano, santome ou pelo português regional.

Nos trabalhos de campo (março/2009, abril-junho/2011, outubro de 2011), percebese pelas entrevistas e conversas pessoais com a população local um interesse maior dos habitantes em geral, e mesmo dos mais jovens, pela língua dos ancestrais. Nos últimos anos, alguns esforços têm sido feitos para preservação da língua. O principense começou a ser ensinado nas escolas como disciplina optativa pelos habitantes mais velhos e alfabetizados da ilha e a rádio local apresenta semanalmente programas em língua. Há uma preocupação do Governo Regional com a recuperação e manutenção da língua dos ancestrais, símbolo da identidade local. Em comparação com a primeira visita a ilha, março de 2009 (início do programa de promoção linguística na rádio regional dedicada a lung’ie e do ensino da língua nas escolas), o acesso aos informantes foi bem mais fácil, além disso já é possível ouvir sentenças de principense na região da cidade de Santo Antônio, na medida que o estigma sobre a língua se efraquece.

Atualmente, menos de cem pessoas tem o principense como a língua materna. Ademais, a grande maioria é bilíngue (ou multilíngue - falam o português, o caboverdiano, o santome) e utiliza o português para comunicação entre si. O principense tem, portanto, um papel secundário. A maioria dos seus falantes tem mais de sessenta anos e, assim como apontado por Maurer (2009:3), os poucos falantes mais jovens têm um comando ativo razoável da língua. Günther (1973) previa o desaparecimento da língua em um período de três décadas. Alguns fatores têm contribuído para a possível obsolescência do principense: o grande prestígio do português reforçado pela escolarização e pela influência da mídia, pela dispersão dos falantes do principense pelo território e pelo grande contigente populacional de falantes do português regional, do caboverdiano e até mesmo do santome. Apesar de essa previsão não ter se consumado, o fato da língua não ter sido transmitida 
aos mais jovens por mais de três gerações e a ausência de homogeneidade territorial dessa comunidade de fala apontam para um possível desaparecimento do principense, caso não haja a implementação de uma política de promoção linguística e cultural agressiva.

Os programas de conscientização linguística voltados à população se mostram de suma importância para despertar, principalmente nos mais jovens, a vontade de aprender a língua e ajudar na sua difusão e, dessa maneira, impedir que a língua desapareça ou fique obsoleta. Embora o prestígio do português faça com que o interesse por falar a língua seja cada vez menor, é preciso destacar a influência das línguas de STP, encontrada nas variedades do português regional, com maior ou menor aproximação do português europeu, ou seja, ora se aproximam mais do português europeu aprendido nas escolas, ora apresentam menor ou maior influência das línguas locais. Hagemeijer (2009) acredita que isso seja determinado por fatores como nível de escolaridade, nível econômico e o ambiente de inserção social (urbano/rural). Para ele, essa variação reflete o conflito entre a norma oficial e a prática local em um passado recente em que o português era a segunda língua para a maioria dos habitantes das ilhas.

\subsection{Material, métodos e forma de análise dos resultados}

Para realizar as pesquisas que deram origem ao dicionário, realizei três trabalhos de campo. O primeiro em abril de 2009, enquanto aluna de graduação. O segundo foi realizado em abril-junho de 2011, no qual permaneci na ilha do Príncipe por mais de dois meses e pude preencher muitas lacunas do material coletado no primeiro trabalho, e o terceiro em outubro de 2011. Segundo Vaux, Cooper e Tucker (2006: 5), o trabalho de campo é necessário a linguistas que não estão trabalhando com sua língua materna, já que julgamentos sobre a gramaticalidade dos dados dependem da intuição do falante-nativo. Além disso, é o 
trabalho de campo que permite nos assegurarmos da situação sócio-linguística da comunidade, bem como ter acesso a uma variedade de usos da linguagem, pois, permite uma coleta de dados variada, a checagem destes dados junto aos falantes nativos, bem como a possibilidade de documentar ocasiões singulares do uso da língua e da interação linguística com os falantes.

Para a coleta de dados, utilizei os métodos apresentados em Payne (1997) e em Vaux, Cooper e Tucker (2006). Além disso, utilizei meu próprio dicionário preliminar compilado na minha iniciação científica. Também tive acesso ao material original coletado por Ana Lívia dos Santos Agostinho, estudante de doutorado que prepara uma tese sobre o principense, sob orientação do professor Gabriel Antunes de Araujo. Ana Lívia permaneceu por cinco meses na ilha do Príncipe e coletou mais de 200 horas de gravação com informantes nativos. Os dados coletados para o desenvolvimento desta pesquisa foram analisados através dos conhecimentos de linguística descritiva e teórica e também de técnicas de descrição da estrutura e análise das línguas crioulas encontradas nos trabalhos de Holm (1988/9), bem como de trabalhos de outras línguas crioulas de base portuguesa (Barrena 1957, Ferraz 1979, Maurer 1995, Gerardo 1998, Rougé 2004). Todos os dados coletados foram compilados no programa Toolbox e depois formatados no programa Texworks.

As sessões com os informantes foram gravadas em equipamento digital gravador Philips, com microfone interno e com filmadora digital. Os dados foram anotados e transcritos utilizando-se o ALUSTP. Houve coleta de material espontâneo e material elicitado. A elicitação dos dados foi feita de diversas formas, incluindo a aplicação de listas de palavras, paradigmas de sentenças, julgamentos de gramaticalidade das palavras coletadas nas fontes secundárias, coleta de textos com história oral, situações do cotidiano, traduções de pequenos textos, diálogos entre dois ou mais informantes, conversas informais etc. Situações não-gravadas (em contextos de gravador desligado) ou não-graváveis (quando havia 
impossibilidade técnica ou impedimento cultural) também forneceram dados para a pesquisa.

O dicionário foi formatado no programa Toolbox ${ }^{2}$, de uso corrente na comunidade científica. Esse programa permite o uso de várias rubricas (tradução, transcrição fonética, informações antropológicas, nome científico, etc.) dentro da mesma entrada lexical. Posteriormente, os dados foram retrabalhados no programa TexWorks (LaTex) para formatação final do dicionário. Finalizado, o dicionário terá três tipos de usuários como público-alvo. Em primeiro lugar, o público-alvo desse dicionário é a comunidade acadêmica que poderá se aproveitar das notações fonética e gráfica. Em segundo lugar, a comunidade santomense poderá se beneficiar da opção gráfica do dicionário. Por conseguinte, o dicionário tornar-se-á um instrumento linguístico (Auroux 1994) que poderá ser utilizado tanto pelos professores como por todos os usuários da língua. Por fim, o dicionário também será útil ao usuário não-especialista, porém interessado em línguas e culturas em geral.

\subsection{Acesso à ilha do Príncipe}

A descrição de uma língua pouco documentada requer trabalho com dados coletados in loco, tanto pela confiabilidade dos dados como pela impossibilidade de encontrar falantes nativos do principense, imersos em suas comunidades de fala, fora de STP. Contudo, o acesso à ilha do Príncipe não pode ser descrito como 'fácil'. Apesar de o Brasil ter uma relação amistosa com a República de São Tomé e Príncipe e possuir uma representação diplomática de alto nível na capital, não há a contrapartida são-tomense no Brasil. Desta forma, o processo de obtenção de visto para a entrada no país é mediado pela Embaixada de STP em Portugal. Além disso, não há voos diretos entre Brasil e São Tomé e Príncipe. O acesso à ilha de São Tomé é feito via Portugal, Cabo Verde ou Angola, o que aumenta os

${ }^{2}$ Disponível em http://www.sil.org. 
custos da viagem. Chegando a São Tomé, há duas maneiras de se atingir a ilha do Príncipe: pela via aérea (o voo dura aproximadamente 40 minutos, realizado de uma a duas vezes por semana, sujeito a cancelamento devido a fatores climáticos ou mesmo problemas com a aeronave, visto que apenas uma atende a essa rota) ou pela via marítima (duração de 8 a 12 horas). A viagem de avião custa cerca de 300 euros (ida e volta) e a de barco uns 200 euros, ida e volta. Ambos os meios de transporte podem envolver um certo nível de precariedade.

A Ilha do Príncipe é uma região autônoma desde 1995. No entanto, essa autonomia limita-se a uma descentralização do Poder Central. De fato, não há interferência do Governo Central nos assuntos considerados internos, exceto no que se refere a serviços em âmbito nacional (defesa, negócios estrangeiros etc.) e aspectos importantes da infraestrutura (segurança pública, serviços de água, luz e esgoto etc). Na prática, contudo, a precariedade do apoio do Governo Central à Administração Regional revela as carências da própria economia de STP como um todo. A Empresa Nacional de Água e Eletricidade (EMAE), por exemplo, que deveria atender ambas as ilhas, porém, assim como outros setores da economia, passa, há algum tempo, por diversos problemas estruturais, causando racionamentos e apagões constantes, tanto em São Tomé quanto no Príncipe. A crise energética é decorrente da dependência dos combustíveis fósseis, matriz da produção energética de STP, de pouca disponibilidade no país. Portanto, o fornecimento de energia e água (pois as bombas são alimentadas por geradores elétricos) é irregular. Aliado a isso, há o elevado custo dos transportes entre as ilhas do Príncipe e São Tomé e problemas no abastecimento do mercado regional. Ao mesmo tempo, a oferta de alimentos industrializados é pequena e irregular. Ademais, o acesso à internet na ilha é precário. Aparte as dificuldades pelas quais passa a região, a população do principense é bastante receptiva e acolhedora, o que facilita a estadia na ilha e a coleta de dados. 


\subsection{Trabalho de campo}

Durante o período de pesquisa (que inclui a iniciação científica) foram realizados três trabalhos de campo, com falantes nativos na cidade de Santo Antonio, entre 2009 e 2011. As visitas à ilha tiveram o apoio financeiro do CNPq e da FAPESP. Além disso, tiveram também o apoio da Embaixada Brasileira em São Tomé e Príncipe e da Presidência do Governo Regional do Príncipe, José Cardoso Cassandra, a quem agradecemos. O primeiro trabalho de campo foi realizado em fevereiro de 2009 (durante a iniciação científica), o segundo de abril a junho de 2011 e o terceiro em outubro de 2011, nos quais fiquei, respectivamente, 15, 72 e 22 dias. Contudo, os dados utilizados no projeto não se limitam a esses, uma vez que, além deles, utilizamos também dados da pesquisadora Ana Lívia dos Santos Agostinho, que no momento elabora uma gramática pedagógica da mesma língua. Agostinho realizou também três viagens à ilha, entre 2009 e 2011, tendo permanecido por um perído de superior a seis meses, no total.

O corpus coletado por mim compreende mais de 100 horas de gravação. No total, foram entrevistados dez informantes, dos quais seis homens e quatro mulheres. A faixa etária dos informantes varia entre 45 e 70 anos. Não há falantes nativos mais jovens. No trabalho de campo, dentre outras atividades, busquei comparar os dados das fontes secundárias com a língua em uso. Desta forma, a elaboração do dicionário requereu uma reflexão sobre as descrições publicadas sobre a língua principense. É importante ressaltar que todos os dados, palavras e sentenças, que aparecem no dicionário foram gravados com os falantes nativos e passaram por múltiplas revisões. 


\subsection{Linguística de contato e considerações iniciais}

Nas situações de multilinguismo podem ocorrer a manutenção de língua, mudança ou criação de novas línguas decorrentes do contato. O processo de mudança e reestruturação para a formação de uma nova língua apresenta graus variáveis de convergência. Situações de contato podem levar a convergência linguística e em muitos casos os processos são similares aos encontrados na formação de crioulos e aquisição de segunda língua.

Em estudos, como os de Vinson (Vinson, 1882, apud Hale, 2001:94 ) era comum cosiderar as línguas crioulas como simplificadas, desviantes, corruptas ou resultado de mau aprendizado. Posteriormente, somente no final dos anos 1950, o estudo de línguas pidgins e crioulas foi estabelecido como disciplina acadêmica. Contudo, ainda não há uma definição precisa para pidgin e crioulo que seja aceita por todos os crioulistas. Não obstante, é consenso entre os estudiosos da área que estas línguas não são versões erradas de outras línguas, mas línguas novas.

O campo da Crioulística tem contribuído em diferentes áreas da linguística, tais como aquisição e aprendizagem de L2, sociolinguística, planejamento linguístico, linguística histórica, entre outras. Os processos de gênese das línguas crioulos e suas características tipológicas têm sido ponto de referência e comparação com outras línguas e variedades resultantes de situações de contato.

\subsubsection{Definição do termo crioulo}

Segundo Myers-Scotton (2002:271), línguas crioulas são aquelas que surgiram do contato entre falantes de variedades coloniais de línguas europeias e falantes de línguas não europeias. Nesse sentido, Arends (1994) aponta para as similaridades históricas no surgimento dessas línguas, que emergiram, em sua maioria, no contexto da expansão colonial europeia a partir do século XV. De acordo com a definição de Siegel (2008:1), pidgins e crioulos são 
línguas novas que se desenvolveram devido a necessidade de comunicação entre pessoas que não dividiam uma língua em comum. Arends (1994) afirma que línguas crioulas são línguas naturais que podem ser categorizadas e agrupadas segundo critérios extralinguísticos que dizem respeito aos aspectos sócio-históricos de sua formação. Atentando para a formação dos crioulos do Golfo da Guiné, onde é falado o principense, essa expansão colonial foi acompanhada por um sistema de economia específica do tipo plantation ${ }^{3}$ baseada na produção em larga escala para atender a demanda do mercado europeu.

Myers-Scotton (2002: 271) aponta que o que diferencia os crioulos de outros fenômenos de contato é o ambiente social e psicolinguístico no qual são formados. Ainda segundo Myers-Scotton, o objetivo era criar uma língua para ampliar a comunicação. A autora considera cinco fatores básicos para a formação de pidgins e crioulos:

1. Primeiramente, falantes de línguas ininteligíveis entre si devem ser colocados lado a lado num sistema plantation isolado;

2. Com a necessidade de se comunicar, faz-se necessária uma língua franca;

3. Na maioria dos casos, nenhuma das línguas dos escravos tem número de falantes suficiente para ser escolhida como língua franca ou não há um grupo majoritário, com prestígio suficiente para impor a sua língua como franca;

4. Assim, de acordo com o quarto fator, outra língua deveria ser elegida e essa outra opção era a língua do colonizador, que tinha valor utilitário e contava com maior prestígio.

\footnotetext{
${ }^{3}$ Embora neste texto tenhamos tratado das plantations, estes não são os únicos ambientes nos quais pidgins e crioulos emergem. Arends (1994) lembra que além das ilhas e das fazendas do tipo plantation, os crioulos também emergiram em fortalezas e em quilombos. Para maiores informações ver Arends (1994) e Bickerton (1988).
} 
5. Por último, como os escravos não passavam muito tempo com os colonizadores, não tinham muitas oportunidades para adquirir a língua, ou seja, a transmissão era frequentemente irregular.

Nas fazendas do tipo plantation, por exemplo, os trabalhadores tinham diversas origens. A maior parte da forma do léxico da nova língua vem de uma das línguas na situação de contato, a chamada de língua lexificadora, do colonizador ou superstrato - normalmente, a língua do grupo em controle onde o contato ocorre. Entretanto, esse léxico passa por um processo de relexificação, assim, os significados e funções das formas lexicais emprestadas, fonologia e regras gramaticais dos pidgins e crioulos, são diferentes das línguas lexificadoras.

Segundo Thomason \& Kaufman (1988:150), a língua que emerge do contato, torna-se a língua da comunidade e é aprendida como primeira língua pelas crianças. A maioria das línguas crioulas atlânticas, como as do Golfo da Guiné, por exemplo, surgiram a partir de pidgins, por um processo de nativização.

That contact therefore expands rapidly into a creole rather than stabilizing as a functionally and linguistically restricted pidgin, though its formative period, before is crystallized as a language, correspond to what generally called a prepidgin stage... since it was needed for a immediately for a much wider range of functions than is the case with most pidgins, and since children were sometimes among its developers, crystallization may have occurred sooner than with most pidgins (Thomason \& Kaufman 1988) .

\footnotetext{
${ }^{4}$ Esse contato, portanto, expande-se rapidamente em um crioulo em vez de se estabilizar como um pidgin funcional e linguisticamente restrito, embora em seu período de formação, antes de se cristalizar como uma língua, corresponde ao chamado estágio pre pidgin ... desde que tenha tido função imediata numa amplidão maior que nos casos de muitos pidgins, e que crianças estivessem envolvidos em sua formação, a cristalização pode ter ocorrido mais cedo do que na maioria dos pidgins.
} 
Por outro lado, estudos com línguas como o sranan e o haitiano, por exemplo, têm demonstrado um desenvolvimento gradual dessas línguas, contrariando portanto a teoria de crioulização abrupta, a qual considera a formação das línguas crioulas em um período de 100 anos com o crioulo se desenvolvendo a partir de um pré-pidgin. Apesar de ser bastante estudada, não é amplamente aceita e, assim como outras teorias, não se aplica a todos os crioulos.

\subsubsection{Hipóteses de formação dos crioulos}

São várias as hipóteses sobre a gênese dos crioulos. Dentre elas destacam-se as teorias substratista, superstratista, universalista e gradualista. Estas são tratadas brevemente abaixo:

1. A hipótese substratista é discutida por Alleyne (1980), Holm (1983) e Mufwene (1993). O termo substrato se refere à influência linguística das línguas dos grupos de menor prestígio, ou seja, para os substratistas, as línguas com menor prestígio refletem as estruturas básicas na formação dos crioulos. Lumsden (1999) propõe que os crioulos refletem as propriedades semânticas e sintáticas das línguas africanas e as formas fonológicas e unidades lexicais derivadas da língua lexificadora. Dessa forma, para essa hipótese as especificidades dos crioulos decorrem do influxo das línguas dos substratos nas línguas lexificadoras. Taylor (1956: 413) argumenta que a simplificação do padrão gramatical europeu pode significar a preservação de algo comum a várias línguas do oeste africano, no caso das línguas crioulas de base portuguesa atlânticas. Para Alleyne (1971: 174-9), os africanos interpretaram padrões estruturais das línguas lexificadoras em termos dos padrões nativos, assim, os fatores socioculturais determinaram o grau de interferência que resultou em variação linguística e instabilidade, que são característicos de qualquer processo aculturativo 
dinâmico. Nesse sentido, o autor afirma que no processo aculturativo, os africanos que tiveram grande contato com os europeus alcançaram mais precisão na reprodução dos padrões estruturais da língua europeia, já os com menor acesso sofreram interferência das línguas nativas na reprodução dos padrões europeus, o que, segundo Siegel (1997: 137) mostra dois tipos de influência de substrato na língua em formação: transferência nas fases iniciais e reforço posterior.

2. A hipótese superstratista refere-se à presença da língua lexificadora na origem dos crioulos. Essa hipótese assume que os escravos tinham como alvo a língua do colonizador, assim, as línguas dos substratos tinham o papel de receptoras enquanto as língua dos superstratos, ou lexificadoras, tinham papel ativo. O principal representante dessa teoria é Chaudenson (1977). Para esse autor, o crioulo não é nada mais que uma variedade regional ou simples variedade das suas línguas de superstrato, aproximando-se dos dialetos regionais primitivos falados pelo colonialistas europeus (citado por Holm 2004:66). Nessa mesma linha estão as teorias monogenéticas propostas por Taylor (1961) e Thompson (1961). Esses autores alegam que todos os crioulos atlânticos surgiram de um pidgin de base portuguesa, durante os séculos XV e XVIII, falado nos fortes e assentamentos comerciais fundados pelos portugueses ao longo da costa oeste africana. Outra proposta teórica é a chamada Baby talk ou Foreigner talk, defendida por Bloomfield (1933) e adaptada por Ferguson (1971). Esses autores assumem que os europeus simplificavam suas línguas quando falavam com os africanos e, assim, estes não tiveram chance de aprender a língua do colonizador, mas uma versão simplificada. No Brasil, Naro e Scherre (1993) relacionam a gênese do português brasileiro à matriz europeia.

3. A hipótese abrupta defende o desenvolvimento rápido dos crioulos. Esta é seguida 
por Thomason \& Kaufman (1988) e corrobora a hipótese universalista, defendida por Bickerton (1974, 1981, 1984, 1988). A hipótese universalista está diretamente atrelada à teoria do bioprograma do mesmo autor que assume que os crioulos são invenções das crianças em desenvolvimento. No ambiente de plantation, elas ouvem um pidgin sem estrutura suficiente para funcionar como língua natural e usam sua capacidade linguística inata para transformar o input pidgin de seus parentes em língua. A ideia geral da hipótese universalista é que os aspectos universais da capacidade linguística humana, no processo de aprendizado, é responsável pelas características específicas dos pidgins e crioulos ${ }^{5}$. O autor rejeita a ideia de influência dos substratos ou da monogênese na formação dos crioulos. A extensiva similaridade entre os crioulos diversos é o resultado de aspectos universais da faculdade da linguagem. Isso contraria a teoria substratista, segundo a qual essas similaridades são decorrentes da transferência de elementos cruciais do substrato para a nova língua. Para Bickerton $(1984,1988)$ e outros, os crioulos emergiram de uma língua pidgin através do processo de nativização em um processo instantâneo ou abrupto que teria se estabilizado em uma ou duas gerações. Dessa forma, os crioulos podem ser considerados pidgins nativizados.

4. Modelo gradualista - Em contraste com a hipótese da crioulização abrupta, surge o modelo gradualista proposto por Carden \& Stewart (1988), Arends (1993), McWhorter (1992). Esses autores consideram que mesmo que a formação de subsistemas nos crioulos tenha se completado rapidamente, pode ter levado um bom tempo para se estabilizar. Esse modelo trata da crioulização como um processo não unigeracional, mas um processo gradual expandido por inúmeras gerações de falantes (Arends 1993:

${ }^{5} \mathrm{O}$ trabalho de Bakker (2002) propõe uma tripartição termilogógica: pidgin, pidgincreole e creole. Para o autor, pidgincreole substitui o termo pidgin extendido sendo, portanto uma outra categoria. 
373). As evidências gradualistas provém dos estudos das línguas sranan (Arends 1989) e saramaccan (Smith 1987), ambas faladas no Suriname. Segundo os autores, além das evidências linguísticas, fatores externos (demográficos) tem papel importante. O desenvolvimento demográfico dessas sociedades escravas foram tais que a nativização foi um processo lento, desse modo, a formação dessas línguas acontece em várias gerações e estágios de estabilização e extensão, sem que a nativização tenha tido papel principal. Arends alega que, no que diz respeito à formação, as mudanças diacrônicas na sintaxe do sranan se deram entre 1700 e 1950, o que aponta para um processo de formação gradual.

\subsubsection{Propostas para a formação dos crioulos do Golfo da Guiné}

Nem sempre, uma mesma teoria pode ser aplicada aos vários processos de crioulização. Assim, Arends (1994:112) mostra que no caso do sranan, a hipótese gradualista é a que melhor se aplica ao fenômeno, que de acordo com estudos empíricos demonstrou um desenvolvimento gradual dessa língua. O contexto histórico do daman (Clements 1996), por exemplo, e também de línguas do Golfo da Guiné, sugere que a formação dos crioulos dessa região aconteceu de forma abrupta, em duas gerações. Hagemeijer (2009), entre outros, defende que as línguas crioulas do Golfo tenham surgido de um proto-crioulo falado em São Tomé, base para os demais crioulos portugueses do Golfo. No início do século XVI, São Tomé era um entreposto de escravos onde teria se formado um primeiro crioulo de base portuguesa dessa área e este foi, então, transplantado para as ilhas do Príncipe e de Ano Bom com o envio de escravos que serviram de mão-de-obra nas fazendas recémimplantadas. Segundo Hagemeijer (2009), o contato entre falantes do português e falantes das línguas africanas inicialmente deu origem a um pidgin na ilha de São Tomé, que rapidamente teria se nativizado entre os descendentes da primeira geração de escravos. Esta 
tese também é defendida por Maurer (2009). Para ele, o principense surgiu provavelmente de uma primeira variedade do protocriulou e isso explica o porquê dessas línguas, bem como os demais crioulos de base portuguesa do Golfo da Guiné, a saber, o angolar e o fa d'ambô, compartilharem parte considerável do vocabulário e estruturas gramaticais.

Pode-se dizer que o termo "língua crioula" apenas se refere ao contexto histórico em que estas línguas surgiram e não à sua suposta excepcionalidade ou à sua estrutura. Não há nada na estrutura de uma língua crioula que não tenha sido observado em outras línguas. A língua permite contato sem limites e mudanças fonéticas, fonológicas, sintáticas, morfológicas e discursivas.

Schuchardt (1979) afirma que todas as línguas são mistas. Não há como negar a influência das línguas de subtrato, por exemplo, nas línguas românicas ou no português do Brasil. Sem dúvida, as línguas crioulas são ligadas também geneticamente à língua de superstrato. As teorias aqui apresentadas são visões complementares que veem o fenômeno com focos distintos, mas com a mesma finalidade e, estas, podem ser combinadas a fim de verificar estas situações linguísticas com maior clareza, não sendo extremista em nenhuma das direções. 


\section{Capítulo 2}

\section{Principense}

\subsection{Introdução}

Neste capítulo, apresento aspectos da língua principense, relevantes como complementação ao dicionário. Em 2.2, faço uma breve apresentação fonológica da língua principense. Este é dividido em 4 seções, nas quais apresento o sistema vocálico em 2.2.1, o sistema consonantal em 2.2.2, sílaba em 2.2.3 e tonologia em 2.2.4. Por fim, a seção 2.3 traz descrição da grafia utilizada no dicionário.

\subsection{Breve descrição fonológica do principense}

Nesta parte, serão descritos alguns aspectos estruturais, dentre eles, os segmentos vocálicos, os consonantais e a constituição silábica da língua da ilha do Príncipe, baseada na descrição fonológica de Maurer (2009) e em nossos próprios apontamentos.

\subsubsection{Sistema vocálico}

O principense apresenta sete vogais orais que se diferenciam pelos diferentes pontos de articulação (anteriores, central, posteriores) e graus de altura (altas, médias e baixas), sendo /i/ e /u/ (vogais altas), / $\varepsilon /$ e /o/ (vogais médias-baixas); /e/ e /o/ (vogais médias-altas), e a vogal baixa /a/. As vogais do principense são as mesmas da língua de superstrato, 
o português. No principense, também encontramos ditongos crescentes e decrescentes, ou seja, vogais na margem do núcleo, como em [ja] burya 'embrulhar' e [ew] em janêw 'janeiro', respectivamente. As semivogais são representadas com os grafemas $<\mathrm{w}>\mathrm{e}<\mathrm{y}>$.

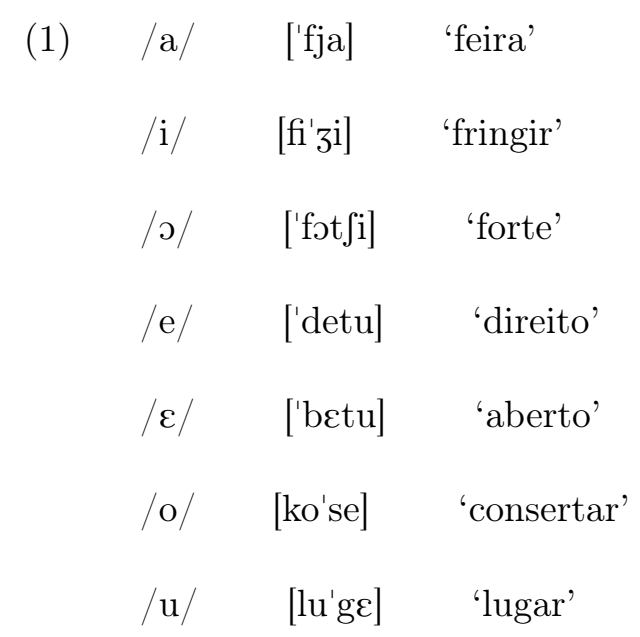

\subsubsection{Sistema consonantal}

O principense possui 20 fonemas consonantais. Estes diferenciam-se quanto ao ponto de articulação, sendo coronais (palatais, alveolares e pós-alveolares), labiais (bilabiais e lábiodentais), dorsal (velares) e duas velo-labiais, ao modo de articulação (oclusivas, fricativas, líquidas e vibrante) e com relação a vibração das cordas vocais (surdas, sonoras). Há oito consoantes oclusivas ( $\operatorname{surdas} / \mathrm{p} /, / \mathrm{t} /, / \mathrm{k} /, / \widehat{\mathrm{kp}} /$, sonoras $^{1} / \mathrm{b} /, / \mathrm{d} /, / \mathrm{g} /, / \widehat{\mathrm{gb}} /$ ), seis fricativas (as surdas $/ \mathrm{f} /, / \mathrm{s} /, / \mathrm{J} / \mathrm{e}$ as sonoras $/ \mathrm{v} /, / \mathrm{z} /, / 3 /$ ) três líquidas (duas laterais $/ \mathrm{l} /, / \mathrm{K} /$ e uma vibrante $/ \mathrm{r} /)$ e três nasais $(/ \mathrm{m} /, / \mathrm{n} /, / \mathrm{n} /)$, conforme ilustrado na Tabela 2.1:

As oclusivas velo-labiais / $\widehat{\mathrm{kp}} / \mathrm{e} / \widehat{\mathrm{gb}} /$ são uma herança do substrato das línguas do Delta do Níger (Hagemeijer 2009). Contudo, Günter (1973) apresenta em seu quadro somente a

\footnotetext{
${ }^{1}$ Quando as consoantes aparecerem em pares, na Tabela 2.1, a da esquerda é surda e a direita é sonora. Quando aparecem sozinhas são sonoras.
} 
Tabela 2.1: Fonemas consonantais

\begin{tabular}{|c|c|c|c|c|c|c|c|}
\hline & bilabial & lábio-dental & alveolar & pós-alveolar & palatal & velar & velo-labial \\
\hline oclusiva & $\mathrm{p}$ & & $\mathrm{d}$ & & & $\mathrm{k} \quad \mathrm{g}$ & $\widehat{\mathrm{kp}} \quad \widehat{\mathrm{gb}}$ \\
\hline fricativa & & $\mathrm{v}$ & $\mathrm{z}$ & 3 & & & \\
\hline nasal & $\mathrm{m}$ & & $\mathrm{n}$ & & $\mathrm{n}$ & & \\
\hline lateral & & & l & & $\Lambda$ & & \\
\hline vibrante & & & $\mathrm{r}$ & & & & \\
\hline
\end{tabular}

oclusiva velo-labial sonora e não considera a velo-labial surda $/ \widehat{\mathrm{kp}} /$ como parte do sistema fonológico do principense. Maurer (2009), por sua vez, sugere que há uma tendência de variação entrs os fonemas velo-labiais $/ \widehat{\mathrm{kp}} / \mathrm{e} / \widehat{\mathrm{gb}} / \mathrm{e}$ os bilabiais $/ \mathrm{p} / \mathrm{e} / \mathrm{b} /$, respectivamente, como em igbê/ibê 'corpo' e ukpaka/upaka 'pele' (Maurer 2009: 9). É importante notar, contudo, que $/ \widehat{\mathrm{gb}} / \mathrm{e} / \mathrm{b} / \mathrm{e} / \widehat{\mathrm{kp}} / \mathrm{e} / \mathrm{p} /$ são fonemas, como demostram os pares mínimos na Tabela 2.2 .

Tabela 2.2: Oposição velo-labiais/labiais

\begin{tabular}{llll}
\hline kpa & 'encostar de lado' & pa & 'para' \\
gba 'ordenar' & baa & 'queimar' \\
gbô & 'defecar' & bôn & 'bom' \\
\hline
\end{tabular}

Apesar de Maurer apresentar a consoante africada [t $\left.\int\right]$ como um fonema da língua, e esta seja transcrita graficamente $<\mathbf{t x}>$, verificamos que este é um alofone, visto que há dados coletados em que falantes ora realizam a consoante palatal [tf] ora a não palatalizada [t].

(2) $\quad$ fi[t $f]$ ixo, fi[t]ixo $\rightarrow$ 'feiticeiro'

$\mathrm{a}\left[\mathrm{t} \int\right] \mathrm{i}, \mathrm{a}[\mathrm{t}] \mathrm{i} \rightarrow{ }^{\prime 2} \mathrm{PS}$ ' 


\subsubsection{Sílaba}

A estrutura fonológica da sílaba se constitui pela ordenação de fonemas vocálicos e consonantais. A vogal em principense pode aparecer sozinha ou com um elemento consonantal, mas não pode ser omitida na sílaba. A posição de coda é muito restrita e o fonema / // é o único que pode ocupar essa posição². Além de todas as consoantes no onset, o pricipense apresenta uma série de onsets completos. As sílabas em principense podem ser constituídas por V, VV, CV, CVV, VCV, CCV, CCCV. Como na maioria dos crioulos de base portuguesa do Golfo da Guiné, o principense apresenta uma preferência pelo padrão silábico CV (não marcado) e por palavras com duas sílabas, sendo que palavras com mais de três sílabas são menos comuns na língua.

$$
\begin{aligned}
& \text { e } \rightarrow \text { 'ele/ela' } \\
& \text { ee } \rightarrow \text { 'sim' } \\
& \text { sa, a } \rightarrow \text { 'estar' } \\
& \text { faa.ta } \rightarrow \text { 'falta' } \\
& \text { êru } \rightarrow \text { 'erro' } \\
& \text { xin.txi.ne.la } \rightarrow \text { 'avião' } \\
& \text { xkri.van } \rightarrow \text { 'escrivão' }
\end{aligned}
$$

Em alguns itens lexicais de origem portuguesa, o acento tônico toma como referência a posição do acento na palavra em português.

$$
\begin{array}{r}
\text { (4) tã'ze } \rightarrow \text { 'tanger' } \\
\text { ta'ka } \rightarrow \text { 'atacar' }
\end{array}
$$

tabala'do $\rightarrow$ 'trabalhador'

${ }^{2}$ Embora no sistema gráfico, as consoantes nasais $<\mathrm{m}>\mathrm{e}<\mathrm{n}>$ ocupem a coda da sílaba, foneticamente nasalizam a vogal precedente. 


$$
\begin{aligned}
& \text { 'sunu } \rightarrow \text { 'sonho' } \\
& \text { 'sulu } \rightarrow \text { 'sul' }
\end{aligned}
$$

Entretanto, não há estudos conclusivos sobre tom e acento em principense, principalmente no que diz respeito as palavras de origem não portuguesa. Para alguns detalhes ver Maurer (2009) and Ferraz \& Trail (1981).

\subsubsection{Tonologia}

Günther (1973) trata o principense como língua tonal e argumenta que o tom pode ter sua origem na língua de substrato bini (do Delta do Níger). O autor faz distinção entre três tons: alto, marcado graficamente com um acento agudo), baixo (não marcado) e ascendente, marcado graficamente com um acento circunflexo. Segundo Günther, não há oposição entre o tom baixo e o tom ascendente. Assim, nas palavras de origem portuguesa, os acentos foram interpretados como tom alto e as vogais não acentuadas com tom baixo. Para Günther, não há exemplos de palavras com tons idênticos aos tipos HH ou LL, pelos menos não em português, do qual $90 \%$ do léxico do principense é derivado. O tom ascendente, para Günther, existe devido à perda da consoante intervocálica de palavras de origem portuguesa (apud em Maurer: 2009:14)

Ferraz \& Traill (1981) afirmam que o principense é uma língua free pitch accent com três pitches: alto, crescente e decrescente e o acento não é completamente ausente. Para os autores, a origem do contraste entre os tons crescentes e decrescentes estão nas simplificações durante a pidginização das palavras de origem portuguesa. Os três tons são funcionalmente idênticos e realizados em diferentes contextos. Segundo os autores, em palavras de duas ou mais sílabas, uma delas deve carregar o tom alto, crescente (R, rise, em inglês) ou decrescente (L, de low, em inglês), mas só um deles deve aparecer, nos casos de mais de uma sílaba, aparece o tom baixo. Assim temos os padrões HL, LH, RL, LR, 
FL, LF. A justificativa para ser uma língua free pitch accent é que qualquer sílaba pode ser proeminente em termos de pitch.

Maurer (2009), no entanto, rejeita a hipótese sobre a tonicidade do principense apresentada em Günther (1973), bem como a de Ferraz \& Traill (1981). Segundo ele, o principense tem dois tons: baixo e alto. Assim, palavras dissilábicas podem ser HH, HL, LH e LL. No que diz respeito ao acento, Maurer afirma que propriedades como intensidade podem ser observadas e que as sílabas acentuadas parecem corresponder ao acento original do português. Maurer (2009) apresenta ao final do livro um glossário com aproximadamente 1650 entradas e todas elas com seus respectivos tons lexicais.

A análise apresentada por Maurer, principalmente quando se leva em conta os pares mínimos que o autor utiliza para a contraposição dos tons alto e baixo, revela que em muitos casos, estes podem ser interpretados como acento e não tom propriamente dito, principalmente nas palavras de origem portuguesa em que o acento da palavra, em muitos casos, permanece na mesma sílaba da palavra de origem.

$$
\begin{aligned}
& \text { fala }[\mathrm{HH}] \text { 'fala' vs. fala }[\mathrm{LL}] \text { 'falar' } \\
& \text { konta }[\mathrm{HH}] \text { 'conta' konta }[\mathrm{LL}] \text { 'contar' }
\end{aligned}
$$

Posto que os trabalhos sobre o tom em principense não são conclusivos, optamos pela não marcação de tom no dicionário aqui apresentado, seguindo o ALUSTP que não determina marcação tonal.

\section{$2.3 \quad$ Grafia}

No início do projeto, optamos por criar um sistema gráfico, uma vez que não havia uma grafia oficial e cada autor apresentava seu próprio sistema grafemático. Assim, a partir de 
exemplo como em (6), seguido por sua transcrição fonética, glosa e tradução para o português, poderíamos ter múltiplas formas gráficas, a depender do autor e de seu sistema de notação (Tabela 2.3). Em meados de 2009, um grupo de linguistas reunidos com o Governo de STP decidiu implementar uma grafia padrão para as línguas de São Tomé e Príncipe, a saber, santome, angolar e principense, criando então o Alfabeto Unificado para a escrita das Línguas Nativas das Ilhas de São Tomé e Príncipe (ALUSTP), um alfabeto híbrido de inspiração fonológica. Seu intuito é proporcionar uma escrita econômica, mantendo-se a relação biunívoca entre cada fonema e sua representação gráfica, não apresentar dificuldades aos aparelhos de suporte à escrita e facilitar a aprendizagem da língua. Contudo, posto que não há sistema gráfico perfeito, alguns pontos apresentam dificuldades e houve uma ou outra adaptação, que será tratada ao longo deste texto.

(6) tfi ku'me piאa igbe'gbe na 'kafi se 2PS comer pilha búzio PREP casa 3POSS 'Você comeu muitos búzios em sua casa.'

Tabela 2.3: Diferenças ortográficas na literatura

\begin{tabular}{ll}
\hline Günther (1973) & Ci kumé píKa igbegbé na káfi se. \\
Rougé (2004) & Txi kume pilya igbêgbê na kaxi se. \\
Mane $(2007)$ & Txi kume piאa igbegbe na kafi se. \\
Maurer $(2009)$ & Txi kume pilha igbegbe na kaxi sê. \\
ALUSTP (2009) & Txi kumê pilha igbegbe na kaxi sê. \\
\hline
\end{tabular}

No que diz respeito as vogais, por exemplo, a oposição entre vogais médias-altas e baixas, no ALUSTP, é marcada pelo uso do diacrítico circunflexo nas médias altas [e] e [o]. As médias-baixas $[\varepsilon]$ e $[\rho]$ não recebem qualquer marcação, conforme a representação gráfica em (Tabela 2.4). 
Tabela 2.4: Ortografia: vogais

\begin{tabular}{cccccc}
\hline$/ \mathrm{i} /$ & $\rightarrow$ & $<\mathbf{i}>$ & $/ \mathrm{u} /$ & $\rightarrow$ & $<\mathbf{u}>$ \\
$/ \mathrm{e} /$ & $\rightarrow$ & $<\hat{\mathbf{e}}>$ & $/ \mathrm{o} /$ & $\rightarrow$ & $<\hat{\mathbf{o}}>$ \\
$/ \mathrm{e} /$ & $\rightarrow$ & $<\mathbf{e}>$ & $/ \mathrm{\jmath} /$ & $\rightarrow$ & $<\mathbf{o}>$ \\
& $/ \mathrm{a} /$ & $\rightarrow$ & $<\mathbf{a}>$ & \\
\hline
\end{tabular}

Segundo Maurer (2009:23), nas palavras de origem portuguesa (caroço $>$ kôôsu e prata $>$ paata) pode-se observar que as vogais longas são resultado da queda de consoantes. Ferraz \& Trail (1981) argumentam que há uma redução no número de sílabas ou mesmo eliminação de certas grupos de consoantes inicial ou médio (cluster, ex. pre.to> peetu).

Segundo o ALUSTP, sempre que houver alongamento de vogal, será marcada com vogal duplicada.

$$
\begin{aligned}
& \text { gaa.vi } \rightarrow \text { 'bonito' } \\
& \text { ga.ba } \rightarrow \text { 'gabar' } \\
& \text { gaan } \rightarrow \text { 'enganar' } \\
& \text { gan } \rightarrow \text { 'grão' }
\end{aligned}
$$

De acordo com o ALUSTP, os segmentos consonantais são marcados com os grafemas listados na Tabela 2.5.

No ALUSTP, os fonemas consoantais velo-labiais $/ \widehat{\mathrm{kp}} / \mathrm{e} / \widehat{\mathrm{gb}} /$ são representados ortograficamente com os símbolos $<\mathrm{kp}>\mathrm{e}<\mathrm{gb}>$, respectivamente. De acordo com a descrição fonológica, /t / não é um fonema da língua, contudo, é representado grafematicamente por $<\mathrm{tx}>$. A adoção do grafema $<\mathrm{tx}>$ é parte de uma das concessões feitas no ALUSTP, posto que $/ \mathrm{t} \int /$ é um alofone e não um fonema. Uma outra concessão feita foi quanto à 
Tabela 2.5: Ortografia: consoantes

\begin{tabular}{ccc|ccc}
\hline$/ \mathrm{b} /$ & $\rightarrow$ & $<\mathrm{b}>$ & $/ \mathrm{p} /$ & $\rightarrow$ & $<\mathrm{p}>$ \\
\hline$/ \mathrm{t} /$ & $\rightarrow$ & $<\mathrm{t}>$ & $/ \mathrm{d} /$ & $\rightarrow$ & $<\mathrm{d}>$ \\
\hline$/ \mathrm{k} /$ & $\rightarrow$ & $<\mathrm{k}>$ & $/ \mathrm{g} /$ & $\rightarrow$ & $<\mathrm{g}>$ \\
\hline$/ \mathrm{gb} /$ & $\rightarrow$ & $<\mathrm{gb}>$ & $/ \mathrm{kp} /$ & $\rightarrow$ & $<\mathrm{kp}>$ \\
\hline$/ \mathrm{m} /$ & $\rightarrow$ & $<\mathrm{m}>$ & $/ \mathrm{n} /$ & $\rightarrow$ & $<\mathrm{n}>$ \\
\hline$/ \mathrm{n} /$ & $\rightarrow$ & $<\mathrm{nh}>$ & & & \\
\hline$/ \mathrm{v} /$ & $\rightarrow$ & $<\mathrm{v}>$ & $/ \mathrm{f}$ & $\rightarrow$ & $<\mathrm{f}>$ \\
\hline$/ \mathrm{z} /$ & $\rightarrow$ & $<\mathrm{z}>$ & $/ \mathrm{s} /$ & $\rightarrow$ & $<\mathrm{s}>$ \\
\hline$/ \mathrm{3} /$ & $\rightarrow$ & $<\mathrm{j}>$ & $/ \mathrm{d} /$ & $\rightarrow$ & $<\mathrm{x}>$ \\
\hline$/ \mathrm{t} /$ & $\rightarrow$ & $<\mathrm{tx}>$ & $/ \mathrm{r} /$ & $\rightarrow$ & $<\mathrm{r}>$ \\
\hline$/ \mathrm{l} / \mathrm{l}$ & $\rightarrow$ & $<\mathrm{l}>$ & $/ \mathrm{K} /$ & $\rightarrow$ & $<\mathrm{lh}>$ \\
\hline$/ \mathrm{w} /$ & $\rightarrow$ & $<\mathrm{w}>$ & $/ \mathrm{j} /$ & $\rightarrow$ & $<\mathrm{y}>$ \\
\hline
\end{tabular}

palavra ũa 'um, uma', outra exceção à simplicidade da escrita por apresentar um diacrítico nasal, sendo o único caso no principense.

Muitas das inconsistências do sistema de escrita português, que geram dificuldades de aprendizagem da escrita da língua e, apesar de o ALUSTP apresentar um sistema gráfico de caráter científico, que teoricamente o distância do padrão da escrita portuguesa, o grupo proponente do ALUSTP acabou por adotar algumas regras da grafia portuguesa, como por exemplo, quanto à representação da nasalidade e o emprego de $<$ m $>$ antes de $<$ p $>$ e $<\mathrm{b}>$, e $<\mathrm{n}>$ em demais contextos. Assim, a nasalização vocálica pode ser representada pela vogal seguida por $<\mathrm{m}>$ ou $<\mathrm{n}>$, exceto ũa.

$$
\begin{aligned}
& \text { kampu } \rightarrow \text { 'campo' } \\
& \text { bumbun } \rightarrow \text { 'abelha' } \\
& \text { alikansa } \rightarrow \text { 'alcançar' } \\
& \text { bôdan } \rightarrow \text { 'bordão' }
\end{aligned}
$$

Apesar das diferenças das três línguas faladas nas ilhas de São Tomé e Príncipe, o compartilhamento de traços gramaticais e lexicais justificam a adoção do alfabeto unificado. 
O alfabeto ainda está em fase de experimentação e, após um período de cinco anos, será feita uma avaliação e as reformulações necessárias. Acreditamos que a publicação de dicionários e outros materiais com a ortografia ALUSTP dará prestígio ao sistema e garantirá sua sobrevivência. 


\section{Capítulo 3}

\section{Lexicografia}

\subsection{Introdução}

Este capítulo aborda as questões metodológicas da elaboração de um dicionário. Primeiramente, em 3.2 apresento algumas das definições apresentadas na literatura para obras lexicográficas e propostas para dicionário bilíngue em 3.3 de acordo com a os critérios paresentados em 3.3.1 de funcionalidade, direcionalidade e reciprocidade. Em 3.4 questões pertinentes a dicionários bilíngues e, logo adiante, em 3.4.1.1 e 3.4.1.2, encontram-se aspectos ligados à macro e microestrutura do dicionário bilíngue principense-português.

\subsection{Definição de uma obra lexicográfica}

Durante grande parte do século XX, a lexicografia era considerada a prática de composição de dicionários. Al-Kasimi (1983: 1) não a considera como ciência, mas como uma atividade sem objetivo teórico, mas prático. A partir do século XX, começam a aparecer trabalhos que tratam a lexicografia como ciência aplicada que teria como produto a investigação linguística de obras tais como dicionário, vocabulário etc., e separando-a da lexicologia, que se situaria na análise de investigação do léxico. É muito comum ainda hoje nomear uma obra lexicográfica ou terminológica como dicionário. Além da definição ser bastante polêmica, 
é míster que o termo dicionário valoriza a obra e lhe confere maior status. Entretanto, definir glossário, vocabulário e dicionário é um tarefa bastante complexa. Contudo, o campo de pesquisa na área lexicográfica vem crescendo e alguns autores propõem definições para cada um dos termos. Haensch (1982) considera glossários e vocabulários sinônimos. O autor trabalha com a conceptualização de dicionário e deixa de lado os termos glossário e vocabulário. Tanto Weinreich (1970) quanto Hartmann \& James (2001) veem o dicionário como uma descrição lexicográfica da língua. Para Hartmann \& James o dicionário é uma obra de consulta, um instrumento didático e também um instrumento sócio-cultural de consumo.

Codifying usage is an important, but not the chief objective of dictionaries.

Most lexicographers derive at least some satisfaction from the knowledge that the product of their labours can help ordinary language users in situations of communicative conflict or deficit ${ }^{1}$.

Barbosa (2001) utiliza alguns critérios para a definição de cada um dos termos lexicógraficos em questão. A autora defende que a distinção é feita segundo os níveis de atualização da língua. Assim, os vocabulários possuem um corpus limitado e frequentemente representa um universo do discurso. Em geral, os vocabulários incluem a entrada lexical (na língua original) e sua tradução. Já os glossários são mais restritos, tanto em número de entradas quanto na abordagem de assuntos. Para a autora, o dicionário contém uma preocupação mais ampla com as entradas lexicais e seus paradigmas. Além da simples tradução, é importante o uso de equivalências, informações morfossintáticas, fonéticas, fonológicas,

${ }^{1} \mathrm{O}$ uso como instrumento de codificação é importante, porém não é o objetivo primeiro dos dicionários. A maioria dos lexicógrafos fica satisfeita em supor que o conhecimento gerado pelo seu trabalho poderá auxiliar os usuários comuns da língua em situações de conflito ou déficit comunicativo. 
discursivas, entre outras. É importante ressaltar que cada informação contida no dicionário dependerá de alguns critérios como alvo, direcionalidade e função, tratados adiante.

As definições propostas por Barbosa são similares às da obra de Muller (1968:20), na qual o autor afirma que o dicionário de uma língua tende a reunir o universo dos lexemas, os quais são as unidades-padrão do sistema. Os vocabulários técnico-científicos e especializados buscam, entretanto, situar-se ao nível de uma norma linguística e sóciocultural, desse modo, o vocabulário fundamental busca reunir os elementos constitutivos de interseç̧ão dos conjuntos-vocabulários de uma comunidade ou de um segmento social. O glossário, encontra-se geralmente no final de certos livros para esclarecer o significado de determinadas palavras ou expressões usadas pelos autores (citado por Ferreira 2005:7-8).

Visto que se trata de um debate recente, não há consenso na definição de cada termo e seu emprego acaba se dando a partir de critérios diferentes, consoante cada autor. Porém, é consenso entre os estudiosos que, dos termos utilizados, o dicionário seria a obra mais abrangente. Ferreira (2005) aponta que as definições de um dicionário estão geralmente direcionadas para a informação que o leitor deve ter para entender uma palavra que não lhe é familiar. A ênfase na palavra e toda a informação dada é sobre o significado, pronúncia, uso ou história da palavra.

Um dicionário deve reunir o maior número possível de unidades lexicais que dê conta de um escopo que cubra a língua de forma mais abrangente possível. Entretanto, o léxico de uma língua está sempre aberto e com possibilidade de crescimento, sendo assim, não pode ser esgotado pela realidade concreta de qualquer vocabulário, uma realidade que, segundo Scantamburlo (1999), é sempre condicionada pelo número infinito de lexemas e de significações. Apesar de um dicionário estar sempre ultrapassado, uma vez que o léxico está 
sujeito à constante transformação, desaparecimento e surgimento de novos vocábulos decorrentes de empréstimos e outros processos linguísticos, é um dos principais instrumentos para consolidação de uma língua.

Além da grande tarefa da compilação de um dicionário, outra dificuldade é o fato de não haver cultura escrita na ilha do Príncipe, enquanto muitos dicionários usam como base material escritos, ficcional e não-ficcional.

\subsection{Dicionário bilíngue e sua proposta}

Em termos gerais, o dicionário bilíngue tem como característica a correspondência entre duas línguas. Apesar de não haver consenso entre as informações que devem aparecer em um dicionário, há princípios e informações básicas que não podem estar de fora no momento da compilação. Dessa forma, as informações contidas devem estar de acordo com a proposta do dicionário. Alguns dicionários bilíngues trazem apenas os equivalentes na língua estrangeira, o que, segundo Farias (1998), pode sugerir uma correspondência biunívoca entre os termos da língua de partida (LP) e da língua de chegada (LC).

A dificuldade no estabelecimento das equivalências, segundo Miranda \& Farias (2011), remete às questões do anisomorfismo línguistico, isto é, refere-se à organização singular de cada língua no seu nível estrutural - fonético-fonológico, lexical e morfossintático evidenciados pelos seus traços genéticos e tipológicos. As autoras reiteram que as línguas apresentam traços e filiações genéticas em comum, mas levando em conta a tipologia, apresentam divergências consideráveis que devem ser levadas em conta. Dessa forma, quando essas línguas apresentam divergências culturais significativas, o fornecimento de informações complementares, além das equivalências, visam satisfazer esse esforço compensatório de uma língua em relação à outra.

Em dicionários bilíngues, a tradução deve se valer do uso de equivalentes, paráfrases 
explanatórias, ou mesmo de outros códigos semióticos como gravuras, áudio etc., para um melhor resultado, principalmente no que diz respeito aos termos da língua que se referem a uma realidade cultural particular.

Um dicionário deve buscar apresentar todas as acepções do verbete. No entanto, na compilação de um dicionário bilíngue, nem todas as acepções são registradas, isso porque algumas resultam de contexto particular no qual está inserida. Para Werner \& Chuchuy (1992: 11), nos dicionários bilíngues, paralelamente ao dicionário monolíngue, a unidade de tratamento lexicográfico é a unidade lexicográfica da língua de partida - palavra ou conjunto de palavras com uma acepção claramente delimitada - e o equivalente - palavra ou conjunto de palavras correspondente na língua de chegada - juntamente com qualquer outra explicação ou informação gramatical, semântica, de uso, exemplos etc. De forma semelhante, Landau (1989) afirma que as principais etapas para elaboração de um dicionário bilíngue são: a tradução para cada palavra na língua fonte, a cobertura completa do léxico, a adição de informações gramaticais, sintáticas e semânticas, a orientação para o usuário, a inclusão de nomes, itens especiais e termos científicos, a grafia e a pronúncia. Ferreira (2005) observa que as informações contidas em um dicionário bilíngue tem o papel de sistematizar o contraste existente entre as duas línguas em questão e, assim, fornecer ao usuário as informações necessárias sobre a língua que lhe é desconhecida.

Visto que o usuário de um dicionário confere a este um papel de uma autoridade sancionadora, é importante ter mente que tipo de informação é relevante para cada dicionário de acordo com o objetivo e público-alvo específico. Contudo, a relevância das informações contidas devem estar de acordo com a direcionalidade e finalidade do dicionário. Nesse sentido, Duran \& Xatara (2010), classificam os dicionários segundo os critérios de funcionalidade, direcionalidade e reciprocidade. 


\subsubsection{Funcionalidade, direcionalidade e reciprocidade}

Segundo Duran \& Xatara (2010), é preciso decidir se o dicionário, por exemplo, tem como propósito dar suporte à codificação em língua estrangeira, assim, a direção apresentada deverá ser da língua materna para a língua estrangeira em que o conteúdo dos vebetes privilegie o uso de equivalentes na língua de chegada. Um dicionário que dê suporte à decodificação deverá apresentar a direção língua estrangeira para a língua materna. No que diz respeito à reciprocidade, é preciso decidir qual o público-alvo do dicionário, assim um dicionário recíproco terá como público-alvo tanto os falantes da língua materna quanto da língua de chegada. Os dicionários não recíprocos são os mais comuns. Hansen (1989) afirma que é preciso levar em conta a competência linguística diferenciada, e isso implica na definição do público-alvo. Para tanto, o autor alega que as distinções entre: língua materna e língua estrangeira, recepção e produção, sentido da tradução (da língua 1 para a língua 2, ou vice-versa) devem ser claras no momento da confecção do dicionário bilíngue. Outro ponto considerado como critério é a direcionalidade. Um dicionário pode ser mono ou bidirecional, ou seja, dadas duas línguas envolvidas, L1 e L2, a direção pode ser de L1-L2, L2-L1 ou ambas as direções. Segundo Duran \& Xatara (2010), as decisões acerca do público-alvo e da função condicionam a direção e a condição de reciprocidade ou não do dicionário, o que significa que a macro e microestrutura deverão ser coerentes com a direção, função e reciprocidade determinadas pelo projeto, possibilitando ao usuário uma boa compreensão da língua.

\subsection{Dicionário principense}

Toda língua apresenta uma organização única em todos os níveis estruturais. Segundo Zgusta (1971), apesar de duas línguas apresentarem alguma relação genética do ponto 
de vista tipológico, por exemplo, apresentam semelhanças consideráveis que podem ser reconhecidas nos níveis fonético-fonológico, lexical e morfossintático. Nos crioulos de base portuguesa, grande parte do léxico é de origem portuguesa, embora haja muitas vezes alteração de forma e significado. Assim, no que diz respeito à fonologia, à semântica, à morfossintaxe e à inteligibilidade são línguas diferenciadas e autónomas.

O dicionário bilíngue principense-português tem a função de documentar uma língua que ainda hoje é vista por alguns falantes locais como uma forma deturpada do português. Além do intuito de servir à comunidade de fala, diante da escassez de instrumentos linguísticos sobre essa língua, visa contribuir com a pesquisa e documentação de uma língua do Golfo da Guiné, pouco estudada até o momento e que pode estar em vias de desaparecimento. Portanto, esse dicionário destina-se à comunidade de fala, ao meio acadêmico e aos possíveis interessados em conhecer a língua principense.

O intuito desse trabalho é registrar o maior número possível de palavras que faça parte do universo lexical principense. Dessa forma, todas as unidades lexicais coletadas tanto nos materiais impressos, quanto nas gravações feitas in loco, com exceção das que geraram alguma dúvida no momento da compilação, fazem parte do corpus do dicionário. O dicionário principense, por se destinar a comunidade, tem como função ajudar na compreensão e comunicação e principalmente, facilitar a aprendizagem da língua, que para a maioria dos membros étnicos principenses da Ilha do Príncipe é segunda língua, apresentando uma seleção de vocábulos classificados segundo a cultura local.

\subsubsection{Macro e microestrutura}

\subsubsection{Macroestrutura}

Muios autores consideram a ordenação alfabética o princípio mais importante para organização da macroestrutura de um dicionário, o que não significa que seja o único modo 
de organização possível. Segundo Ferreira (2005) a macroestrutura compreende a organização do dicionário construída a partir da escolha das entradas, da escolha do conteúdo, ordenação e tratamento dos lexemas.

Como discutido, alguns procedimentos devem ser levados em conta no momento da compilação de um dicionário bilíngue para que facilite o entendimento da língua pelo usuário. As necessidades do usuário são fundamentais para efeitos macroestruturais no momento da elaboração do dicionário.

As entradas estão em ordem alfabética. As palavras que se iniciam com os fonemas velo-labiais / $\widehat{\mathrm{gb}} / \mathrm{e} / \widehat{\mathrm{kp}} /$ aparecem, no dicionário, nas letras $\langle\mathrm{g}>\mathrm{e}<\mathrm{k}>$, respectivamente. Assim, palavras como gbôgbô 'migalha', por exemplo, aparecere juntamente com as entradas em $<\mathrm{g}>$. Todas as unidades lexicais coletadas foram conferidas com falantes nativos e mais de $80 \%$ são apresentadas acompanhadas de exemplos da língua, com a respectiva tradução para o português, de modo a permitir melhor compreensão do significado.

Os lexemas com a mesma forma e significados diferentes são tratados da forma seguinte: os que possuem traços semânticos em comum constituem um único verbete e serão organizados em uma mesma entrada (polissemia) com os vários significados numerados em sequência horizontal. As palavras distantes com relação ao significado e que não compartilham de traços semânticos serão tratadas em entradas separadas (homonímia) para especificar as suas diferenças, com os significados numerados verticalmente.

\subsubsection{Microestrutura}

Hartmann (2001) descreve a microestrutura como o desenho interno do verbete, que fornece informações detalhadas sobre cada entrada, informações formais e semânticas (grafia, pronúncia, rubrica gramatical, definição, uso, etc). A microestrutura envolve, portanto, a fixação de um programa de informações previamente estabelecidas, o que foi contemplado 
com o uso da plataforma Toolbox. Este programa é uma ferramenta para gestão e análise de dados que permite a codificação e análise de textos, bem como recurso de exportação dos dados para produção de dicionários para publicação. No Toolbox são estabelecidos os campos que apresentam informações detalhadas a cerca de cada entrada lexical.

Tabela 3.1: Esquema de entradas no Toolbox.

\begin{tabular}{l|ll}
\hline$\backslash \mathrm{x}$ & Lexeme & adi \\
$\backslash \mathrm{ph}$ & Phonetics & {$[\mathrm{a}$ 'di] } \\
$\backslash \mathrm{ps}$ & Part of speech & n. \\
$\backslash \mathrm{gn}$ & Gloss national & andim \\
$\backslash \mathrm{ge}$ & Gloss german & Andim-Frucht. \\
$\backslash \mathrm{rf}$ & Source & G.73:43 \\
$\backslash \mathrm{xv}$ & Example & N mêsê fya pwêma adi ũa. \\
$\backslash \mathrm{xn}$ & Translation & Quero uma folha de palmeira andim. \\
$\backslash \mathrm{sc}$ & Scientific name & Azadirachta \\
$\backslash \mathrm{dt}$ & Date & $05 /$ Dec $/ 2010$ \\
\hline
\end{tabular}

Os verbetes então apresentam a notação gráficas, conforme proposta ortográfica do ALUSTP, transcrições fonéticas, rubrica gramatical (que informa se a entrada é um verbo, pronome, substantivo etc.) e sua respectiva tradução em português. Para o equivalente de cada vocábulo e sua respectiva tradução, empregamos o termo mais próximo tomando como referência os traços semânticos próprios que os distinguem.

O dicionário Principense-Português apresenta cerca de três mil verbetes. Como proposto por Barbosa (1993), o dicionário contém uma preocupação mais ampla com as entradas lexicais. Dicionários desse tipo podem ser organizados de forma semasiológica ou onomasiológica. Esta parte da significação para a designação linguística dos conceitos ou objetos e aquela busca o sentido da palavra para descrever seu significado. Desse modo, a primeira trata dos sentidos, de forma descritiva, enquanto a segunda trata das designações. É mister, portanto, definir, em termos gerais, nossa proposta de dicionário. Em primeiro lugar, foi produzido um dicionário alfabético (em detrimento de um dicionário que privilegiasse as relações entre conceitos e que, quase sempre, os agrupa sem considerar 
a ordem alfabética). O dicionário contém a entrada lexical em sua forma gráfica, seguida de suas formas fonéticas. Imediatamente depois, há a rubrica gramatical (verbo, pronome, substantivo etc.). O sentido (semasiologia) do lexema vem em seguida.

Quando há sentenças retirados de material publicado, as referências bibliográficas seguem o padrão G.1973:10 sendo G(ünther), referente ao nome do autor, 1973 ao ano de publicação e 10 à pagina. As referências no padrão V.2011 dizem respeito ao nome de quem coletou os dados e o ano da coleta, no caso Vanessa. Assim, G.2008 diz respeito aos dados coletados pelo orientador da pesquisa em 2008, ALSA.2011 aos dados coletados por Ana Lívia dos Santos Agostinho e, V.2009 e V.2011 dizem respeito aos dados coletados por mim. As demais abreviaturas estão descritas na lista de abreviaturas, neste trabalho. A referência é sempre da primeira fonte onde foi encontrada com exceção dos casos em que uma palavra aparecia de diferentes forma em duas ou mais listas, nesses casos, a entrada da coleta mais atualizada foi a escolhida. No dicionário, os particípios são classificados como adjetivos, os verbos seriais como expressão idiomática (idiom.) e alguns topônimos também foram listados.

Nenhum dicionário é completo sem abordar o tema da variação. Como o principense está em fase de obsolescência, com pouco uso diário na comunidade, associado ao fato de ter poucos falantes nativos, a variação linguística é reduzida. Por vezes, os próprios falantes discutem entre si a possibilidade de variação e, comumente, chegam a um consenso. No dicionário, as formas variantes se remetem à forma mais comum, ou mais aceita pelo maior grupo de falantes. 


\section{Capítulo 4}

\section{Considerações finais}

O trabalho aqui apresentado é composto por quatro capítulos, além das referências bibliográficas e do dicionário em si, no ANEXO. Os capítulos apresentam as etapas da compilação do dicionário bilíngue principense-português bem como questões que foram levadas em conta no momento da compilação.

No primeiro capítulo, além de apresentar a proposta do dicionário e sua justificativa, trato do material utilizado e como será feita a análise dos dados obtidos. Ademais a dificuldade em se fazer um dicionário onde não há cultura escrita, trato do acesso à ilha, um enorme obstáculo, visto o grande custo e tempo necessários. Esse capítulo apresenta ainda considerações à cerca da linguística de contato e ainda questões pertinentes a definições do termo crioulo, além de algumas propostas para a formação das línguas crioulas, mais especificamente abrangendo a área do Golfo da Guiné. O segundo capítulo trata da língua principense. Nesse capítulo encontra-se uma breve descrição da fonologia da língua com ênfase no sitema vocálico, consonantal, silábico e traços da tonologia e referentes a ortografia adotada. O capítulo três apresenta a metodologia teórica utilizada na elaboração do dicionário, questões da definição de obra lexicográfica e do dicionário bilíngue, além dos aspectos de macro e microestrutura.O quarto capítulo apresenta estas considerações finais e o quinto as referências bibliográficas. Logo a seguir, no anexo, o dicionário principense-português. 
O dicionário, por fim, apresenta cerca de 3 mil vocábulos. As coletas de dados in loco permitiram preencher várias lacunas. Com a transcrição do material coletado na ilha, muitas correções foram feitas. Os problemas decorrentes de divergências nas entradas retirados da literatura/fontes foram resolvidos levando em consideração o grande período entre uma coleta e outra, que ultrapassa mais de trinta anos, no caso de Günther (1973) e Maurer (2009), por exemplo. Há alguns vocábulos descritos na literatura/fonte que não foram reconhecidos ou desconsiderados pelos informantes como sendo vocábulos da língua. Nesses casos, houve a exclusão de alguns vocábulos e, em outros, resolveu-se manter a entrada e, quando possível foram adicionados um vocábulo ou variante.

O trabalho com os dados coletados permitiu reconstituir o léxico global da língua principense, hoje falada principalmente pela população mais velha da ilha. É possível que, com a publicação do dicionário e da gramática pedagógica de Agostinho (em preparação), estes possam servir de instrumentos linguísticos importantes para aprendizagem e divulgação da língua, despertando o interesse dos mais jovens pela língua. 


\section{Capítulo 5}

\section{Referências bibliográficas}

AGOSTINHO, Ana Lívia dos Santos. em preparação. Gramática Pedagógica do Principense. USP, São Paulo.

AITCHISON, J. 2001. Language Change: Progress or decay? Cambridge: Cambridge University Press.

AL-KASIMI, A. M. 1983. Linguistics and Bilingual Dictionaries. Leiden: E. J. Brill.

ALLEYNE, Mervin. 1971. Aculturation and the cultural matrix of creolization. In: Hymes, Dell (ed.). Pidginization and Creolization of Languages. Cambridge: Cambridge University Press.

ALlEYNE, Mervyn. 1980. Comparative Afro-American. Ann Arbor: Karoma.

ARAGONÉS, P. J; CAMACHO, G. 2004. Diccionario, léxico y cultura. Huelva: Universidad de Huelva.

ARAUJO, Gabriel Antunes de. 2009. Dados de trabalho de campo na Ilha do Príncipe. USP, Inédito.

ARAÚJO, Vanessa Pinheiro de. 2011. Relatório de Mestrado à FAPESP, projeto Dicionário Principense. USP, Inédito.

ARAÚJO, Vanessa Pinheiro de. 2009. Relatório de Iniciação Científica à FAPESP, projeto Dicionário Principense. USP, Inédito.

ARENDS, Jacques. 1989. Syntactic Developments in Sranan. Unpublished dissertation, Catholic University of Nijmegen.

ARENDS, Jacques. 1994. The socio-historical background of creoles. In

ARENDS, Jacques; Muysken, Pieter; Smith, Norval. Pidgins and Creoles: An Introduction, 15-24. Philadelphia: John Benjamins.

ARENDS, Jacques; Muysken, Pieter; Smith, Norval. 1994. Pidgins and Creoles: An Introduction. Philadelphia: John Benjamins.

ARENDS, Jacques. 1993. Towards a gradualist model of creolization. In: Frank Byrne; Holm, John (eds). Atlantic meets Pacific: A Global View of Pidginization and Creolization. Amsterdam: John Benjamins.

AUROUX, Sylvain. 1994. A revolução tecnológica da gramatização. Campinas: Ed. da Unicamp. 
BAKER, Peter. 2002. Pidgin inflectional morphology and its implications for creole morphology. Yearbook of Morphology. Dordrecht: Kluwer Academic Publishers.

BARBOSA, Maria A. 2001. Dicionário, vocabulário, glossário: concepções. In: ALVES, I. M. (Org.). A constituição da normalização terminológica no Brasil. 2 ed. São Paulo: FFLCH/CITRAT.

BARBOSA, Maria A. 1993. O léxico e a produção da cultura: elementos semânticos. Anais do I Encontro de Estudos Linguísticos de Assis. Anais. Assis: UNESP.

BARRENA, Rvdo. P. Natalio. 1957. Gramatica Annobonesa. Madrid: Consejo Superior de Investigaciones Cientificas.

BICKERTON, Derek. 1988. "Creole languages and the bioprogram". In Newmeyer, F. J., Linguistics: The Cambridge survey 2. Cambridge: Cambridge University Press.

BICKERTON, Derek. 1984. The language bioprogram hypothesis. Behavioral and Brain Sciences 7:173-221.

BICKERTON, Derk. 1981. Roots of Language. Ann Arbor: Karoma.

BICKERTON, Derek. 1977. Pidginization and creolization: language acquisition and language universals. In A. Valdraan (ed.), Pidgin and creole linguistics. Bloomington: Indiana University Press. pp. 49-69.

CARDEN, G.; Stewart, W.A. 1988. Binding Theory, Bioprogram and Creolization: Evidence from Haitian Creole. Journal of Pidgin and Creole Languages 3, 1-68.

CHAUDENSON, Robert. 1977. Toward the reconstruction of the social matrix of Creole language. In A. Valdman (ed.), Pidgin and creole linguistics. Bloomington: Indiana University. 259-76.

CLEMENTS, J. Clancy. 1996. The Genesis of a Language. Amsterdam: John Benjamins.

COUTO, Hildo Honório do. 1996. Introdução ao estudo das línguas crioulas e pidgins. Brasília: Editora da UnB.

COUTO, Hildo Honório do. 1994b. Introdução ao estudo das línguas crioulas e pidgins. Brasília: Editora da UnB.

COUTO, Hildo Honório do. 1994a. O crioulo português da Guiné-Bissau. Hamburgo: Helmut Buske.

CRYSTAL, David. 2000. Language Death. Cambridge: Cambridge University Press.

DEGRAFF, Michel. 2003. Against Creole Exceptionalism. Language 79: 391-410 .

DURAN, M. S. ; XATARA, C. 2007. Critérios para categorização de dicionários bilíngües. In: Aparecida Isquerdo. (Org.). As ciências do léxico, v. 3, 311-320. Campo Grande/São Paulo: Ed. UFMS/HUMANITAS.

FARIAS, V.S. 1998. La presentación del comentario semántico en los diccionarios escolares. Revista Letras 70.

FERGUSON, C.A. 1971. Absence of Copula and the Notion of Simplicity: A Study of Normal Speech, Baby Talk, Foreigner Talk and Pidgins. In Hymes, D. (ed). Pidginization and Creolization of Languages. Cambridge: Cambridge University Press. 
FERRAZ, Luiz I. 1979. The Creole of São Tomé. Johannesburg: Witwatersrand University Press.

FERRAZ, Luiz I. 1976. A origem e o desenvolvimento de quatro crioulos portugueses do Golfo da Guiné. Revista Brasileira de Lingüistica 3 (2): 70-76.

FERRAZ, Luiz I.; TRAILL, Anthony. 1981. The interpretation of tone in Principense creole. Studies in African Linguistics 22-2:205-15.

FERREIRA, Vitória R. Spanghero. 2005. Estudo lexical da lingual Matis: subsídios para um dicionário bilíngüe. Universidade Estadual de Campinas. Unicamp - Campinas. SP.

GARFIELD, Robert. 1992. A History of São Tomé Island (1470-1655). The Key to Guinea. San Francisco: Mellen Research University Press.

GERARDO, Lorenzino. 1998. The Angolar Creole Portuguese of São Tomé: its grammar and sociolinguistic history. Munique: LINCOM Europa.

GÜNTHER, Wilfried. 1973. Das portugiesische Kreolisch der Ilha do Príncipe. Marburg an der Lahn: Im Selbstverlag.

HAENSCH, G. 1982. Tipología de las obras lexicográficas e Aspectos prácticos de la elaboración de diccionarios. In: Ettinger, S. et al. (eds.) La lexicografía. De la linguística teórica a la lexicografia práctica. Madrid: Gredos.

HAGEMEIJER, Tjerk. 2009. As Línguas de S. Tomé e Príncipe. Revista de Crioulos de Base Lexical Portuguesa e Espanhola 1: 27.

HALE, Ken; Kenstowicz, Michael. 2001. A life in languages (ed). Cambridge: Massachusetts.

HANSEN, Gitte Baunebjerg. 1990 Artikelstruktur im zweisprachigen Wörterbuch. Tübingen: Niemeyer.

HARTMANN, R. R. K; JAMES, G. 2001. Dictionary of Lexicography. London: Routledge.

HOLM, John. 2004. Languages in Contact: The Partial Restructuring of Vernaculars. Cambridge: Cambridge University Press.

HOLM, John. 2000. An introduction to pidgins and creoles. Cambridge: Cambridge University Press.

HOLM, John. 1988/9. Pidgins and creoles (2 vols). Cambridge: CUP.

LANDAU, S. I. 1989. Dictionaries: the art and craft of lexicography. Cambridge: Cambridge University Press.

LUMSDEN, John. 1999. Language acquisition and creolization. In Michel DeGraff (ed) 1999: $129-157$.

MANE, Djiby. 2007. Os crioulos portugueses do Golfo da Guiné: quatro línguas diferentes ou dialetos de uma mesma língua? Tese de doutorado, Universidade de Brasília, UNB, Brasília.

MAURER, Phillippe. 2009. Principense (Lung'Ie) Grammar, Texts, and Vocabulary of the Afro-Portuguese Creole of the Island of Principe, Gulf of Guinea. BattleBridge. London UK. 
MAURER, Philippe. 1995. L'angolar: Um créole afro-portugais parlé à São Tomé. Hamburgo: Helmut Buske Verlag.

MCWHORTER, John H. 1992. Substratal influence in Saramaccan serial verb construction. Journal of Pidgin and Creole Languages 7:1. pp. 1-53.

MUFWENE, S. 2007. What do creoles and pidgins tell us about the evolution of language?. In: Laks, Bernard; Cleiziou, Serge; Demoule, Jean-Paul; Encrevé, Pierre (eds.). The origin and evolution of languages: approaches, models, paradigms. London: Equinox.

MUFWENE, S. 2001. The Founder Principle in the development of creoles. In: Mufwene, S. The Ecology of Language Evolution. Cambridge: CUP.

MUFWENE, S. (ed.) 1993. Africanisms in Afro-American Language Varieties. Athens: University of Georgia Press.

MIRANDA, Félix Valentin Bugueño; FARIAS, Virginia Sita. 2011. Demandas curriculares e lexicografia: os dicionários escolares são adequados para a produção textual? ReVEL 9(17). [www.revel.inf.br].

MULLER, Ch. 1968. Initiation à la statistique linguistique. Paris: Larousse.

MYERS-SCOTTON, C. 2002. Contact Linguistics: Bilingual Encounters and Grammatical Outcomes. Oxford: Oxford University Press.

NEGREIROS, Antônio de Almada. 1895. História Ethnográphica da Ilha de São Tomé. Lisboa.

PAYNE, Thomas E. 1997. Describing Morphosyntax: A Guide for Field Linguists. Cambridge University Press.

REIS, Fernando. 1969. Povô Flogá/O povo brinca: folclore de São Tomé e Príncipe. São Tomé: Câmara Municipal de São Tomé.

ROUGÉ, Jean Louis. 2004. Dictionnaire étymologique des créoles portugais d'Afrique. Paris: Karthala.

SCANTAMBURLO, L. 1999.Dicionário do Guineense Vol. I, Introdução e Notas Gramaticais. Lisboa/Bissau: Edições Colibri/FASPEBI.

SCHUCHARDT, Hugo. 1979. The ethnography of variation: Selected writings on pidgins and creoles. Edited and translated by T.L. Markey. Ann Arbor: Karoma.

SIEGEL, J. 2008. The emergence of pidgin and creole languages. Oxford: Oxford University Press.

SIEGEL, Jeff. 1997. Mixing, Leveling, and Pidgin in Creole Development. In: Spears, A.K \& Winford, D. (eds). The Structure and Status of Pidgins and Creoles. Vol. 19. Creole Language Library. Amsterdam: John Benjamins.

SMITH, Norval. 2008. Creole phonology. In KOWENBERG, S.; SINGLER, J.V. (eds.), Handbook of pidgin and creole studies. Malden: Blackwell.

SMITH, Norval. 1987. The Genesis of the Creole Languages of Surinam. Unpublished dissertation, Universiteit van Amsterdam.

TAYLOR, Douglas. 1971. Grammatical and Lexical Affinities of Crioules. In: Hymes, Dell (org). Pidginization and Creolization of Languages. Cambridge: Cambridge University Press. 293-296. 
TAYLOR, Douglas. 1961. New languages for old in the West Indies. In: Comparative Studies in Society and History. vol. 3. Jstor: Cambridge University Press. 277-288.

TAYLOR, Douglas. 1956. Language Contacts in the West Indies. Word 12. pp. 391-414.

THOMASON, Sarah G., KAUFMAN, Terrence. 1988. Language contact, creolization, and genetic linguistics. Berkeley: University of California Press.

THOMASON, Sarah G. 2008. Pidgins/Creoles and Historical Linguistics. In: Kouwenberg, S.; Singler, J. V.(eds.) The Handbook of Pidgin and Creole Studies. Oxford: Blackwell.Windford.

THOMPSON, R.W. 1961. A note on some possible affinities between the creole dialects of the Old World and those of the New. In Le Page, Creole Language Studies.

VALKHOFF, Marius F. 1966. Studies in Portuguese and Creole. Johannesburg: Witwatersrand University Press.

VALKHOFF, Marius-François. 1960. Contributions to the study of Creole. African Studies 19(3): 113-25.

VAUX, Bert; Cooper, Justin; Tucker, Emily. 2006. Linguistic Field Methods. Eugene: Oregon.

WEINREICH, U. 1970. La Définition Lexicographique dans la Sémantique Descriptive. Languages 19. pp. 69-86.

WERNER, R.; CHUCHUY, C. 1992. ¿Qué son los equivalentes en el diccionario bilingüe? In: G. Wotjak (ed.). Estudios de lexicología y metalexicografía del español actual. Tübingen: Max Niemeyer Verlag.

ZGUSTA, Ladislav. 1971. Manual of Lexicography. The Hague: Mouton. 
Apêndice A

Dicionário Principense-Português 


\section{A}

a ['a] 1. disc. Marcador de pergunta. Ê sa dwentxi a? Ele está doente? 2. part. Cf. ka. 3. part. Cf. sa. 4. $v$. Estar. $\hat{\mathbf{E}}$ a vendê banan karu. Ele vende caro as bananas.

abadi [aba'di] $n$. Rifle.

abe [a'be] 1. v. Avisar. 2. v. Confirmar.

abya [a'bja] $n$. Ribeira.

abôtô [a'boto] n. Aborto.

ade [a'de] neg. Não. Ade. $\mathbf{N}$ sa mêsê kwi sê fa. Não. Eu não quero isso.

adi [a'di] n. Andim. Azadirachta.

adiminixtradô [adminiftra'do] $n$. Administrador.

afe $\left[a^{\prime} f \varepsilon\right] n$. Fé.

Afika ['afika] top. África.

afikana [afi'kana] adj. Africana.

afyetxi [a'fjet $\left.\int i\right] n$. Alfaiate.

agama [aga'ma] $n$. Ser muito grande. Kaxi tê agama. Sua casa é muito grande.

agya ['agja] $n$. Águia.

akara [aka'ra] $n$. Fatias fritas de banana.

akarê [aka're] $n$. Sapo.

akpawa [akpa'wa] n. Pargo. Pagrus caeruleostictus.

akpen [a'kpẽ] n. Akpen. Personagem de histórias tradicionais.

akê [a'ke] n. Pote de barro.

algôdan [algo'dã] $n$. Cf. Alugudan.

alifandiga [ali'fãdiga] $n$. Alfândega.

alima ['alima] $n$. Cf. zalima.

alikansa [alikã'sa] $v$. Alcançar.

alisapan [alisa'pã] $n$. Alçapão.

alugudan [alugu'dã] $n$. Algodão.

alunu [a'lunu] $n$. Aluno.

amanhan [ama'jã] $a d v$. Amanhã.

amarela [ama'rela] $n$. Febre amarela.

ami [a'mi] 1. pro. Eu. Ami ka fala ingêxi bon fêtu. Eu falo inglês muito bem. 2. pro. Comigo. Ê sa mêsê faa ku ami. Ele quer falar comigo. 3. pro. Mim. ???

amwê [a'mwe] n. Amor. 
amêrikanu [ameri'kãnu] 1. adj. Americano. 2. n. Americano.

aneli [a'ncli] $n$. Anel.

anikineli [aniki'nعli] Fórmula usada pelos contadores para se iniciar uma história.

anima [ani'ma] $n$. Animal.

antxi ['ãti] conj. Antes. Antxi pwe gaani me mwê ê kaba pelipeli ê vya mangu peli ki osu. Antes do meu avô morrer, ele ficou pele e osso.

antxi pa ['ãt]i 'pa] conj. Antes de. Antxi pa n we posan, $\mathbf{n}$ pasa we oso. Antes de passar pela cidade, passei pela roça.

anu ['anu] n. Ano.

anzu ['ãzu] 1. $n$. Anjo. 2. n. Criança.

apa [a'pa] 1. interj. Ora bolas! 2. $n$. Pá.

apasê [apa'se] $v$. Aparecer.

arê [a're] n. Rei.

ariba ['ariba] $n$. Capim.

arku ['arku] 1. $n$. Arco. Cf. aruku. 2. n. Arco. Cf. ufeew.

arimazen [arima'z $\tilde{\varepsilon}] n$. Cf. Rumazen.

arôtô [a'roto] $n$. Arroto.

aruku ['aruku] n. Arco.

aruku-ve ['aruku 've] $n$. Arco-íris.

arumari [aru'mari] $n$. Cf. kantxya.

arya [a'rja] n. Areia.

atêra [ate'ra] 1. $v$. Aterrar. 2. v. Aterrisar.

atu ['atu] adj. Alto.

atun $\left[a^{\prime} t u ̃\right] ~ n$. Atum.

atxi ['at $\left.\int i\right] n$. Profissão.

atxi [a'tsi] 1. pro. Você. 2. pro. Te.

avenida [ave'nida] $n$. Avenida.

avyan [a'vjã] $n$. Avião.

awa ['awa] n. Água.

awadenti [awa'dẽti] $n$. Aguardente.

awmôsa [awmo'sa] v. Cf. rômôsu.

awtura [aw'tura] 1. adj. Altura. 2. n. Altura.

awtu ['awtu] n. Cf. atu.

axa $\left[\mathrm{a} \int \mathrm{a}\right]$ 1. v. Achar. 2. v. Encontrar. 
axi [a'fi] adv. Assim. Axi... mo(di). Assim como.

axi mesu [a'fi 'mesu] conj. Embora. A:2011. Axi mesu ki $\mathbf{n}$ tava mêsê fa... Embora eu não quisesse... avô [a'vo] n. Avô.

aza ['aza] n. Asa.

aza [a'za] v. Azar. 
ba ['ba] int. Onde está. Kasô tê ba? Seu cachorro, onde está?

baa ['ba:] 1. adj. Ligada. 2. v. Arder. 3. v. Brilhar. 4. v. Queimar.

baabu ['ba:bu] 1. adj. Bravo. 2. adj. Selvagem.

baa fefefe $\left[f \varepsilon f \varepsilon^{\prime} f \varepsilon\right]$ idiom. Muito brilhante.

baanku ['bã:ku] . Branco.

baanku fenene ['bã:ku fẽnẽ'ne] idiom. Branquíssimo.

baasa ['ba:sa] $n$. Cf. zonda.

baasa [ba:'sa] $v$. Abraçar.

baata ['ba:ta] $n$. Barata.

baatu ['ba:tu] $n$. Barato.

baba [ba'ba] $v$. Babar.

bababa [baba'ba] ideo. Cf. vêmê bababa.

babêw [ba'bew] $n$. Barbeiro.

babulêta [babu'leta] $n$. Borboleta.

babya [ba'bja] $v$. Barbear.

badi ['badi] $n$. Balde.

baga [ba'ga] 1. $v$. Desmanchar. 2. $v$. Destruir.

bagasera [baga'scra] $n$. Bagaceira.

bainha ['baĩna] 1. $n$. Bainha. 2. $n$. Zíper.

Baji [ba'zi] top. Brasil.

bakatxi [ba'kat $[i] n$. Abacate.

bakaya [baka'ja] $n$. Bacalhau.

bakin [ba'kĩ] n. Barco.

baaku-fora ['ba:ku 'fora] idiom. Ânus.

bala ['bala] $n$. Bala.

balakan [bala'kã] $n$. Balcão.

balansa [ba'lãsa] $n$. Balança.

balisama [balisa'ma] $v$. Embalsamar.

bamu ['bamu] $v$. Vamos. Bamu baya kêtê pidi tê dya za ki $\mathbf{n}$ baya fa. Vamos dançar um pouco porque tem dias já que eu não danço.

bana ['bãna] $n$. Banana. 
banan [ba'nã] $n$. Banana.

bandeza [bã'deza] $n$. Bandeja.

bandidu [bã'didu] $n$. Bandido.

bandona [bãdo'na] $v$. Abandonar.

bandu ['bãdu] $n$. Proclamação.

bandya [bã'dja] $n$. Bandeira.

bandôli [bãdo'li] $n$. Bandolim.

bangwe [bã'gwe] $n$. Ombro.

banha ['baja] n. Banha.

banhu ['baju] n. Banho.

banômi [ba'nomi] $n$. Banana-pão.

bara ['bara] n. Barra.

baru ['baru] n. Bar.

barwa [ba'rwa] $v$. Esconder.

basa [ba'sa] $v$. Abaixar.

basadu [ba'sadu] adj. Fraco.

batata [ba'tata] $n$. Batata.

batê [ba'te] $v$. Bater.

batêdô [bate'do] $n$. Batedor.

batidu [ba'tidu] adj. Abatido.

bau [ba'u] n. Baú.

baxta ['bafta] $v$. Bastar.

baxtan [ba $\int^{1}$ tã] $n$. Bastão.

baxya [ba' Jja] $n$. Bacia.

baya [ba'ja] $v$. Dançar.

bayu ['baju] n. Baile.

baza ['baza] n. Brasa.

bazadu [ba'zadu] adj. Agachado.

Baziw [ba'ziw] top. Brasil.

bê ['be] 1. $a d j$. Bem. 2. $a d v$. Bem. 3. $a d v$. Também. Ê tava fika ki riman maji tamen ê vya ka kwida di riman maji mogomogo. Os irmãos mais velhos também cuidavam dos irmãos menores.

bêbê [be'be] 1. $n$. Bebê. 2. v. Beber.

bebeda [bebs'da] 1. v. Embebedar-se. 2. v. Embriagar-se.

bebedadu [bebs'dadu] adj. Bêbado. 
bêbu ['bebu] adj. Bêbado.

bebudu [be'budu] $n$. Bebida alcoólica.

bele ['belc] 1. adj. Anão. 2. n. Cf. gugu. 3. adj. Pequeno.

bele [be'le] $a d v$. Rápido. Bele ubuka. Fala rápida.

benfêtu [bẽ'fetu] 1. adj. Bem-feito. 2. adj. Educado. 3. adj. Excelente.

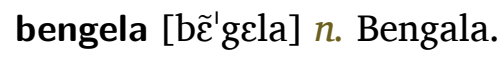

bensa ['bẽsa] $n$. Benção.

benzê [bẽ'ze] $v$. Benzer.

bêra ['bera] $n$. Beira.

bera $\left[\mathrm{b} \varepsilon^{\prime} \mathrm{ra}\right] \nu$. Berrar.

beru ['beru] $n$. Berro.

betu ['betu] adj. Aberto.

beza $\left[\mathrm{b} \varepsilon^{\prime} \mathrm{za}\right] v$. Beijar.

bêza-fôli ['beza 'foli] $n$. Beija-flor.

bêzu ['bezu] $n$. Beijo.

bêzubêzu ['bezu'bezu] n. Queixo.

bibi ['bibi] $n$. Bibe.

bibliôteka [biblio'tzka] $n$. Biblioteca.

bigadô [biga'do] $n$. Briguento.

bigodi [bi'gadi] $n$. Bigode.

bigu ['bigu] $n$. Umbigo.

bii ['bi:] v. Abrir.

bii ubaaku ['bi: u'ba:ku] idiom. Cavar.

biku ['biku] $n$. Cf. ubiku.

bili ['bili] $n$. Bílis.

bilibili ['bili'bili] $n$. Frieira.

bilidadi [bili'dadi] $n$. Habilidade.

bilêtê [bi'lete] $n$. Bilhete.

bin ['bĩ] ideo. Cf. peetu bin.

binku ['bĩku] $n$. Brinco.

binzela [bĩzzcla] $n$. Berinjela.

biolôgu [bi'Jlogu] $n$. Biólogo.

bixidu [bi'fidu] adj. Vestido. 
bixiga [bi'Jiga] $n$. Bexiga.

bisu ['bisu] 1. $n$. Animal. 2. $n$. Bicho.

bisu-ope ['bisu o'pe] 1. $n$. Bicho de pé. 2. $n$. Pulga.

bixi [bi'fi] $v$. Vestir.

bixidu [bi'Sidu] $n$. Vestido.

bixiga [bi'figa] $n$. Bexiga.

bixiketa [bifi'keta] $n$. Bicicleta.

bixpô ['bifpo] $n$. Bispo.

bizu ['bizu] $n$. Larva de cupim.

bôa ['boa] n. Brôa.

boba ['bsba] $n$. Abóbora.

bôbô [bo'bo] 1. adj. Maduro. 2. n. Banana madura.

bôbô ['bobo] n. Bobo.

bôbô [bo'bo] v. Subir.

bôbôdu [bo'bodu] adj.

bôbô-fiitu [bo'bo 'fi:tu] $n$. Banana frita.

bodan [bว'dã] $n$. Bordão.

bôdu ['bodu] $n$. Borda.

bofeta [bof'́ta] $n$. Bofetada.

bogo [bJ'gJ] v. Quebrar.

boka [bj'ka] 1. v. Beijar. 2. v. Derramar. 3. v. Emborcar. 4. v. Entornar.

bôka-xtômagu ['boka J'tomagu] $n$. Boca do estômago.

bôkô [bo'ko] v. Ser folgado.

bola ['bola] $n$. Bola.

boliboli ['boli'boli] $n$. Pequena porção.

bôlô ['bolo] $n$. Bolo.

bôlô [bo'lo] v. Esfregar (remédio).

bôlu ['bolu] $n$. Cf. bôlô.

bômbêw [bõ'bew] $n$. Bombeiro.

bomon [bว'm̃̃] $v$. Agitar.

bomu ['bomu] v. Cf. Bamu.

bon ['bõ] 1. adj. Bom. Bon dya ô! Bom dia! 2. $a d v$. Bom.

bônê [bo'ne] $n$. Boné. 
bongôlo [b̃̃gว'l’] adv. Sozinho. Ami so bongôlô. Eu estou sozinho.

bônitô [bo'nito] n. Bonito. Caranx crysos.

bonto [bõ'to] n. Botão.

bôô ['bo:] v. Cagar.

bora ['bora] $n$. Borra.

bororo [boro'ro] 1. ideo. Cf. seku bôrôrô. 2. ideo. Cf. kensê bôrôrô.

bôsa ['bosa] $n$. Bolsa.

bôsê [bo'se] $v$. Aborrecer.

bôsêdu [bo'sedu] 1. adj. Bravo. 2. adj. Entediado. 3. adj. Triste.

bôswa [bo'swa] $n$. Vassoura.

bota $\left[\mathrm{b} \jmath^{\prime} \mathrm{ta}\right] v$. Botar.

botxi ['bot $\left.\int \mathrm{i}\right] n$. Bote.

bôtxiza [bot [i'za] $v$. Batizar.

bôtxizadu [bot $\left.\int i{ }^{\prime} z a d u\right]$ adj. Batizado.

boya ['boja] $n$. Bóia.

boya [bj'ja] v. Boiar.

bôyadu [bo'jadu] adj. Boiado.

bubu [bu'bu] n. Espinho do mar.

bufa [bu'fa] $v$. Bufar.

bujina [bu'zina] $n$. Cf. Buzina.

buka [bu'ka] $v$. Buscar.

buku ['buku] 1. adj. Mau. 2. adj. Mau carácter.

buli [bu'li] 1. $v$. Bulir. 2. v. Mexer.

buluza [bu'luza] $n$. Blusa.

buluzan [bulu'zã] $n$. Blusão.

bumbu [bũ'bu] 1. n. Abelha. 2. v. Voar (onomatopéia). $\mathbf{N}$ sa mêsê vwa mo pasu. Eu queria voar como um pássaro.

buna [bu'na] 1. adj. Crescido. 2. v. Crescer. 3. v. Tornar-se adulto.

buneka [bu'ncka] $n$. Boneca.

buru ['buru] n. Burro.

burya [bu'rja] $v$. Embrulhar.

buseta [bu'seta] 1. n. Bolsa. 2. n. Caixa.

busu ['busu] $n$. Bucho.

butan [bu'tã] n. Botão. 
butikin [buti'kĩ] $n$. Bar.

butxiza [but $\left.\int i^{\prime} z a\right] v$. Batizar.

buutu ['bu:tu] adj. Bruto.

buxixa [bu'fifa] $n$. Bochecha.

buza [bu'za] v. Abusar.

buzina [bu'zina] $n$. Buzina.

buzu ['buzu] 1. $n$. Búzio. 2. $n$. Caracol.

bwa ['bwa] 1. adj. Boa. 2. adj. Cf.Bon.

bwê ['bwe] n. Barril.

bwe ['bwع] 1. $a d v$. Muito. 2. n. Terreiro. Cf. Txyô.

bweba ['bweba] $n$. Barba.

bwêbwê ['bwe'bwe] n. Peixinho. Larvas de peixe, localmente denominados 'peixinho'.

bwega ['bwega] $n$. Barriga.

bwetê ['bwعte] $n$. Chapéu.

bweva ['bweva] n. Gêmeos.

bwin ['bwĩ] $n$. Fugitivo.

byan dôdô ['bjã do'do] $n$. Abelha.

byogo [bja'gj] v. Escorregar.

byororo [bjכro'ro] ideo. Cf. Sendê byororo.

byê ['bje] $v$. Cozinhar.

byongô ['bjõgo] $n$. Baba.

byongô [bjõ'go] v. Babar. 


\section{D}

da $[$ 'da] 1. v. Dar. 2. v. Doar.

da abôtô [da a'boto] idiom. Abortar.

da fôkôtô ['da fo'koto] idiom. Dar pancadas.

dadu bê ['dadu 'be] 1. adj. Giro. 2. adj. Legal.

dagan [da'gã] $n$. Dragão.

da kabu ['da 'kabu] 1. idiom. Dar cabo. 2. idiom. Finalizar.

daka tega [da'ka tz'ga] idiom. Entregar.

daki [da'ki] $a d v$. Daqui. $\mathbf{N}$ sa vê ningê daki a vendê izê fa. Eu não vi ninguém aqui vendendo camarão.

dama ['dama] $n$. Drama.

dama ['dãma] n. Dama.

dana [da'na] 1. v. Danar. 2. $v$. Estragar.

danadu [da'nadu] adj. Estragado.

dansa [dã'sa] $v$. Dançar.

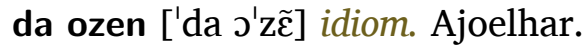

daru ['daru] v. Esfregar.

da topi ['da 'topi] idiom. Tropeçar.

da uman ['da u'mã] idiom. Consertar.

dêdu-di-ane ['dedu 'di a'nc] $n$. Dedo anelar.

dêdu-gaani ['dedu 'ga:ni] $n$. Dedo polegar.

dêdu-indikadô ['dedu ĩdika'do] n. Dedo indicador. G:2008.

dêêtu ['de:tu] adj. Direito.

dêêtê [de:'te] $v$. Derreter.

deferentxi [defe'rẽtsi] adj. Diferente.

dêfêtu [de'fetu] $n$. Defeito.

degadadu [dega'dadu] adj. Degredado.

dêja [de'za] v. Desejar. Cf. di kê.

dêkê [de'ke] conj. Do que. Pata me maxi gaani dêkê ki tê. Meu pato é maior do que o seu.

dêkêê [de'ke:] dem. Daquela. Minu me ê maxi gôdu dêkêê pôsan. Meu filho é o mais gordo daquela cidade.

dêli ['deli] 1. poss. Dela. 2. poss. Dele.

demanda [d $\varepsilon^{\prime}$ mãda] $n$. Barulho. 
dêmanda [de'mãda] 1. $n$. Briga. 2. $n$. Demanda.

denti ['dẽti] adj. Ardente.

dêputadu [depu'tadu] n. Deputado.

dêpôji [de'pozi] $a d v$. Depois.

dêsa [de'sa] $v$. Deixar.

dêsu ['desu] n. Deus. G:1973:116. Dêsu paga txi da mi ô! Deus te pague!

dêsê $[$ de'se] $v$. Descer.

dêsendentxi [desẽ'dẽtfi] 1 . $n$. Ascendente. $2 . n$. Descendente.

deva ['deva] 1. $n$. Dádiva. 2. n. Estrela d'Alva.

dêvê [de've] 1. v. Dever. 2. v. Cf. pudya.

dêwba [dew'ba] $v$. Derrubar.

dêxa ['defa] n. Dêxa. Dança tradicional.

dexi ['d $\varepsilon f i]$ num. Dez.

deximu ['defimu] num. Décimo.

dêzanima [dezani'ma] $v$. Desanimar.

dezembu [de'zẽbu] $n$. Dezembro.

dezenhu [d $\left.\varepsilon^{\prime} z \tilde{e} n u\right] n$. Desenho.

di ['di] 1. prep. De. Riman me ê bixidu di vêdadi. Meu irmão está bem vestido de verdade. 2. prep. Desde. Di ontxi ki sa kumê ko nho fa. Desde de ontem que eu não como nada.

diferentxi [difع'rẽtt]i] adj. Diferente. Ê difêrentxi pasa lung'ie. Ela é mais diferente que principense.

difisi [di'fisi] adj. Difícil.

difuntu [di'fũtu] $n$. Defunto.

dijigasa [dizi'gasa] $n$. Desgraça.

dimi [di'mi] $v$. Dormir.

dimijoni [dimi' 3 J̃ni] $n$. Garrafão.

dimira [dimi'ra] $v$. Admirar.

dimiradô [dimi'rado] adj. Admirado.

dina [di'na] 1. prep. $\mathbf{N}$ fika ki dô dina kwata fya pêmyan. No meu primeiro parto eu fiquei com dor desde quarta-feira. 2. conj. Então. Dina, no ka vê amanhan! Então, nos veremos amanhã ! 3. conj. Já que.

dindin [didĩ] $n$. Pessoa mais velha.

dinixi [di'nifi] conj. Então. Dinixi sodadi ki tava di xintxinela, a punta li ningê ki tava na xintxinela. Então o soldado estava de guarda e perguntaram para ele quem estava na sentinela.

dinora [di'nora] 1. $a d v$. Antigamente. 2. $a d v$. Nos velhos tempos.

disa [di'sa] $v$. Deixar. 
dixgôxtu [dif'goftu] $n$. Desgosto.

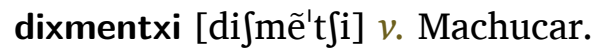

divida ['divida] $n$. Dívida.

divididu [divi'didu] adj. Dividido.

diventxixta [divẽ't $\left.\int \mathrm{S} \int \mathrm{ta}\right] n$. Adventista.

divya [di'vja] $v$. Deveria.

dixipulu [di'fipulu] $n$. Discípulo.

dixizan [difi'zã] $n$. Decisão.

dixkubi [difku'bi] $v$. Descobrir.

dixkusu [dif'kusu] n. Discurso.

dixpidi [diكpi'di] $v$. Despedir-se.

dixtxinu [di $\left.\int^{\prime} t \int i n u\right] n$. Destino.

dizanove [diza'nəve] num. Dezenove.

dizasetxi [diza'set]i] num. Dezessete.

dizasêy [diza'sej] num. Dezesseis.

dizawêtu [diza'wetu] num. Dezoito.

dizodi [di'zodi] 1 . $n$. Desordem. 2. $n$. Problema.

dizôitu [di'zoitu] num. Dezoito.

dô ['do] n. Dor.

doba $\left[\mathrm{d} \jmath^{\prime} \mathrm{ba}\right] \nu$. Dobrar.

doba ['dəba] $n$. Dobra (moeda de STP).

dobadu [də'badu] 1. adj. Dobrado. 2. n. Em dobro.

dôdôsu [do'dosu] num. Ambos. Pô mi, dôdôsu gaavi. Para mim, ambos são bons.

dômônhô [do'mõno] 1. n. Demônio. 2. n. Diabo.

dôna ['dõna] 1. n. Avó. 2. n. Mulher mais velha.

doni ['doni] $n$. Dono.

donu ['dənu] 1. $n$. Dono. 2. $n$. Homem mais velho.

dôsu ['dosu] num. Dois.

dôtô [do'to] $n$. Doutor.

doxi ['d Jji] 1. adj. Gostoso. 2. n. Doce.

dôzê ['doze] num. Doze.

dudi ['dudi] 1. $a d v$. Por nada. 2. $a d v$. Sem motivo. 3. $a d v$. Vazio.

dumu [du'mu] 1. $v$. Esfregar. 2. v. Moer. 
dumu [dũ'mu] $v$. Pisar.

durantxi [du'rãtfi] $a d v$. Durante. $\hat{\mathbf{E}}$ ka fika vijya ningê duranti dya tudu pe. Ela fica vigiando as pessoas durante o dia todo.

duuba [du:'ba] $v$. Derrubar.

duzentu [du'zẽtu] num. Duzentos.

dwa ['dwa] $v$. Doer.

dwintxi ['dwĩt]i] $v$. Adoecer.

dwenti ['dwẽt $\left.\int \mathrm{i}\right]$ 1. adj. Doente. 2. n. Doente.

dya ['dja] n. Dia.

dyabin [dja'bĩ] $n$. Diabinho.

dyabu ['djabu] $n$. Diabo.

dya-dimingu ['dja di'mĩgu] $n$. Domingo.

dyadingu ['dja 'dĩgu] $n$. Domingo.

dyantxi ['djãtfi] prep. Ôzê pô dyantxi. Hoje em diante.

dyareya [dja'reja] $n$. Diarréia.

dyô ['djo] n. Dinheiro. 
ê ['e] 1. pro. Ela. Ê sa ki reva di mosu sê. Ela está com raiva do seu filho. 2. pro. Ele. $\hat{\mathbf{E}}$ sa ki reva di mosu sê. Ele está com raiva do seu filho.

e $[' \varepsilon]$ 1. pro. -a. 2. pro. -o. 3. pro. Ela. 4. pro. Ele. 5. pro. Seu. 6. pro. Sua. 7. pro. Cf. êli.

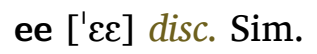

êê ['ee] disc. Sim.

e'e $\left[\varepsilon^{\prime} \varepsilon\right]$ disc. Não. e-e ô. Não.

êê ['ee] É!

êli ['eli] 1. pro. Ela. Xi êli da mi infomasan tudu fa n ke ki me. Se ela não der toda a informação eu vou embora. 2. pro. top. Ele. 3. pro. OI Ele.

êlifantxi [eli'fãt $\left.\int i\right] n$. Elefante.

envê [ẽ've] $a d v$. Em vez de. Envê di ê vika ki kompwe paage ê xyê. Em vez de vir com seu amigo papagaio ele saiu.

envêxi [ễ'vefi] $a d v$. Em vez. Envêxi ê we xkola ê fika na kaxi. Em vez de ir à escola ele ficou em casa. era ['era] $v$. Era.

êru ['eru] n. Erro.

êswa [e'swa] $v_{\text {. Espirrar. }}$

etxi ['ct $\left.\int i\right] n$. Leste.

êxkrivan [eJkri'vã] $n$. Escrivão. 
fa ['fa] neg. Não.

faa ['fa:] $v$. Falar.

faata ['fa:ta] $n$. Falta.

faakêza [fa:'keza] $n$. Fraqueza.

fabrika ['fabrika] $n$. Fábrica.

faku ['faku] adj. Fraco.

fala [fa'la] $v$. Cf. Faa.

faladô [fala'do] adj. Falador.

falya [fa'lja] $\nu$. Falhar.

fama ['fãma] adj. Fama.

famenta [fa'mẽta] $n$. Ferramenta.

fansêji [fã'sezi] 1. adj. Francês. 2. n. Francês.

fasanha [fa'sãna] $n$. Façanha.

faxili ['faJili] adj. Fácil.

fasu ['fasu] adj. Falso.

fata ['fata] $n$. Falta.

fata [fa'ta] $\nu$. Faltar.

fatxya [fa't $\left.\int j a\right] n$. Fatia.

favô [fa'vo] n. Favor.

fawta ['fawta] 1. $n$. Falta. 2. $n$. Flauta.

faya ['faja] $n$. Falha.

fazenda [fa'zẽ da] $n$. Fazenda.

fê ['fe] adj. Feio.

fêbê [fe'be] $v$. Ferver.

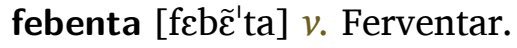

febentadu [feb $\tilde{\varepsilon}^{\prime}$ tadu] adj. Cozido.

febi ['febi] $n$. Febre.

fedi ['fedi] $v$. Feder.

fêê [fe:] $v$ Fazer.

fêêxku ['fe:Jku] adj. Fresco.

fêêw ['fe:w] $n$. Ferreiro. 
fefe $\left[f \varepsilon^{\prime} f \varepsilon\right] n$. Armadilha para pássaros.

fefefe $\left[f \varepsilon f \varepsilon^{\prime} f \varepsilon\right]$ ideo. Cf. Baa fefefe.

fêê fora ['fe: 'fora] idiom. Defecar.

fega [f( $\left.\varepsilon^{\prime} g a\right]$ v. Esfregar.

fêgê [fe'ze] 1. n. Amante. 2. $n$. Freguês.

fegêja [fع'geza] $n$. Freguesa.

fêgêja [fe'geza] $n$. Freguesia.

fêgwa [fe'gwa] $n$. Figura.

fêlixidadi [felifi'dadi] $n$. Felicidade.

fêmêra [fe'mera] $n$. Enfermeira.

fene $\left[f \varepsilon^{\prime} n \varepsilon\right]$ 1. $v$. Estilhaçar. 2. $v$. Quebrar.

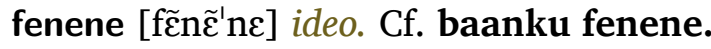

fenza [fг̃'za] $n$. Cf. fenzan.

fenzan [fर्ع́zã] $n$. Feijão.

ferya ['ferja] $n$. Férias.

fêsê [fe'se] $v$. Oferecer.

fexku ['f $\left.\varepsilon \int k u\right]$ adj.

fêsuku ['fesuku] adj. Cf. fêêxku.

fêtu ['fetu] adj. Feito.

fêvê [fe've] $v$. Ferver.

fêvêrêw [feve'rew] $n$. Fevereiro.

fêzê [fe'ze] $v$. Fazer.

fifi [fi'fi] v. Chupar.

figadu ['figadu] $n$. Fígado.

fii [fi:] $v$. Ferir.

fiida ['fi:da] $n$. Ferida.

fiidu ['fi:du] adj. Ferido.

fiji [fi'zi] $v$. Fritar.

fika [fi'ka] v. Ficar.

filada [fi'lada] $1 . n$. Afilhada. 2. $n$. Cf. Fyada.

filadu [fi'ladu] $n$. Afilhado.

fiminga [fi'mĩga] $n$. Formiga.

fina ['fina] 1. adj. Fina. 2. adj. Magra. 
finda [fî'da] 1. v. Acabar. 2. v. Findar.

finji [fí' $\left.z^{i}\right] v$. Fingir.

finka [fí'ka] $v$. Fincar.

finu ['finu] 1. adj. Fino. 2. adj. Magro.

firya [fi'rja] 1. v. Esfriar. 2. v. Resfriar.

fisa [fi'sa] 1. $v$. Fechar. 2. $v$. Travar.

fisadwa [fisa'dwa] $n$. Fechadura.

fisu ['fisu] 1. $n$. Ofício. 2. $n$. Profissão.

fita ['fita] $n$. Fita.

fitxixô [fit $\left.\mathrm{i}^{\prime} \int \mathrm{o}\right] n$. Bruxa.

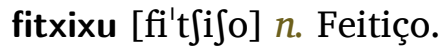

fitxixô [fitfi'fo] $n$. Feiticeiro.

fitu ['fitu] adj. Frito.

fixi [fi'fi] v. Cf. Fuxi.

fo ['f’] 1. $a d v$. Fora. Ôzê ê dimi fo di kaxi. Hoje ele dormiu fora de casa. 2. v. Vir de.

fôdê [fo'de] $v$. Foder.

fôfô [fo'fo] 1. v. Ficar oco. 2. v. Inflamar.

fôfôdu [fo'fodu] 1. adj. Inflamado. 2. adj. Oco.

fôfôka [fofo'ka] $v$. Fofocar.

foga [fว'ga] 1. v. Afogar. 2. v. Brincar. 3. v. Relaxar.

fogan [fว'gã] $n$. Fogão.

fôgôya [fogo'ja] v. Empolar.

foka ['foka] n. Forca.

foka $\left[\mathrm{fJ}^{\prime} \mathrm{ka}\right] v$. Enforcar.

fôkôtu [fo'kotu] n. Barulho.

fôkôtô [fo'koto] n. Problema.

fôkôtô [foko'to] 1. v. Empurrar. 2. v. Teimar.

fola ['f́la] n. Pulga.

fola [f'la] 1. v. Esfolar. 2. v. Florescer. 3. v. Pelar.

foli ['foli] n. Flor.

fôlôgô ['fologo] $n$. Fôlego.

foma ['foma] $n$. Forma.

foma [fว'ma] $v$. Formar(-se). 
fomasan [fama'sã] $n$. Informação.

fomi ['fomi] $n$. Fome.

fon ['fõ] $n$. Careta.

fonta [fว̃'ta] 1. v. Afrontar. 2. v. Perturbar.

fontadu [fõ'tadu] 1. adj. Ganancioso. 2. adj. Oportunista.

fontxi ['f̃̃t $\left.\int i\right] n$. Fonte.

fooza ['fว:za] $n$. Ferrugem.

fora ['fəra] $n$. Cf. fo.

fôrô ['foro] 1. n. Forro. 2. n. Santome.

fosa ['fosa] $n$. Força.

fotxi ['fot $\left.\int \mathrm{i}\right]$ adj. Forte.

foxfari ['fJffara] 1. $n$. Fósforos. 2. $n$. Cf.foxfulu.

fu ['fu] 1. v. Lavar. 2. v. Limpar.

fuba ['fuba] 1. $n$. Farinha de milho. 2. $n$. Fubá.

fudu ['fudu] 1. adj. Bem lavado. 2. adj. Limpo.

fugu ['fugu] $v$. Desordem.

fugu [fu'gu] 1. v. Chacoalhar. 2. v. Por de ponta cabeça.

fugudu [fu'gudu] 1. adj. Bagunçado. 2. adj. Desarrumado. 3. adj. Nervoso.

fuxi [fu'fi] $v$. Fugir.

fuketa [fu'keta] $n$. Forquilha.

fukyan [fu'kjã] 1. n. Forquilhão. 2. n. Prumo.

fulanu [fu'lanu] $n$. Fulano.

fuma $\left[f u^{\prime} \mathrm{ma}\right]$ 1. $v$. Inchar. 2. $v$. Fumar.

fumadu [fu'madu] adj. Defumado.

funda [fũ'da] $v$. Afundar.

fundan [fũ'dã] $n$. Pista de dança.

fundu ['fũdu] adj. Fundo.

fusa [fu'sa] $v$. Espumar.

fusa ['fusa] $n$. Garrafa feita de barro.

futibo [futi'bJ] n. Futebol.

futufutu ['futu'futu] adj. Depressa.

futufutu [futufu'tu] adj. Rápido.

fuuta ['fu:ta] 1. $n$. Fruta. 2. $n$. Fruta-pão. 
fuuta [fu:'ta] 1. v. Furtar. 2. v. Roubar.

fuxi [fu'fi] $v$. Fugir.

fuxidu [fu'fidu] $n$. Fugitivo.

fwa ['fwa] $v$. Furar.

fya ['fja] 1. n. Feira. 2. n. Mercado.

fyan ['fjã] $n$. Farinha.

fyansa ['fjãsa] $n$. Confiança.

fyeli ['fjeli] adj. Fiel.

fyô ['fjo] adj. Frio. 
gaani ['ga:ni] adj. Grande.

gaava ['ga:va] n. Goiaba.

gaavi ['ga:vi] 1. adj. Bom. 2. adj. Bonita. 3. adj. Bonito.

gaba [ga'ba] v. Gabar.

gabadô [gaba'do] adj. Gabador.

Gaban [ga'bã] top. Gabão.

gadi ['gadi] 1. n. Grade. 2. n. Prisão.

gafugafu [gafu'gafu] 1. $a d v$. Seco. M:2009:219. Peli me fika gafugafu. 2. $n$. Espinha.

gamala [ga'mala] n. Gamela.

gan ['gã] 1. n. Grão. 2. $n$. Cf.Ikpe. 3. v. Enganar. 4. v. Ganhar. 5. $v$. Vencer.

ganiga [gani'ga] $n$. Virilha.

gara [ga'ra] v. Agarrar.

garafa [ga'rafa] 1. n. Garrafa. 2. n. Cf. rodoma.

gasa ['gasa] n. Garça.

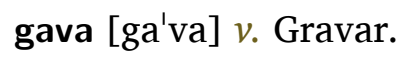

gavadô [gava'do] n. Gravador.

gavata [ga'vata] $n$. Gravata.

gaveta [ga'veta] $n$. Gaveta.

gaxta [ga''ta] v. Gastar.

gayola [ga'jJla] n. Gaiola.

gazolina [gazo'lina] $n$. Gasolina.

gba ['gba] 1. adj. Em ordem. 2. v. Ordenar.

gbarara [gbara'ra] $n$. Precipício.

gbê ['gbe] 1. v. Amassar. 2. v. Esmagar. 3. v. Pisar.

gbene ['gbene] $v$. Amarrar.

gbin ['gbĩ] ideo. Peetu gbin. Muito preto.

gbô ['gbo] $v$. Defecar.

gbo ['gbJ] $v$. Pisar.

gbôgbô [gbo'gbo] n. Migalha.

gbungbun ['gbũ'gbũ] $n$. Osso cartilaginoso de tubarão ou arraia.

ge $[$ 'ge $] n$. Guerra. 
geevi ['ge:vi] n. Greve.

gêêza ['ge:za] $n$. Igreja.

gidigidi ['gidi'gidi] 1. ideo. Cf. têmê gidigidi. 2. n. Arrepio.

giitu ['gi:tu] $n$. Grito.

ginhan [gi'jã] $n$. Galinha.

giryan [gi'rjã] 1. n. Cabo. 2. n. Grilhão.

gita [gi'ta] $v$. Gritar.

gôdô ['godo] adj. Gordo.

gôgô [go'go] n. Gôgô. Planta medicinal.

gogo [gว'gJ] 1. v. Gostar. 2. n. Parabéns.

golo [gว'l’] 1. v. Cavar. 2. v. Pegar com um gancho.

golodu [go'lodu] adj. Cavado.

gomon [gว'm̃̃] 1. v. Germinar. 2. v. Nascer. 3. v. Surgir.

gonda [g̃̃'da] $v$. Confortar.

go ['go] v. Chorar.

gôôpa ['go:pa] n. Garoupa. Epinephelus adscensionis.

goopin [go:'pĩ] n. Garoupinha. Cephalopholis fulva.

goosu ['go:su] adj. Grosso.

goosu-goosu ['gว:su'gว:su] adj. Importante (pessoa).

gorya ['gərja] adj. Glória.

gota ['gota] n. Gota.

govena [gəve'na] $v$. Governar.

govenadô [gəena'do] n. Governador.

g venu [go'venu] $n$. Governo.

goxta di ['gJfta 'di] idiom. Gostar.

goxtoza [gJ't'tza] adj. Gostosa.

gôxtô ['gofto] adj. Feliz.

gôxtu ['goftu] 1. n. Prazer. 2. n. Vontade.

gôza [go'za] 1. v. Gozar. 2. v. Melhorar.

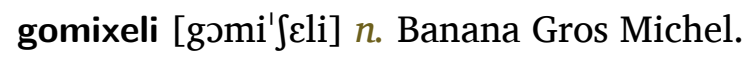

gugu [gu'gu] $n$. Anão.

guli [gu'li] $v$. Engolir.

gumi ['gumi] $n$. Teto. 
gumita [gumi'ta] $v$. Vomitar.

gumitu [gu'mitu] n. Vômito.

gunia [gu'nja] adj. Agonia.

gwada ['gwada] $n$. Guarda.

gwadadu [gwa'dadu] adj. Guardado.

gwenta [gwẽ'ta] v. Aguentar.

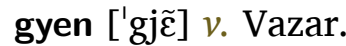




\section{I}

i ['i] conj. E. Suva suvê ontxi muntu i awa lenta udentu da kaxi. Choveu muito ontem e entrou água dentro da minha casa.

ibi [i'bi] $n$. Carvão.

ibiba [ibi'ba] n. Ibiba. Planta.

idadi [i'dadi] $n$. Idade.

identxi [i'dẽt $\left.\int i\right] n$. Dente.

idu [i'du] n. Piolho.

idô ['ido] n. Pilão.

ie ['ic] 1. n. Ilha. 2. top. Ilha do Príncipe.

ifi [i'fi] $n$. Fio.

ifigbô [i'figbo] $n$. Felispote (prato feito de mandioca ou milho, sal, açúcar, envolto em folha de bananeira e cozido em fogo).

ifikumin [i'fikumĩ] $1 . n$. Caminho. 2. $n$. Estrada. 3. $n$. Rua.

igbê [i'gbe] $n$. Corpo.

igbêê [i'gbe:] n. Quarto.

igbêgbê [igbe'gbe] 1. $n$. Casca de coco. 2. $n$. Cf. ikpêkpê.

igbêtê [igbe'te] $n$. Bordão de São José.

igbô [i'gbo] n. Nativo da Ilha Príncipe.

igigu [i'gigu] $n$. Fumo.

ikiri [iki'ri] $n$. Rodilha.

ikpe [i'kpe] 1. n. Grão. 2. $n$. Testículo.

ikpene [i'kpenc] $n$. Urtiga. Fleurya aestuam.

ikpêkpê [ikpe'kpe] $n$. Caracol.

ikôkô [iko'ko] n. Matabala. Colocasia esculentum.

iku [i'ku] $n$. Lixo.

$\operatorname{imin}\left[i^{\prime} \operatorname{mĩ}\right] n$. Milho.

impin [ĩ'pĩ] $n$. Espinho.

impota [ĩpo'ta] $v$. Importar.

indala [ĩda'la] $n$. Palmeira.

indika [ĩdi'ka] v. Indicar.

ine ['inc] 1. pro. Elas. Inê migu me kupa bii agama pwê oso sê. Meus amigos ocuparam aquele terreno. 2. pro. Eles. Inê migu me kupa bii agama pwê oso sê. Meus amigos ocuparam aquele terreno. 
infenu [î'fєnu] $n$. Inferno.

infimêw [ĩfi'mew] $n$. Enfermeiro.

infin [ĩ'fi] $a d v$. Fim. Infin me sa xiga. Meu fim está chegando.

ingêxi [î'gefi] 1. adj. Inglês. 2. $n$. Inglês.

ingola [î̀'gola] 1. $n$. Cf. ngola. 2. top. Cf. ngola.

ingoro [î'gวrग] adj. Cf. ngoro.

ingêrêrê [ĩgere're] 1. n. Cacete. 2. n. Ingêrêrê.

inhan [i'nã] $n$. Lenha.

ini [i'ni] $n$. Elefante.

injizu [1̂́'zizu] $n$. Jejum.

inkomoda [îkəmว'da] $v$. Incomodar.

insetu [î̃sctu] $n$. Inseto.

intensan [îtẽ'sã] $n$. Intenção.

inton [î́'tõ] $n$. Coceira.

intendê [ĩtẽ'de] $v$. Entender.

intêru [î'teru] $n$. Inteiro.

intêstinu [ĩtes'tinu] $n$. Intestino.

inxê [1̃̂] $\mathrm{e}] v$. Encher.

inzolu [î́z’lu] $n$. Anzol.

ipin [i'pĩ] $n$. Espinho.

irixi [i'riji] $n$. Nariz.

ise [i'sc] n. Esteira.

isê [i'se] dem. Isto. Isê karu muntu. Isto é muito caro.

isengi [i'sẽgi] $n$. Sangue.

isolu [i'solu] $n$. Sol.

ivin [i'vĩ] $n$. Vinho.

ixaki [iكa'ki] dem. Isso aqui.

ixala [ifa'la] $a d v$. Lá.

ixi ['iji] dem. Esse.

ixila [ifi'la] dem. Aquilo. Ixila karu muntu. Aquilo e muito caro.

ixima [i'Sima] prep. Em cima. Cf.Xima.

ixizê [i'fize] $n$. Cinza.

ixka ['i $\left.\int k a\right] n$. Isca.

izê [i'ze] $n$. Camarão.

ize ['ize] $n$. Izaquente.

izêtxi [i'zetfi] 1. n. Azeite. 2. $n$. Óleo.

izoladu [i'zoladu] adj. Isolado. 


\section{$\mathbf{J}$}

ja ['za] $a d v$. Já. Unwa pasê ja. A lua já apareceu.

jaa ['za:] v. Jorrar.

jadin [za'dĩ] $n$. Cf. jyadin.

jaka ['zaka] $n$. Jaca.

janga ['jãga] 1. $n$. Junção. 2. $n$. Junta.

janta [zã̃ta] $v$. Jantar.

janêw [ja'new] n. Janeiro.

jaru ['zaru] n. Jarra.

jêlêra [ze'lera] $n$. Geladeira.

jentxi ['zẽtsi] $n$. Gente.

jenu ['żnu] $n$. Gênio.

jêsan [ze'sã] $n$. Injeção.

jigijigi [zi'gi zi'gi] adj. Densa. Umatu jigijigi. Floresta densa.

jijibi [3i'zibi] 1. n. Cf. jinjibi. 2. n. Genviva.

jikitxi [3iki'ti] adj. Jiquiti (Habitante de Príncipe nascido no campo).

jinebi [3i'nebi] $n$. Genebra.

jinela [3i'ncla] $n$. Janela.

jinga [3 $\left.\tilde{1}^{1} g a\right] v$. Agitar.

jingantxi [3ĩ'gat $\left.\int i\right]$ adj. Gigante.

jinja ['3ĩza] $a d v$. Depressa. Txi po vika lêlê mi jinja? Você pode vir aqui depressa?

jinjan ['zĩzã] $a d v$. Rápido. Minu sê vika jinja. Essa criança veio rápido.

jinjibi [31̃'zibi] 1. n. Gengibre. 2. $n$. Gengiva.

jinku ['zîku] $n$. Zinco.

jintxi [3ĩ't $t \mathrm{i}] n$. Pagão.

jôgu ['zogu] n. Jogo.

jonali [zว'nali] $n$. Jornal.

jujan [3u'zã] 1. n. Varanda. 2. $n$. Zona não urbanizada.

jwê ['zwe] $n$. Joelho.

jwêlha [3we' $K a] v$. Joelhar.

jyadin [zja'dĩ $n$. Jardim. 


\section{$\mathbf{K}$}

ka ['ka] 1. $a d v$. Aqui. Ê ke ka wo sê mesu. Ele virá agora mesmo. 2 . part. Txi ka po da bakaya kêtê da mi a? Você pode trazer bacalhau para mim?

kaa ['ka:] n. Cara.

kaaga [ka:'ga] v. Carregar.

kaa kontraryo ['ka: kõ'trarjo] idiom. Cara de bravo.

kaalu ['ka:lu] adj. Claro.

kaasu ['ka:su] n. Cainho.

kaata [ka:ta] n. Carta.

kaaxi ['ka: $\mathrm{i}]$ n. Classe.

kaba ['kaba] n. Cabra.

kaba [ka'ba] $v$. Acabar.

kabamentu [kaba'mẽtu] $a d v$. Fim.

kabasa [ka'basa] n. Cabaça. Cf. Kabese.

kabe $[\mathrm{ka}$ 'be $]$ n. Cabeça.

kabelu [ka'belu] $n$. Cabelo.

kabese [ka'bese] $n$. Cabeça.

kabungu [kabũ'gu] $n$. Pinico usado nos tempos antigos.

kabuvêdi [kabu'vedi] top. Cabo Verde.

kadadu [ka'dadu] adj. Escaldado (prato local feito à base de peixe, caldo de peixe e farinha). $\mathbf{N}$ sa ke fêzê kadadu pêxi. Eu vou fazer escaldado de peixe.

kadavêli [ka'daveli] $n$. Cadáver.

kadenu [ka'denu] $n$. Caderno.

kadya $\left[\mathrm{ka}{ }^{\prime} \mathrm{dja}\right]$ 1. $n$. Bunda. 2. $n$. Nádegas. 3. $n$. Cadeia. 4. $n$. Cadeira. 5. $n$. Luz.

kadyadu [ka'djadu $n$. Cadeado.

kafe $[\mathrm{ka} / \mathrm{f} \varepsilon] n$. Café.

kagu ['kagu] 1. n. Bagagem. 2. n. Cargo.

kaimba ['kaîba] $n$. Caimbra.

kain ['kaĩ] adj. Avarento.

kajamanga [kaza'mãga] $n$. Cajamanga.

kaju $\left[\mathrm{ka}^{\prime} 3 \mathrm{u}\right]$ n. Caju.

kajuêru [ka'zueru] n. Cajueiro.

kaka $\left[\mathrm{ka} \mathrm{k}^{\mathrm{k} a}\right]$ 1. v. Secar. 2. n. Seco. 
kakanha d'ôpe [kaka'ja do pe] n. Calcanhar.

kakanhan [kaka'jã] $n$. Calcanhar.

kakaw [ka'kaw] n. Cacau.

kala [ka'la] v. Calar.

kalambola [kalã'bola] $n$. Carambola.

kalisa ['kalisa] v. Calçar.

kalisan [kali'sã] n. Calção.

kalixinha [kali'Sina] $n$. Calcinha.

kalima ['kalima] n. Calma.

kalô $[k a ' l o] n$. Calor.

kalsa [kal'sa] v. Calçar.

kalu ['kalu] $n$. Caldo.

kama ['kama] 1. n. Cama. 2. n. Escama.

kambêw [kã'bew] n. Latrina.

kamiza [ka'miza] $n$. Camisa.

kampanha ôtô [kãpa'na o'to] $n$. Úvula.

kampu ['kãpu] n. Campo.

kana ['kana] n. Cana.

kandya [kã'dja] n. Candeia.

kaneku [ka'neku] n. Caneca.

kanêta [ka'neta] $n$. Caneta.

kanga ['kãga] $n$. Canga.

kani ['kani] $n$. Carne.

kani kabese [ka'ni ka'bese] idiom. Colocar-se cabeça para baixo.

kaniveti [kani'veti] $n$. Canivete.

kanja ['kãza] n. Canja.

kampanha [kãpa'na] $n$. Campainha.

kansa [kã'sa] v. Descansar.

kansadu [kã'sadu] adj. Cansado.

kanta [kã'ta] $v$. Cantar.

kantora [kã't’ra] $a d v$. Quando. Kantora txi ka xyê a? Quando você sairá?

kantu ['kãtu] $a d v$. Quanto. Kantu anu ki mosu Toni tê? Quantos anos tem o filho do Antonio? kantu [kã'tu] n. Canto. 
kantxiga [kã't $\left.\int i g a\right] n$. Cantiga.

kanu ['kãnu] $a d v$. Quando.

kanu ['kanu] n. Cano.

kanwa [ka'nwa] $n$. Canoa.

kapa [ka'pa] 1. v. Capar. 2. v. Castrar.

kapadu [ka'padu] adj. Capado.

kapela [ka'pela] $n$. Capela.

kapintêw [kapĩ'tew] $n$. Carpinteiro.

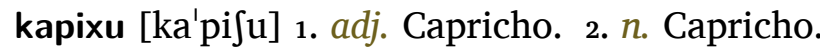

kapule $[\mathrm{ka}$ 'pule] $n$. Armadilha para pássaros.

kapwêra [ka'pwera] $n$. Campo.

kara [ka'ra] n. Caranguejo.

karibu [ka'ribu] n. Tarântula.

karu ['karu] 1. n. Caro. 2. adj. Claro.

karya [ka'rja] $v$. Encardir.

kasa [ka'sa] v. Caçar.

kasan [ka'sã] $n$. Caixão.

kaseda [ka'seda] n. Maxilar.

kasô [ka'so] n. Cachorro.

kata ['kata] n. Carta.

kataw $[k a ' t a w] n$. Catarro.

katêw [ka'tew] n. Carteiro.

katêra [ka'tera] $n$. Carteira.

katoliku [ka'təliku] $n$. Católico.

katôzi [ka'tozi] n. Catorze.

kava [ka'va] $v$. Cavar.

kavalu [ka'valu] n. Cavalo.

kaxa ['kaJa] n. Caixa.

kaxi ['kaji] n. Casa.

kaxi ginhan [kafi 'gijã] $n$. Capoeira.

kaxika [kafi'ka] v. Descascar.

kaximbu [ka'fĩbu] n. Cachimbo.

kaxinha [ka'Jina] $n$. Calcinha. 
kata ['kata] n. Tipo.

kaxtiga [kafti'ga] v. Castigar.

kaxtigu [kaJ'tigu] n. Castigo.

kayman [kaj'mã] $n$. Goma de mandioca.

kaza ['kaza] v. Casar.

kazadu [ka'zadu] adj. Casado.

kazaku [ka'zaku] n. Casaco.

kazali [ka'zali] n. Casal.

kazamentu [kaza'mẽtu] $n$. Casamento.

ke ['ke] $v$. Ir. N sa ke uga posan. Estou no caminho para a praça.

kêba [ke'ba] $v$. Quebrar.

keba ['keba] v. Rachar.

kebadu [ke'badu] adj. Quebrado.

kêdita [kedi'ta] $v$. Acreditar.

kêdê ['kede] quant. Cada. Kêdê ningê sa sêbê kwa ki sa fêzê. Cada pessoa sabe o faz.

kêê ['ke:] $\nu$. Crer.

kêju [keju] n. Queijo.

keka ['keka] $v$. Vir. Txi sêbê za ya sumana ki keka ten Sôlensu a? Você já sabe que semana que vem tem a festa de São Lourenço?

keke $\left[k \varepsilon^{\prime} k \varepsilon\right] n$. Espinho de folha de palmeira.

keletu [ke'lctu] $v$. Aprovar.

kêma ['kẽma] v. Queimar.

ken ['kẽ] $v$. Azedar.

kendu ['kẽdu] $n$. Azedo.

keni ['keni] v. Cair.

kensê bôrôrô [kẽ'se boro'ro] idiom. Quase esquecer.

kentxi ['kẽt]i] adj. Quente.

kêsê [ke'se] v. Crescer.

kêsentxi [ke'sẽti] $n$. Crescente.

kêtê [ke'te] 1. adj. Pequeno. Minu kêtê. Menino pequeno. 2. adv. Pouco.

ketekete [ketcks'te] ideo. Cf. Ve ketekete.

kexa $\left[\mathrm{k} \varepsilon^{\prime} \int \mathrm{a}\right] \nu$. Acusar.

kêza ['keza] n. Queixa.

kêzu ['kezu] n. Queijo. 
ki ['ki] 1. prep. Com. 2. conj. E. N we Santome ki Ie. Eu fui a São Tomé e Príncipe. 3. int. Qual. Ki kô ki badya tê? Qual a cor da bandeira? 4. conj. Que. 5. int. Que.

ki pasa [ki'pasa] $a d v$. Bastante. Upanu me danadu ki pasa. Minha roupa está bastante estragada.

kidarê ['kidare] interj. Di têêxi vêsê têtuuga vya txya kidarê. Pela terceira vez a tartaruga chorou por ajuda.

kidi ta [kidi'ta] v. Acreditar.

kifara [kifa'ra] idiom. Que fará. Ki fará êli da vida xi mye? Que ele fará da vida sem mulher?

kiima ['ki:ma] n. Clima.

kika ['kika] 1. v. Clicar. 2. n. Vagina.

kilala [ki'lala] $n$. Tenda.

kili ['kili] v. Enrolar.

kilu ['kilu] n. Quilo.

kimôni [ki'moni] $n$. Blusa.

kinhentu [ki'jẽtu] num. Quinhentos.

kinji ['kĩzi] num. Quinze.

kinta-fya ['kĩta'fja] $n$. Quinta-feira.

kintu ['kĩtu] num. Quinto.

kintxiba [kĩtfi'ba] $n$. Cachimbo.

kinzê ['kĩze] num. Quinze.

kiringa [kirĩ̃'ga] $n$. Macaco kiringa.

kirya [ki'rja] v. Criar. M:2009:223.

kiryadu [ki'rjadu] adj. Criado.

kiryô [ki'rjo] adj. Crioulo.

kitembu [ki'tẽbu] $n$. Trabalho comunitário.

kitxi [ki'tsi] $a d v$. Pouco. Arya kêtê. Pouca areia.

kitxin [ki'tĩ] adj. Curto.

kixipa [kifi'pa] $n$. Pequena cabana feita de folhas de palmeira.

kizômba [ki'zõba] n. Kizomba.

kô ['ko] n. Cor.

ko nho ['kว'ภว] $n$. Quinhão.

kobo ['kJbs] n. Cobra.

koda [kJ'da] $v$. Acordar.

kôdan [ko'dã] n. Cordão.

kode [kJ'de] adj. Caçula. 
kôitadu [koi'tadu] adj. Coitado.

kôki ['koki] v. Colocar.

koko $\left[\mathrm{kj} \mathrm{k}^{\mathrm{k}} \mathrm{j}\right]$ v. Cacarejar.

kôkô ['koko] n. Grito.

kôkôkô ['kokoko] ideo. Cf. Fyô kôkôkô.

kolan [kj'lã] n. Colar.

kôlega [ko'lega] n. Colega.

kôli ['koli] idiom. Com ele. Owo po fala pôtugêzê kôli. Nós podemos falar português com ele.

kolika ['kolika] n. Cólica.

kôlôka [kolo'ka] v. Colocar.

kombina [kõ'bina] $v$. Consertar.

kômesa [kome'sa] v. Começar.

kômpanha [kõpa'na] v. Acompanhar.

kômpanhô [kõpa'no] n. Companheiro.

kompasu [kõ'pasu] $n$. Compasso.

kômpendê [kõpẽ'de] v. Compreender.

kômpidu [kõ'pidu] adj. Comprido.

kompwe [kõ'pwe] n. Compadre.

koneta [kJ'neta] $n$. Corneta.

konhan [kJ'jã] $n$. Colhões.

konhan [ko'jã] $n$. Penis.

kondê [kõ'de] $v$. Esconder.

kondêdu [kõdedu] adj. Escondido.

kondison [kõdi'sõ] $n$. Condição.

konkubina [kõku'bina] $n$. Concubina.

koni ['kכni] n. Corno.

konkoda [kõ'koda] v. Concordar.

konkon [kõ'kõ] n. Konkon.

kono ['kənว] n. Vagina.

konsê [kõ'se] 1. v. Conhecer. 2. v. Consertar. 3. n. Conselho.

konsigi [kõsi'gi] $v$. Conseguir.

konta ['kõta] n. Conta.

konta [kõ'ta] 1. v. Contar. 2. v. Encontrar. 
kontenta [kõtẽ'ta] v. Contentar.

kontenti [kõ'tcti] adj. Contente.

kontrariw [kõ'trariw] n. Contrário.

kontrê ['kõtre] n. Contrário.

kontxinwa [kõt $\int i$ 'nwa] $v$. Continuar.

kontu ['kõtu] v. Contar.

konvesa [kõ'vesa] $n$. Conversa.

konvida [kõvi'da] v. Convidar.

kôôa ['ko:a] n. Coroa.

kooko ['kJ:kJ] n. Garganta.

kôôsê [ko:'se] v. Consertar.

kôôsu ['ko:su] n. Caroço.

koota ['ko:ta] $v$. Cortar.

kopa [ks'pa] $v$. Comprar.

kopa ['kэpa] n. Copa.

kopu [kว'pu] n. Copo.

kôrê [ko're] 1. v. Correr. 2. v. Cf. Kwê.

kôrenti [ko'rẽti] $n$. Corrente.

kôrêyu [ko'reju] n. Correio.

kôryôzu [ko'riozu] adj. Curioso.

kôsa [ko'sa] v. Coçar.

kôsan [ko'sã] n. Coração.

kôsêdô [kose'do] n. Mecânico.

kôsô ['koso] n. Coxa.

kota [ko'ta] adj. Cortar.

kôtadu [ko'tadu] $n$. Cortado.

kôtisa [ko'tisa] n. Cortiça.

kôtô [ko'to] 1. v. Cortar. 2. n. Pescoço.

kotokoto [kətวks'to] ideo. Cf. Danadu kotokoto.

kotokoto [kJ'tıko'to] ideo. Cf. Suzu kotokoto.

kova ['kəva] n. Cova.

kovadu [ko'vadu] adj. Covarde.

kôvi ['kovi] n. Couve. 
kôvinô [ko'vino] n. Corvina.

koxe $\left[k J^{\prime} \int \varepsilon\right] n$. Crochê.

koxi ['kofi] n. Coisa.

kôxyan [ko'fjã] $n$. Cozinha.

kôzê [ko'ze] v. Cozer.

kpa ['kpa] v. Encostar de lado.

kpanu ['kpanu] $v$. Arrancar.

kparara [kpara'ra] ideo. Cf. Seku kparara.

kpôkpô [kpo'kpo] v. Engatinhar.

kriô ['krio] adj. Crioulo.

krya ['krja] $v$. Criar.

kryadu ['krjadu] adj. Criado.

kren ['krẽ] $v$. Crer.

ku ['ku] conj. Com. Xi txi ten dyô kômpa ôtô i vika ku êli. Se você tem dinheiro compra outro e venha com ele.

kubeta [ku'beta] n. Cobertura de casa.

kubetô [kube'to] n. Cobertor.

kubi [ku'bi] v. Cobrir.

kubu ['kubu] n. Cubo.

kwida [kwi'da] $v$. Cuidar.

kuda $\left[\mathrm{ku} \mathbf{d}^{\mathrm{da}}\right]$ v. Achar.

kudadu [ku'dadu] $n$. Cuidado.

kudi [ku'di] 1. v. Acudir. 2. v. Responder. 3. v. Permitir.

kukundya [ku'kũdja] $n$. Coco.

kukunu [ku'kunu] v. Agachado.

kukunu [kuku'nu] $n$. Defecar.

kukuru [ku'kuru] n. Escuro.

kulêtê [ku'lete] $n$. Colete.

kumandê [ku'mãde] n. Comadre.

kumbina [kũbi'na] v. Combinar.

kumesa [kume'sa] v. Começar.

kumê [ku'me] v. Comer.

kumêsa [kume'sa] $v$. Começar.

kumi ['kumi] $n$. Cume. 
kumin [ku'mĩ] $n$. Lugar.

kumida [ku'mida] $n$. Comida.

kumin [ku'mĩ] 1. $n$. Caminho. 2. $n$. Estrada. 3. $n$. Sítio.

kumin di gada ukaru [ku'mĩ di ga'da u'karu] n. Armazém.

kumpadi [ku'padi] $n$. Compadre.

kumpimidu [kũpi'midu] $n$. Comprimido.

kunfundi [kũfũ'di] v. Confundir.

kunfya [kũ'fja] $v$. Confiar.

kunfyansa [kũ'fjãsa] $n$. Confiança.

kunhadu [ku'nadu] $n$. Cunhado.

kuntitxi [kũ'vitfi] n. Convite.

kunxintxi [kũ $\int 1$ 't $\left.t \mathrm{i}\right]$ v. Permitir.

kupa [ku'pa] v. Ocupar.

kupa ['kupa] n. Culpa.

kupa [ku'pa] v. Morder.

kupasan [kupa'sã] adj. Ocupado.

kupi [ku'pi] v. Cuspir.

kupin [ku'pĩ] $n$. Cuspi.

kura [ku'ra] v. Curar.

kura ['kura] 1. $n$. Feitiço. 2. $n$. Remédio.

kurandêw [kurã'dew] $n$. Terapeuta tradicional.

kurativu [kura'tivu] n. Curativo.

kuru ['kuru] n. Madrugada.

kustela [kus'tela] n. Costela.

kustipasan [kustipa'sã] adj. Gripado.

kusu ['kusu] n. Curso.

kusukusu [kusu'kusu] n. Cuzcuz.

kuta $\left[\mathrm{ku} \mathbf{\prime}^{\prime} \mathrm{ta}\right] v$. Escutar.

kutisa [ku'tisa] n. Cortiça.

kutu [ku'tu] n. Costa.

kutu ['kutu] adj. Curto.

kutu [ku'tu] v. Engrossar.

kutu-bê ['kutu 'be] n. Bainha. 
kutuvêlu [kutu'velu] $n$. Cotovelo.

kutwa [ku'twa] n. Cultura.

kuuzu ['ku:zu] n. Cruz.

kuva ['kuva] $n$. Curva.

kuvida [kuvi'da] v. Convidar.

kuxan [ku' $\left.\int \tilde{a}\right] n$. Cozinha.

kuxi [ku' $\mathrm{ji}]$ v. Cozinhar.

kuxta $\left[\mathrm{ku} \int^{1} \mathrm{ta}\right] \nu$. Custar.

kuxtipadu [kuSti'padu] adj. Constipado.

kuxtuma [kuftu'ma] v. Acostumar.

kuxtumadu [kuftu'madu] adj. Acostumado.

kuxya [ku' jja] v. Cozinhar.

kuza ['kuza] n. Coisa.

kuza [ku'za] v. Cruzar.

kuza ['kuza] n. Orgão sexual.

kwa ['kwa] 1. $n$. Corda. 2. $n$. Coisa. 3. int. O que. Pedu kwa txi fêzê a? Pedro, o que você fez?

kwadu ['kwadu] 1. adj. Difícil. 2. adj. Pesado.

kwadô $[k w a ' d o] ~ 1 . ~ n$. Coador. 2. $n$. Peneira.

kwaji ['kwazi] $a d v$. Quase.

kwakwa [kwa'kwa] n. Várias coisas. No tava sa fêzê kwakwa. Nós estávamos fazendo várias coisas.

kwali ['kwali] int. Qual. Kwali ki txi mêsê? Qual você quer?

kwami [kwa'mi] pro. Comigo. Txi tê têmpu ôzê di we paxya kwami fa. Você não tem tempo hoje para ir passear comigo?

kwantu ['kwãtu] int. Quanto. Kwantu dyô txi paga na ukaru a? Quanto dinheiro você pagou no carro?

kwarenta [kwa'rẽta] num. Quarenta.

kwata fya ['kwata 'fja] $n$. Quarta-feira.

kwatu ['kwatu] num. Quatro.

kwatusentu [kwatu'sẽtu] num. Quatrocentos.

kwazi ['kwazi] $a d v$. Quase. N sa kwazi xiga za. Eu estou quase chegando.

kwê ['kwe] n. Coelho.

kwe ['kwe] n. Colher.

kwê [kwe] v. Correr.

kwê ['kwe] $v$. Escorrer. 
kwê manda ['kwe mã'da] int. Por que. Kwê manda txi gaxta dyô tudu pe? Por que você gastou todo o dinheiro?

kwêa ['kwea] n. Correia.

kwêda ['kweda] n. Corrida.

kwêdô [kwe'do] $n$. Corredor.

kwêlu ['kwelu] n. Coelho.

kwêsa [kwe'sa] int. O que. Kwêsa? O que está acontecendo?

kwêtadu [kwe'tadu] adj. Coitado.

kwidadu [kwi'dadu] $n$. Cuidado.

kwidansan [kwi'dãsã] $n$. Cuidados.

kwisê ['kwise] dem. Isto.

kya ['kja] v. Criar.

kyebu ['kjebu] n. Quiabo.

kyê ['kje] 1. interj. Epa! 2. v. Cair.

kyede ['kjed $\varepsilon]$ 1. $n$. Esquerda. 2. adj. Caído.

kyen ['kjẽ] adj. Azedo.

kyenta [kjếta] $v$. Esquentar.

kyentxi ['kjẽtfi] adj. Quente.

kyensê [kjẽ'se] $v$. Esquecer.

kyêwu ['kjewu] n. Pedra. 
la ['la] $a d v$. Lá.

laanza ['lã:za] $n$. Laranja.

ladran [la'drã] n. Ladrão.

ladu ['ladu] 1. n. Parte. 2. n. Lado.

lagan [la'gã] $n$. Lagaia.

lagatixa [laga'tifa] $n$. Lagartixa.

lagu ['lagu] 1. n. Lago. 2. adj. Largo.

Iala [la'la] $a d v$. Lá.

Ialala [lala'la] $a d v$. Lá.

lama ['lama] n. Lama.

lampada ['lãpada] $n$. Lâmpada.

lampya [lã'pja] v. Relampejar.

lampyan [lã'pjã] n. Lampião.

landa [lã'da] $v$. Nadar.

lansa [lã'sa] 1. v. Lançar. 2. v. Vomitar.

lapa ['lapa] top. Lapa.

larya [la'rja] adj. Amargo.

salantxi [sa'lãt\}i] adj. Plano.

lasu ['lasu] $n$. Laço.

lata ['lata] n. Lata.

lava [la'va] 1. v. Lavar. 2. v. Lavrar.

lavadya [lava'dja] $n$. Lavanderia.

lavaya [la'vaja] $n$. Canivete.

lavaya [na'vaja] $n$. Navalha.

lavin [la'vĩ] $n$. Navio.

lê ['le] $v$. Ler.

lega [le'ga] 1. v. Largar. 2. v. Dissolver.

legi ['lezi] adj. Alegre.

leje $\left[1 \varepsilon^{\prime} z^{\varepsilon}\right]$ adj. Lesionado.

lêkê [le'ke] v. Advertir.

lekeleke [leks'leks] ideo. Cf. Finu lekeleke. 
lêlê [le'le] $v$. Visitar.

lemba [lẽ'ba] $v$. Lembrar.

lemi ['lkmi] 1. $n$. Leme. 2. $n$. Vagina.

lensu ['lẽsu] $n$. Lenço.

lenswe [lẽ'swe] $n$. Lençol.

lêmunha [le'muja] $n$. Remo.

lenta [lẽ'ta] $v$. Entrar.

leta ['leta] 1. $n$. Alerta. 2. $n$. Letra.

lêtan [le'tã] n. Leitão.

lêtatu [le'tatu] $n$. Retrato.

lêtê ['lete] n. Leite.

letxi ['lefti] n. Leste.

levi ['levi] n. Leve.

levilevi ['levi'levi] n. Tudo bem!

lezadu [le'zadu] adj. Aleijado.

li ['li] pro. Ele.

libedi [li'bedi] adj. Falador.

liman [li'mã] $n$. Limão.

limitxi [li'mit $\left.\int i\right] n$. Limite.

limpa [lî́pa] $v$. Limpar.

limpu ['lĩpu] n. Limpo.

linda ['lĩda] adj. Linda.

linha ['lina] $n$. Linha.

lisan [li'sã] $n$. Lição.

lisense [li'sẽse] $n$. Licença.

litu ['litu] n. Litro.

liva [li'va] $v$. Livrar.

livu ['livu] 1. $n$. Arquivo. 2. $n$. Livro.

livê ['live] adj. Livre.

lo ['lo] 1. v. Moer. 2. n. Rolo.

logu ['logu] $a d v$. Logo.

loja ['l’za] n. Loja.

lola ['’’la] $n$. Rola. 
lômbiga [lõ'biga] n. Lombriga.

lômbu ['lõbu] $n$. Ombro.

longô ['lõgo] adj. Alto.

longu ['lõgu] $n$. Longa.

longu ['lũgu] adj. Longe.

lonswe [lõ'swe] $n$. Lençol.

lorozu [lo'rozu] 1. $n$. Relógio. 2. $n$. Cf. Rolozu.

lorya ['lorja] $n$. Rolha.

loza ['loza] n. Loja.

Iwasan [lwa'sã] $n$. Menstruada.

lubina [lu'bina] $n$. Neblina.

luge $\left[\mathrm{lu}^{\prime} \mathrm{g} \varepsilon\right] n$. Lugar.

luji ['luzi] $n$. Luz.

luji [lu'zi] v. Luzir.

lunge ['lũge] $n$. Língua.

lung'ie [lũg'ic] $n$. Principense. $\mathbf{N}$ xina lung'Ie. Eu aprendi principense.

lung'ie [lũ'gie] $n$. Língua da ilha. No sa ke palixa na lung'Ie. Nós vamos falar na língua do Príncipe. luta [lu'ta] v. Lutar.

lutu ['lutu] 1. $n$. Luta. 2. n. Luto.

luxi [lu'fi] $v$. Luzir.

luzi ['luzi] n. Luz.

lyan [ljã] $n$. Leão. 
ma ['ma] 1. v. Colar. 2. $a d v$. Mais. Ê podi ma fa. Ele não consegue mais. Cf. Maxi. 3. conj. Mas. $\mathbf{N}$ goxta di txi ma txi goxta di mi fa. Eu gosto de você, mas você não gosta de mim. Cf. Maji. 4. conj. Mas Cf. Maji. 5. adj. Mau. 6. adj. Ruim.

Maa ['ma:] n. Maria.

maadu ['ma:du] $n$. Marido.

maakpalu [ma:kpa'lu] $n$. Tipo de pássaro. $\mathbf{N}$ tê maakpalu na kaxi me sa krya. Eu tenho um makpalu na minha casa.

madê [ma'de] $n$. Útero.

madi ['madi] $n$. Madre.

madô [ma'do] adj. Esperto.

madya [ma'dja] n. Madeira.

magôzu [ma'gozu] adj. Amargo.

maji ['mazi] conj. Cf.Maxi.

maka ['maka] 1. n. Cicatriz). 2. n. Marca.

maka [ma'ka] v. Marcar. Cf. Ôkê.

makaku [ma'kaku] n. Macaco.

makine [maki'nc] ideo. Gaani makine. Muito grande.

makita [ma'kita] $n$. Malagueta.

makuku [ma'kuku] $v$. Tomar posse.

mala ['mala] $n$. Mala.

malandu [ma'lãdu] adj. Malandro.

malha ['maরa] $n$. Malha.

mali ['mali] $a d v$. Mal.

malimboki [malî́'boki] $n$. Espécie de fruta.

malmentê [mal'mẽte] idiom. Mais ou menos.

malôkô [ma'loko] adj. Maluco.

mama [ma'ma] $v$. Mamar.

maman [ma'mã] $n$. Mamão.

mampata [mã'pata] $n$. Resíduo de óleo. Cf. Riman.

mana ['mana] $n$. Irmã.

manda [mã'da] int. Mandar. Kwê manda ki sa podi lê nu identu kômpasu fa? Por que você não pode ler direito?

mandaki [mã'daki] $n$. Colchão. 
mandasa [mã'dasa] n. Madrasta.

mandya [mã'dja] $n$. Madrinha.

mandyoko [mã'djəkə] n. Mandioca.

manga ['mãga] 1. n. Cabo. 2. n. Manga.

mangasan [mã'gasã] n. Mangação.

mangi ['mãgi] n. Mangue.

mangu ['mãgu] adj. Magro.

manha ['mãna] n. Manhã.

mani [ma'ni] v. Lavar (roupa).

manikiryadu [maniki'rjadu] adj. Malcriado.

maninga [ma'nĩga] $n$. Raiva.

mansa [mã'sa] v. Amassar (pão).

manse [mã'se] adj. Rapaz.

manu ['manu] 1. n. Irmão. 2. n. Irmão.

Maa ['ma:] n. Maria. Cf. Maa.

mara [ma'ra] v. Amarrar.

mareladu [mare'ladu] adj. Amarelado.

marelu [ma'relu] n. Amarelo.

maa uman [ma: u'mã] v. Casar.

marôta [maro'ta] v. Amassar.

masa ['masa] n. Massa.

masadu [ma'sadu] n. Machado.

masan [ma'sã] n. Banana-maçã.

masariku [masa'riku] n. Massarico (ave).

masu ['masu] n. Março.

masêtê [ma'sete] n. Macete.

mata [ma'ta] v. Matar.

matabisu [mata'bisu] n. Café da manhã (português local: matabicho).

matan [ma'tã] n. Pus.

matega [mã'tega] $n$. Manteiga.

matelu [ma'tclu] n. Martelo.

matu ['matu] n. Floresta.

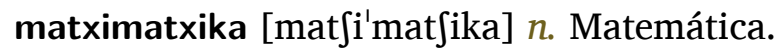


matxina [ma't $t$ ina] $n$. Matinas.

maw ['maw] adj. Mau.

maxi [ma' $\left.\int i\right] n$. Facão.

maxi ['mafi] 1. adv. Mais. Riman me maxi fotxi pasa ami. O meu irmão é mais forte que eu. 2. conj. Mas. Maxi n mêsê fêzê êli nada di favô fa. Mas eu não quis fazer nenhum favor.

maxila [ma'fila] $n$. Maxilar.

maxinêw [mafi'new] n. Marceneiro.

mayo [ma'jo] adj. Maior.

mbaka ['mbaka] $n$. Facão.

m'basa ['mbasa] 1. n. Costela. 2. n. Nervo. Cf. Bigu.

mbigu [m'bigu] $n$. Umbigo

me ['mع] 1. poss. Meu. Karu me ê limpu. Meu carro está limpo. 2. poss. Minha. Kaxi me ê limpu. Minha casa é limpa.

mêanotxi [mea'nət]i] n. Meia-noite.

mêdu ['medu] n. Medo. Cf. Mêsê.

mêê ['me:] v. Amar.

meli ['meli] n. Mel.

Mene n.

menemene [me'ne me'ne] ideo. Cf. Doxi menemene.

mênu ['menu] $a d v$. Menos. I kinji mênu kwatu, kantu ê ka da? E quinze menos quatro, quanto dá? mêrêsê [mere'se] $v$. Merecer.

mêsê [me'se] 1. v. Gostar. 2. v. Querer. 3. v. Precisar. 4. v. Cf. Mêê.

Merika ['merika] top. América.

mesu ['mesu] $a d v$. Mesmo. Êli mesu sa goxta di faa ki Maa fa. Ele mesmo não gosta de falar com a Maria.

metedi [me'tedi] quant. Metade.

mêtê [me'te] v. Meter.

metxi ['met $\mathrm{i}] \mathrm{n}$. Mestre.

meya ['mعja] $n$. Meia.

meydya [mej'dja] $n$. Meio dia.

meze $[$ 'meze] $n$. Mesa.

mêzê ['meze] $n$. Mês.

mi ['mi] 1. pro. Me. 2. pro. Mim. 3. pro. Cf. Ami.

midi [mi'di] $v$. Medir.

migu ['migu] $n$. Amigo. 
miida ['mi:da] $n$. Medida.

mikondo [mikõ'do] $n$. Mikondo.

milagi [mi'lazi] $n$. Milagre.

mili ['mili] num. Mil.

miloru [mi'bru] $a d v$. Melhor. Mwin no miloru za? A nossa mãe está melhor?

mina ['mina] $n$. Menina.

minda [mĩ:'da] $n$. Medida

mindi ['mĩdi] $v$. Medir.

minga ['mĩga] $n$. Tamanho.

mingwantxi [mĩ'gwãt $\left.\int i\right]$ adj. Minguante.

mini kôkô ['mini ko'ko] $n$. Verruga.

mininu [mi'ninu] 1. n. Menino. 2. n. Cf. Minu.

minixtu [mi'niftu] $n$. Ministro.

mintxya $\left[\mathrm{min}^{\prime} \mathrm{t} \int \mathrm{ja}\right] n$. Mentira.

minu ['minu] 1. n. Menino. 2. adj. Pequeno. 3. $a d v$. Pouco.

minu dedu ['minu 'dedu] $n$. Dedo mindinho.

minu muzwa ['minu mu'zwa] $n$. Gesto.

minu tômbêta ['minu tõ'beta] $n$. Flauta.

minu ôtô ['minu o'to] $n$. Úvula.

mira [mi'ra] $v$. Olhar.

mire $[\mathrm{mi} ' r \varepsilon] n$. Mil réis.

misa ['misa] $n$. Missa.

misanga [mi'sãga] $n$. Dobradiça.

mixidadi [mi $\left.\int i ' d a d i\right] ~ n$. Necessidade.

mixkitu [mi $\left.\int^{\prime} k i t u\right] n$. Mosquito.

mixtadô [mifta'do] $n$. Administrador.

miza [mi'za] $v$. Urinar. Cf. Modi.

mo ['mo] int. Como. Modi n ka fêzê kwisê a? Como que eu faço isso?

mô ['mo $n$. Doença do pé.

moa [mə'a] $v$. Molhar.

môdê [mo'de] $v$. Morder.

modenu [mว'denu] $n$. Jovem.

modi ['modi] 1. conj. Como. 2. int. Como. Modi txi mêsê a? Como você quer? 3. prep. Como. 4. n. Maneira. 
modi modi ['modi'mədi] $a d v$. De qualquer maneira. Modi modi n ka sama txi na posan. De qualquer modo, eu vou ligar para você na cidade.

modi sê ['modi 'se] $a d v$. Dessa maneira.

môfada [mo'fada] $n$. Almofada.

mogomogo [mว'gว mə'gว] ideo. Cf. Kasô mogomogo.

mola [mo'la] v. Amolar.

moli ['moli] $n$. Mole.

molimoli ['moli'moli] adv. Nda molimoli. Andar lentamente

môlômbi [molõ'bi] $n$. Amendoim. Cf. Molimoli.

momoli [mə'məli] adj. Lento.

mona ['mona] n. Macaco grande.

mondyoko [mõ'djəkə] n. Mandioca.

mongomongo [mõ'gวmõ'gว] ideo. Cf. Minu mongomongo.

montxi ['mõt $\left.\int i\right]$ 1. n. Monte. 2. $a d v$. Muito.

môônô ['mo:no] adj. Morno.

môra [mo'ra] v. Morar.

môrada [mo'rada] $n$. Morada.

mosa [mo'sa] v. Mostrar.

mosa ['məsa] n. Moça.

mosu ['məsu] 1. n. Filho. 2. n. Moço.

moto ['moto] $n$. Moto.

motokêw [mətə'kêw] $n$.

motxi ['mot $\mathrm{i}]$ 1. $n$. Morte. 2. adj. Morto.

môvimentu [movi'mẽtu] 1. $n$. Agitação. 2. $n$. Movimento.

môxê [mo'se] $v$. Mexer.

môyô ['mojo] 1. n. Molho. 2. n. Penca.

mpin [ĩ'pĩ] 1. $n$. Espinha. 2. $n$. Espinho.

mpota [mps'ta] $v$. Importar(-se).

muda [mu'da] v. Mudar.

mudu ['mudu] $n$. Mudo.

mufada [mu'fada] $n$. Almofada.

mufinu [mu'finu] $n$. Cobra.

mukêlê [mu'kele] $n$. Bagunça.

mukêlê [muke'le] $n$. Problema. 
mulele $\left[m u l \varepsilon^{\prime} l \varepsilon\right] n$. Algo danificado ou rasgado.

munda [mũ'da] v. Mudar.

mundya [mũ̃dja] 1. v. Por-se de pé. 2. v. Parar.

mundyadu [mũ'djadu] adj.

musa [mu'sa] $v$. Mostrar.

musu ['musu] quant. Musu xinku. Todos os cinco.

musuka ['musuka] n. Mosca.

musêgu [mu'segu] n. Morcego.

musêw [mu'sew] n. Mosteiro.

mutambu [mu'tãbu] $n$. Armadilha para pássaros.

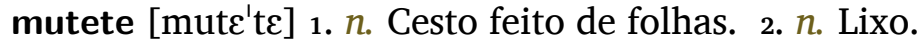

mutendê [mutẽ'de] $n$. Palmeira de Andim.

mutôrô [mu'toro] n. Motor.

muntu ['mũtu] $a d v$. Muito. $\mathbf{N}$ sa goxta muntu de fika na ubasu banan. Eu gosto muito de ficar embaixo da bananeira.

muxikitô [mufi'kito] $n$. Mosquito.

muxila [mu'fila] $n$. Mochila.

muzengê [muzẽ'ge] $n$. Muzengue (comida típica).

mwa ['mwa] v. Molhar.

mwadu ['mwadu] adj. Molhado.

mwê ['mwe] v. Morrer.

mwin ['mwĩ] $n$. Mãe.

myansa [mjã'sa] v. Ameaçar.

mye $[$ 'mje] $n$. Mulher.

myo ['mjJ] adv. Melhor.

myôlô ['mjolo] $n$. Miolo. 
n ['n] pro. Eu. N vê mye. Eu vi a mulher.

na ['na] prep. Em. Txi po we na paa? Você pode me encontrar na praia?

na modi ki ['na 'mədi 'ki] idiom. De acordo com. Na modi ki ê sa na livu. De acordo com o livro.

namôra [namo'ra] $v$. Namorar.

nanaji [na'nazi] $n$. Ananás. Cf.Mwin gaani.

nani ['nãni] n. Avó.

nasê [na'se] $v$. Nascer.

na sêbê ['na 'sebe] idiom. De fato.

natali [na'tali] $n$. Natal.

nda ['nda] v. Andar. Cf.Indala.

ndala ['ndala] $n$. Palma.

ndili ['ndili] adj. Anil.

nêgôxyô [ne'gofjo] n. Negócio.

neli ['ncli] $n$. Anel.

nêli ['neli] pro. Nele.

nenga [nẽ'ga] $v$. Negar.

nengu ['nẽgu] 1. n. Qualquer instrumento de trabalho. 2. adj. Empregado.

netu ['netu] $n$. Neto.

nevu ['nevu] $n$. Nervo.

Nexi ['nefi] $n$. Inês. Cf.Ingêrêrê.

ngêrêrê [ngere're] $n$. Espécie de árvore.

ngola ['ygola] 1. $n$. Trabalhador contratado. 2. top. Angola.

ngola [ngว'la] $n$. Angolar.

ngola ['ygola] top. Angolares.

ngoma [ygว'ma] $v$. Engomar.

ngoro ['ngəro] adj. Criança que não se desenvolveu bem.

nhan ['nã] $a d v$. Sim. Nhan, da mi dôsu môyô di banômi. Sim, dê-me duas pencas de banana-pão.

nhanga [nã'ga] $v$. Rasgar.

nhangadu [nã'gadu] adj. Rasgado.

nhanha [na'na] n. Gato selvagem.

nhanu [na'nu] $v$. Arranhar. 
nhanu ['nanu] v. Coçar.

nhanva [nã'va] $v$. Alinhavar.

nhemi ['nemi] $n$. Inhâme.

nhe $[$ 'nع] $v$. Apertar.

nho ['ñ] 1. $a d v$. Nada. $\mathbf{N}$ tê ko nho pa $\mathbf{n}$ fêzê fa. Eu não tenho nada para fazer. 2. quant. Nenhum. 3. $a d v$. Nunca.

ni ['ni] $a d v$. Aqui. Txi vika ni txi fêzê kwa ũa. Se você está aqui você fez alguma coisa. Cf.Nixi.

nii ['ni:] quant. Nenhum. $\mathbf{N}$ ten fa nii vinten fotxi. Eu não tenho nenhum vintém.

nili ['nili] n. Anil.

nimigu [ni'migu] $n$. Inimigo.

nina [ni'na] $v$. Doer. Cf.Ni.

nixi ['nifi] $a d v$. Aqui.

nixima [ni'Sima] prep. Sobre. Toya nixima meze. A toalha está sobre a mesa.

nkomoda [nkəmว'da] $v$. Incomodar.

n n ['n 'n] $a d v$. Não.

no ['no] 1. pro. Nós. No sa ke fya kopa izêtxi pwema. Nós vamos ao mercado comprar azeite de palma. 2. poss. Nosso. Iê no sê gaavi. A nossa ilha é bonita. Cf.Nosu.

noda ['nəda] $n$. Nódoa.

nomi ['nכmi] $n$. Nome.

nosa ['nəsa] poss. Nossa.

nosu ['nəsu] poss. Nosso. Padê nosu. Pai nosso.

nota ['nota] $n$. Nota.

noti ['nət $\left.\int i\right]$ adj. Norte.

nova igbê ê ['nəva i'gbe 'e] idiom. Tudo bem?

nove ['nəve] num. Nove.

novela [nว'vela] $n$. Novela.

noventa [nว'vẽta] num. Noventa.

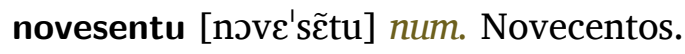

novin [n’'vĩ] adj. Novo.

novu ['nəvu] adj. Novo.

nu ['nu] $n$. Nu. Minu nu pelipeli. Ele está $n u$.

nunka ['nũka] $a d v$. Nunca.

Nunxya ['nũfja] $n$. Nossa Senhora.

Nunxyô ['nũfjo] $n$. Nosso senhor. 
nutxisa [nu't tisa] $n$. Notícia.

nuvi ['nuvi] $n$. Nuvem.

nuvêw [nu'vew] $n$. Novelo.

nwese ['nwese] $n$. Metade de coco usado para pegar comida.

nwêva ['nweva] $n$. Noiva.

nwêvu ['nwevu] n. Noivo.

nzesan [nze'sã] $n$. Injeção. 
ô [o] conj. Ou.

ô ['o] interj. Ô! Bon dya ô! Bom dia!

oba ['Jba] $n$. Obra.

ôbigasan [obiga'sã] $n$. Obrigação.

obobo [วbว'bs] $n$. Prato tradicional de Príncipe.

ôbôgôdô [obogo'do] ideo. Cf. Xyadu ôbôgôdô.

obyomon [วbjว'mõ] adj. Feio.

odi ['Jdi] $n$. Ordem.

ogbo [J'gbo] n. Prato local.

ogbo ope [ว'gbo ว'pe] n. Calcanhar.

ôgbôsô [ogbo'so] adj. Albino.

oka [o'ka] n. Ocá.

ôkê ['oke] $n$. Macaco.

okere $\left[\supset k \varepsilon^{\prime} r \varepsilon\right] n$. Canto.

okori [ə'kəri] n. Larva.

okori-wê [ว'kori 'we] n. Secreção nos olhos.

okpo [ว'kpэ] $n$. Massa alimentar.

ôkpô [o'kpo] n. Pântano.

okulu ['Jkulu] $n$. Óculos.

ôkyê [o'kje] 1. n. Encosta. 2. n. Ladeira.

omi ['Jmi] $n$. Homem.

omo [o'mo] adj Raspado.

omu ['omu] n. Mestre.

onji ['õzi] num. Onze.

onra ['õra] $n$. Honra.

onra [õ'ra] $v$. Honrar.

ontontxi [õ'tõt $\left.\int \mathrm{i}\right] a d v$. Anteontem.

ontxi ['õt $\left.\int \mathrm{i}\right] a d v$. Ontem.

onzê ['õze] num. Onze.

ôôôô ['o:] interj.

ope $\left[\jmath^{\prime} p \varepsilon\right] n$. Pé. 
opo [o'po] n. Pó.

ora ['ora] 1. $a d v$. Quando. 2. n. Hora. 3. $a d v$. Ora.

ôrôkô ['oroko] $n$. Rato pequeno.

ôru ['oru] n. Ouro.

ôryô [o'rjo] n. Diarréia.

osami [ว'sami] $n$. Óssame.

ose [ว'sc] $n$. Céu.

oso ['Jsว] n. Roça.

osoko [วsว'kJ] n. Laço para pegar animais.

osu ['osu] n. Osso.

ota ['Jta] $n$. Horta.

ôtalisa [ota'lisa] $n$. Hortaliças.

ôtô ['oto] n. Garganta.

ôtu ['otu] $a d v$. Outro.

ovu ['วvu] $n$. Ovo.

ôvyô [o'vjo] 1. n. Selva. 2. n. Floresta.

owo ['Jwว] pro. Vocês. Owo minu santome. Vocês são sãotomenses.

owô ['Jwo] 1. pro. Vós. 2. poss. Vossa. 3. poss. Vosso.

ôzê [o'ze] $a d v$. Hoje.

ôzêgê [o'zege] n. Osga.

ôzen [o'zẽ] $n$. Juntas. 
pa ['pa] conj. Para.

paa ['pa:] $n$. Praia.

paage $\left[\mathrm{pa}:{ }^{\prime} \mathrm{g} \varepsilon\right] n$.

paasô [pa:'so] interj. Tchau!

paata ['pa:ta] $n$. Prata.

paatu ['patu] $n$. Prato.

padasu [pa'dasu] $n$. Padrasto.

padêw [pa'dew] $n$. Padeiro.

padi ['padi] $n$. Padre.

padin [pa'dĩ] $n$. Padrinho.

paga [pa'ga] 1. v. Apagar. 2. v. Pagar.

pagamentu [paga'mẽtu] $n$. Pagamento.

palapala ['pala'pala] $n$. Banana da terra verde frita em fatias finas.

palasu [pa'lasu] $n$. Palácio.

palava [pa'lava] $n$. Palavra.

palixa [pali'fa] $v$. Conversar. Cf.Teempi.

panela [pa'nela] $n$. Panela.

panguli [pãgu'li] adj. Guloso.

panha [pa'na] 1. v. Apanhar. 2. v. Pegar.

pankada [pã'kada] n. Pancada.

papa [pa'pa] $v$. Papar.

papu ['papu] n. Papo.

para [pa'ra] v. Parar.

parêsê [pare'se] $v$. Parecer.

pasadu [pa'sadu] n. Passado.

pasadô [pasa'do] $n$. Corredor.

pasu ['pasu] $n$. Pássaro.

pasu kuuzu ['pasu 'ku:zu] $n$. Andorinha.

pasê [pa'se] $v$. Aparecer.

pasenta [pa'sẽta] $n$. Placenta.

pasêw [pa'sew] $n$. Parceiro. 
pata ['pata] $n$. Pato.

patan [pa'tã] n. Patrão.

patu ['patu] n. Parto.

patxi ['pat $\left.\int i\right] n$. Parte.

pawma uman ['pawma u'mã] $n$. Palma da mão.

paxense [pa'fẽse] $n$. Paciência.

paxtô [paS'to] n. Pastor.

paxya $\left[\mathrm{pa}{ }^{\prime} \int \mathrm{ja}\right]$ v. Passear.

paya ['paja] $n$. Palha.

pazê [pa'ze] $n$. Prazer.

pe ['pe] ideo. Cf.Tudu pe.

pêda ['peda] $n$. Perda.

pedasu [pe'dasu] $n$. Pedaço.

pêdê [pe'de] $v$. Perder.

pêdêw [pe'dew] $n$. Pedreiro.

pedi $\left[p \varepsilon^{\prime} d i\right] n$. Peido.

peegu ['pe:gu] $n$. Prego.

peesa [pe:'sa] $v$. Emprestar.

pêêsu ['pe:su] $n$. Preço.

peetu ['pe:tu] adj. Preto.

peetu bin ['pe:tu 'bĩ] idiom. Nigérrimo.

peezu ['pe:zu] adj. Preso.

pega $\left[\mathrm{p} \varepsilon^{\prime} \mathrm{ga}\right] v$. Pegar.

pêga ufogu [pe'ga u'fogu] idiom. Confusão.

pelabubu [pelabu'bu] $n$. Pequeno morcego.

peli ['peli] $n$. Pele.

pêlu ['pelu] $n$. Pêlo.

pêmê [pe'me] 1. $v$. Espremer. 2. $v$. Torcer.

pemyan [pe'myã] $v$. Pela manhã.

pena ['pena] $n$. Perna.

pene $\left[p \varepsilon^{\prime} n \varepsilon\right] \nu$. Depenar.

pene ['penc] 1. $n$. Dó. 2. $n$. Pêlo (animal e humano). 3. $n$. Pena (ave). 4. $n$. Pena (caneta).

penedu [pe'nedu] adj. Depenado. 
pempen [pẽ'pẽ] $v$. Raspar.

pensa [pẽ'sa] $v$. Pensar.

pensamentu [pẽsa'mẽtu] $n$. Pensamento.

pensê [pẽ'se] $v$. Pensar.

pentê ['pẽte] $n$. Pente.

pentê ['pẽtsi] $n$. Púbis.

pepeli [pe'peli] $n$. Papel.

pêru [pe'ru] $n$. Peru.

pêsadu [pe'sadu] $v$. Emprestar.

pesegu ['pescgu] n. Pêssego.

pesena [pe'sena] $n$. Pestana.

pesena wê [pe'scna 'we] $n$. Sobrancelha.

peta $\left[\mathrm{p} \varepsilon^{\prime} \mathrm{ta}\right] \nu$. Apertar.

petadu [pe'tadu] adj. Apertado.

pete $\left[\mathrm{p} \varepsilon^{\prime} t \varepsilon\right]$ adj. Liso.

pêtensê [petẽ'se] $v$. Pertencer.

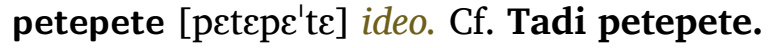

petepete $\left[p \varepsilon^{\prime} t \varepsilon p \varepsilon^{\prime} t \varepsilon\right]$ ideo. Cf. Vêdê petepete.

petoli [pe't’li] $n$. Petróleo.

pêtu ['petu] $n$. Peito.

petu ['petu] $a d v$. Perto.

pêxi ['pe $\mathrm{i}] \mathrm{n}$. Peixe.

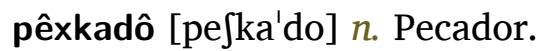

peza $\left[\mathrm{p} \varepsilon^{\prime} z a\right]$ v. Pesar.

pezadu [pe'zadu] adj. Duro.

pêzêdentxi [peze'dẽt $\left.\int i\right] n$. Presidente.

pêzentê [pe'zẽte] $n$. Presente.

pêzu ['pezu] $n$. Balança.

pezu ['pezu] $n$. Preso.

pi [pi] 1. ideo. Cf. Unotxi pi. 2. n. Pio.

pia ['pia] n. Pia.

pidi [pi'di] $v$. Pedir.

pidi ['pidi] 1. conj. Por isso. 2. conj. Porque. 
pidi dêsu ['pidi 'desu] idiom. Por favor. Pidi dêsu fisa pôtô da mi! Por favor, feche a porta para mim! pidi kwê manda ['pidi 'kwe mã'da] int. Por quê? Txi sêbê pidi kwê manda ki ê fika dwintxi a? Você sabe porque ele ficou doente?

pidi kwêsa [pi'di 'kwe'sa] int. Por que. Txi vika sedu fa pidi kwi sa? Você não veio cedo por quê? piigu ['pi:gu] $n$. Perigo.

pika [pi'ka] v. Picar.

pikan [pi'kã] top. Picão.

pikarêta [pika'reta] $n$. Picareta.

piku ['piku] 1. n. Pico. 2. top. Pico.

pilha ['piKa] 1. $a d v$. Muito. Ê fê pilha fôkôtu. Ele fez muito barulho. 2. n. Pilha.

pimyô [pi'mjo] num. Primeiro.

pimenta [pi'mẽta] n. Pimenta.

pimentan [pimẽ'tã] $n$. Pimentão.

pinda [pĩ'da] $v$. Pendurar.

pindadu [pĩ'dadu] adj. Pendurado.

pingada [pĩ'gada] $n$. Espingarda.

pingôpingô ['pĩgo'pĩgo] 1. $n$. Cicatriz. 2. n. Pinta.

pinsa [pĩ'sa] $v$. Empurrar.

pinseza [pĩ'scza] $n$. Princesa.

pinsu ['pĩsu] $n$. Empurro.

pinta [pĩ'ta] $v$. Pintar.

pinxipi ['pĩ $\left.\int i p i\right] ~ n$. Príncipe.

pipinu [pi'pinu] $n$. Pepino.

pirata [pi'rata] $n$. Pirata.

pitxitxi [pi't $\left.\int i t \int i\right] n$. Apetite.

pitxi [pi't $\left.\int i\right] n$. Pequi.

pixiza [pi $\left.\int i^{\prime} z a\right] v$. Precisar.

pixka [pif'ka] $v^{\prime}$ Pescar.

pixkadô [pifka'do] $n$. Pescador.

piza [pi'za] $v$. Pisar.

planta [plã'ta] v. Plantar.

po ['po] $v$. Poder.

pobi ['pobi] adj. Pobre.

pôbêma [po'bema] $n$. Problema. 
pôdê ['pode] adj. Podre.

podi [po'di] $v$. Poder.

pôdôrôzu [podo'rozu] adj. Poderoso.

pôdya [po'dja] v. Podia.

pôfêsô [pofe'so] $n$. Professor.

pogama [po'gama] $n$. Programa.

pojetu [po'zetu] $n$. Projeto.

pôji ['pozi] conj. Pois.

pôkê [po'ke] 1. int. Porque. 2. int. Por que.

pôkô ['poko] 1. n. Porco. 2. $a d v$. Pouco.

pômbali [põ'bali] n. Pombal.

pômbô ['põbo] n. Pombo.

pomesa [po'mesa] $n$. Promessa.

ponta ['põta] n. Ponta.

ponta [põ'ta] $v$. Apontar.

ponta ope ['põta ว'pe] $n$. Chute.

pontada [põ'tada] $n$. Pontada.

pontu ['põtu] $n$. Ponto.

pontxi ['põt $\left.\int i\right] n$. Ponte.

pooda [po:'da] $v$. Perdoar.

poota [po:'ta] v. Importar-se.

popi ['popi] $n$. Próprio.

pôpô [po'po] n. Cabelo branco.

pôsan [po'sã] $n$. Cidade.

pôsô ['poso] n. Poço.

pota [po'ta] $v$. Transportar.

pôtêw [po'tew] n. Porteiro.

poti ['pot $\left.\int i\right] n$. Pote.

poto ['psts] $n$. Porta.

potopoto [pstวps'ts] ideo. Cf. Mwadu potopoto.

pôtu ['potu] $n$. Porto.

potxi ['pot $\mathrm{i}] n$. Recipiente.

poova ['pэ:va] $n$. Prova. 
pôva [po'va] $v$. Provar.

pôvô ['povo] n. Povo.

pôvêta [pove'ta] $v$. Aproveitar.

poxta ['pJ]ta] $n$. Aposta.

poxta $\left[\mathrm{p} J \int^{\prime} \mathrm{ta}\right] n$. Apostar.

pôxtu ['poftu] $n$. Posto.

pôzisan [pozi'sã] $n$. Posição.

pu ['pu] prep. Por. N vika ôbôgôdô Ie pu Santomé. Eu vim para a ilha do Príncipe por São Tomé.

puden [pu'dẽ] $n$. Poder.

pudya [pu'dja] 1. v. Podia. 2. v. Devia.

pufya [pu'fja] $v$. Desputar.

pukê [pu'ke] int. Porque. Maxi pukê modi a? Mas por quê?

pulixya [pu'lifja] $n$. Polícia.

puluman [pulu'mã] $n$. Pulmão.

pulumunia [pulumu'nia] $n$. Pneumonia.

pusu ['pusu] n. Pulso.

Putuga [putu'ga] top. Portugal.

putugêzê [putu'geze] 1. adj. Português. 2. n. Português.

puunta [pũ:'ta] v. Perguntar.

puxa [pu'Ja] $\nu^{\prime}$ Puxar.

puzuntu [pu'zũtu] n. Presunto.

pwe ['pwe] n. Pai.

pwe ['pwe:] $\nu$. Parir.

pwê ['pwe] v. Pôr.

pwêdê ['pwede] $n$. Parede.

pwê gaani ['pwe 'ga:ni] $n$. Avô.

pwema ['pwema] $n$. Palma.

pwêra ['pwera] $n$. Poeira.

pwibi [pwi'bi] $v$. Proibir.

pya ['pja] 1. v. Espiar. 2. v. Olhar. 3. $v$. Ver.

pyada ['pjada] $n$. Piada.

pyenepyene $[p j \varepsilon ' n \varepsilon$ pje'n $\varepsilon]$ ideo. Cf. Limpu pyenepyene.

pyôpyô [pjo'pjo] ideo. Cf. Ponta pyôpyô.

pyoro [pjo'ro] v. Piorar.

pyula ['pjula] n. Pílula. 
ra ['ra] $v$. Errar.

rakwa [ra'kwa] v. Recuar.

ranha ['rãna] $n$. Rainha.

ranhu ['raju] $n$. Barulho.

ranja [rã'za] v. Arranjar.

ranka [rã'ka] 1. v. Arrancar. 2. v. Sair.

rapariga [rapa'riga] $n$. Rapariga.

rara ['rara] $v$. Passar folha no fogo para ficarem maleáveis.

rarara [rara'ra] ideo. Cf. Vemya rarara.

raru ['raru] n. Raro.

rarya [ra'rja] $n$. Amargo.

rasan [ra'sã] $n$. Ração. Cf. Roxpoxta.

raxpoxta [raJ'posta] $n$. Resposta.

raza [ra'za] $v$. Rezar.

razu ['razu] adj. Raso.

re ['re] adj. Real.

rêbenta [rebẽ'ta] $v$. Arrebentar.

rêda [re'da] $v$. Herdar.

rêdê [rede] $v$. Arder.

rêdê ['rede] $n$. Rede.

rêdêw [re'dew] $n$. Herdeiro.

redya ['redja] $n$. Rédea.

rêgê [re'ge] 1. v. Arder. 2. v. Levantar. 3. v. Erguer. 4. v. Guardar.

reji ['rezi] $n$. Raiz.

rêjiônali [rezio'nali] adj. Regional.

rekadu [re'kadu] $n$. Recado.

rêkama [re'kama] $v$. Reclamar.

rekya $\left[\mathrm{r \varepsilon}^{\prime} \mathrm{kja}\right]$ v. Arquear.

rema $\left[\mathrm{re}^{\prime} \mathrm{ma}\right] v$. Remar.

renda [rẽ'da] $v$. Arrendar.

rendê [rẽ'de] 1. v. Contrair hérnia. 2. v. Quebrar. 3. v. Separar. 4. v. Render. 
rendêdu [rẽ'dedu] $v$.

rendêw [rẽ'dew] $n$. Rendeiro.

rendidu [rẽ'didu] adj. Com hérnia.

rêpendê [rẽpẽ'de] $v$. Arrepender.

rêpentxi [re'pẽt $\mathrm{i}$ ] $a d v$. De repente. Ê xiga rêpentxi. Ele chegou de repente.

rêpondi [repõ'di] $v$. Responder.

rêsêbê [rese'be] $v$. Receber.

rêsponsavêw [respõ'savew] adj. Responsável.

rew ['rعw] $n$. Réu.

reva ['reva] $n$. Raiva.

rezan [rع'zã] $n$. Razão.

riku ['riku] n. Rico.

rikêza [ri'keza] $n$. Riqueza.

riman [ri'mã] $n$. Irmão.

rimi [ri'mi] v. Preparar comida.

rimidô [rimi'do] adj. Fofoqueiro.

rin ['rĩ] $v$. Rir.

rinji ['rĩzi] $n$. Rim.

rinka ['rîka] $n$. Fenda entre as nádegas.

riri [ri'ri] $v$. Sorrir.

rizu ['rizu] $n$. Difícil.

roda ['roda] $n$. Roda.

rôdô ['rodo] $n$. Extra.

rôdôma [ro'doma] n. Garrafa.

rodondo [ro'd̃̃də] adj. Redondo.

rodya [ro'dja] $v$. Rodear.

rodyadu [ro'djadu] adj. Rodeado.

roka ['roka] n. Machado roka.

rôkôpêra [rokope'ra] $v$. Recuperar.

rôkwê [ro'kwe] 1. v. Recolher. 2. v. Guardar.

rolozu [ro'lozu] $n$. Relógio.

romba [rõ'ba] $v$. Arrombar.

rômpê [rõ'pe] quant. Romper. 
romosa [romı'sa] v. Almoçar.

romosu [ro'məsu] $n$. Almoço.

ronka [rõ'ka] $v$. Roncar.

ropa ['ropa] $n$. Roupa.

rôrô ['roro] $n$. Rolo.

rosada [rosa'da] v. Capinar.

rosan [ro'sã] n. Oração.

rota $\left[\mathrm{r}{ }^{\prime}\right.$ ta] $v$. Arrotar.

rota $[$ 'rota] $n$. Arroto.

rovwe $\left[r^{\prime} \mathrm{vw}\right] \mathrm{n}$. Orvalho.

roxpoxta $\left[\operatorname{ro} \int^{\prime} \mathrm{p} \int \mathrm{fta}\right] n$. Resposta.

rozantxi [ro'zãtfi] $n$. Maré alta.

rozantxi d'omwê [ro'zãt $\int i$ do'mwe] $n$. Alto mar.

ruma [ru'ma] v. Arrumar.

rumazen [ruma'zẽ] n. Armazém.

runyan [ru'njã] $n$. Reunião.

rupêw [ru'pew] 1. adj. Europeu. 2. n. Europeu.

rusuji [rusu'zi] v. Ressurgir.

rwin ['rwĩ] adj. Ruim.

rya ['rja] $v$. Ser/estar deprimido.

ryadu ['rjadu] adj. Desanimado. 


\section{S}

sa ['sa] 1. v. Estar. Livu sa beetu. O livro está aberto. 2 . v. Ser. $\mathbf{N}$ mêsê pa minu me sa pixkadô. Eu quero que meu filho seja pescador.

saa ['sa:] 1. n. Esticar. 2. v. Fechar.

saban [sa'bã] $n$. Sabão.

sabudu [sabu'du] $n$. Sábado.

sabunêtê [sabu'nete] $n$. Sabonete.

sada ['sada] $n$. Enxada.

sadu ['sadu] adj. Assado.

sagô [sa'go] 1. v. Latir. 2. v. Queixar.

sagwa [sa'gwa] $v$. Enxaguar.

saka [sa'ka] 1. n. Formiga. 2. v. Vomitar.

saku ['saku] 1. n. Saco. 2. n. Sacola.

sala ['sala] $n$. Sala.

salusu [sa'lusu] $n$. Soluço.

salva [sal'va] $v$. Salvar.

sama [sa'ma] $v$. Chamar.

samadu [sama'du] adj. Chamado.

san ['sã] $n$. Senhora.

sanga [sã'ga] v. Sangrar.

sengi ['sẽgi] $n$. Sangue.

santa ['sãta] v. Engomar.

Santa-Bweba ['sãta 'bweba] top. Santa Bárbara.

Santantoni [sãtã'toni] top. Santo Antônio.

Santome [sãto'me] top. São Tomé.

Santome ki le [sãto'me ki i'e] top. São Tomé e Príncipe.

santope [sãtว'pe] $n$. Centopeia.

sanu [sa'nu] 1. v. Colher. 2. $v$. Encontrar. 3. $v$. Escolher.

sapatu [sa'patu] $n$. Sapato.

sapatêw [sapa'tew] n. Sapateiro.

sape $[\mathrm{sa}$ 'pe] $n$. Chapéu.

sapusapu [sapu'sapu] n. Graviola. 
sapêlin [sape'lĩ] $n$. Chapelinho.

sata [sa'ta] $v$. Saltar.

satu ['satu] n. Voar.

satxixfêtu [sat $\left.\int i \int^{\prime} f e t u\right]$ adj. Satisfeito.

satya di ubuka [sa'tja di u'buka] $v$. Cantar.

saudi [sa'udi] n. Saúde.

savi ['savi] $n$. Chave.

savina ['savina] $n$. Xícara.

sawdadi [saw'dadi] $n$. Saudade.

sawidi [saw'idi] $n$. Saúde.

se $\left[\right.$ 'sc] $\nu_{0}$ Assar.

sê ['se] dem. Esse. Mosu sê ê fê muntu. Esse menino é muito feio.

sê ' [se] $v$. Selecionar.

sê ['se] 1. poss. Seu. Mosu me ê kaa pwe sê. Meu filho é bem parecido com pai. 2. poss. Sua.

sêbê [se'be] $v$. Saber.

sebola [se'bola] $n$. Cebola.

sêdê ['sede] $n$. Sede.

sedu ['sedu] $n$. Cedo.

sedya $\left[s \varepsilon^{\prime} d j a\right] n$. Sardinha.

seenu ['sc:nu] $n$. Sereno.

segedu [se'gedu] $n$. Segredo.

segu ['segu] adj. Cego.

sêgunda-fya [se'gũda 'fja] $n$. Segunda-feira.

sêgundu [se'gũdu] num. Segundo.

sêgwa [se'gwa] v. Segurar.

sêka [se'ka] $v$. Cercar.

seka [se'ka] v. Secar.

sekadu ['sckadu] adj. Secado.

sêku ['seku] n. Seco.

sêku bôrôrô ['seku boro'ro] idiom. Sequíssimo.

sêkura [se'kura] $n$. Secura.

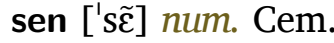

sena ['sena] $n$. Aceno. 
sêmpi ['sẽpi] $n$. Sempre.

sendê [sẽ'de] 1. $v$. Acender. 2. $v$. Estender.

sendê byororo [sẽ'de bjərว'rı] idiom. Todo esticado.

sengê [sẽ'ge] 1. adj. Negro. 2. n. Pássaro sengê.

seni ['seni] $n$. Cherne.

sensu ['sẽsu] $n$. Incenso.

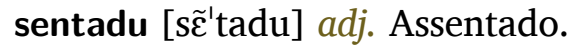

senti ũa ['sẽti 'ũa] num. Cento e um.

sentu ['sẽtu] 1. num. Cem. 2. num. Cento.

sepelin [seps'lin] n. Guarda-chuva.

sêputa [sepu'ta] v. Sepultar.

sera $\left[s \varepsilon^{\prime} r a\right] \nu$. Cheirar.

sera ['scra] $n$. Serra.

seradô [scra'do] adj. Serrador.

seru ['scru] $n$. Cheiro.

sêsa ['sesa] $n$. Pássaro sêsa.

sêsenta [se'sẽta] num. Sessenta.

setenta [se'tẽ̃ta] num. Setenta.

seti ['sct]i] num. Sete.

setu ['setu] $a d v$. Certo.

setxi ['setfi] num. Sete.

setxisentu [sct $\int i$ 'sẽtu] num. Setecentos.

sêvêja [se'veza] $n$. Cerveja.

sêxta-fya ['sefta 'fja] $n$. Sexta-feira.

sêy ['sey] num. Seis.

seya ['scja] n. Saia.

sêysentu [sej'sẽtu] num. Seiscentos.

sêzora [se'zəra] num. Seis horas.

siga [si'ga] v. Chegar.

$\sin$ ['sĩ] $a d v$. Já.

sinifika [sinifi'ka] $v$. Significar.

sintwa [sĩ'twa] $n$. Cintura.

sitwasan [sitwa'sã] $n$. Situação. 
so ['ș] 1. conj. Então. So ôzê ki txi mêsê muda di kaxi a? Então hoje que você mudou de casa? 2. adj. Sozinho.

sobadu [so'badu] adj. Sobrado.

sodadi [so'dadi] $n$. Soldado.

sôfê [so'fe] $v$. Sofrer.

soga ['soga] $n$. Sogra.

sogu ['sogu] n. Sogro.

soka [so'ka] $v$. Laçar.

soka ['soka] n. Sapato.

sôkô ['soko] n. Choque.

sôkô [so'ko] n. Festa religiosa.

sôkô ['soko] n. Soco.

sôkôrô [so'koro] n. Socorro.

sola ['sola] $n$. Sola.

Sôlensu [so'lẽsu] $n$. São Lorenço.

sômba ['sõba] v. Assombrar.

somba ['s̃̃ba] $n$. Sombra.

sômbasya [sõba'sja] $n$. Sobrancelha.

sonha [so'na] $v$. Sonhar.

sônhu ['sonu] $n$. Sonho.

sono [so'no] $\nu$. Desprezar.

sônôsônô [so'no so'ñ] ideo. Cf. Riku sônôsônô.

sônu ['sonu] $n$. Sono.

sôôkô ['so:ko] n. Peixe sôôko.

sôpa ['sopa] n. Sopa.

sôpa [so'pa] v. Soprar.

sosega [sosc'ga] $v$. Sossegar.

sosegadu [səse'gadu] adj. Sossegado.

sota [sJ'ta] v. Soltar.

sotxi ['sot $\left.\int \mathrm{i}\right] n$. Sorte.

sôtxi ['sot]i] $n$. Açoite.

sôvê [so've] $v$. Chover.

sôwô [so'wo] n. Prato local feito de frutas, peixe, vegetais e óleo de palma.

subebu [su'bebu] $n$. Soberbo. 
subi [su'bi] v. Subir.

sudu ['sudu] adj. Surdo.

suga [su'ga] v. Enxugar.

sugadu [su'gadu] $n$. Seco.

suka ['suka] $n$. Açúcar.

suku ['suku] n. Suco.

suku [su'ku] v. Descer.

sulu ['sulu] $n$. Sul.

sumana [su'mana] $n$. Semana.

sume $\left[\mathrm{su}^{\prime} \mathrm{m} \varepsilon\right] n$. Senhor.

sumi ['sumi] n. Ciúme.

sumi [su'mi] $v$. Sumir.

sumidô [sumi'do] $n$. Sumidouro.

sumu ['sumu] n. Suco.

sun ['sũ] $n$. Senhor.

sunu ['sunu] $n$. Sono.

supa [su'pa] v. Chupar.

supada [su'pada] $n$. Espada.

supê [su'pe] $n$. Espelho.

supetu [su'petu] adj. Esperto.

supiga [su'piga] $n$. Espiga.

supitu [su'pitu] n. Espírito.

suplikasan [suplika'sã] $n$. Explicação.

supya [su'pja] v. Assobiar.

suva ['suva] $n$. Chuva.

suvê [su've] $v$. Chover.

suxtu ['suftu] 1. n. Susto. 2. v. Sujar.

suza $\left[\right.$ su'za] $^{\prime}$. Sujar.

suzadu [su'zadu] adj. Sujo.

suzu ['suzu] adj. Sujo.

swa ['swa] 1. v. Assoar. 2. n. História. 3. v. Suar.

swaa ['swa:] v. Transpirar. 
ta ['ta] $v_{\text {. Estar. }}$

taada ['ta:da] adj. Talhada.

taafa ['ta:fa] $n$. Tarrafa.

taan ['tã:] v. Tomar.

taanha ['ta:ja] $n$. Peixe tainha.

taaxi [ta:'Si] adv. Atrás. Taaxi upa. Atrás da árvore.

tabaladô [tabala'do] $n$. Trabalhador.

tabwe [ta'bwe] n. Trabalho.

tada [ta'da] $v$. Tardar.

tadi ['tadi] adv. Tarde.

taka [ta'ka] v. Atacar.

taki ['taki] $n$. Ataque.

tali ['tali] $a d v$. Tal.

talvêzê [tal'veze] $a d v$. Talvez.

tama [ta'ma] $v$. Fumar.

tama ['tama] $v$. Pegar.

tama patxi [ta'ma 'patfi] $v$. Participar.

tambô [tã'bo] $n$. Tambor.

tamwin [ta'mwĩ] 1. n. Tamanho. 2. adj. Velho.

tamyan [ta'mjã] $n$. Tigela.

tanga ['tãga] $n$. Tanga.

tantan [tã'tã] ideo. Cf. Usolu tantan.

tanu [ta'nu] $v$. Desamarrar.

tanzê [tã'ze] 1. v. Chamar. 2. v. Tanger.

tapa [ta'pa] v. Tampar.

tapesa [tape'sa] $v$. Tropeçar.

tapese [ta'pese] $n$. Banquinho.

tusondu [tu'sondu] adj. Sentado.

tata [ta'ta] $v$. Tratar.

tatadu [ta'tadu] adj. Tratado.

tatata [tata'ta] ideo. Cf. Têmê tatata. 
tava ['tava] $v$. Estava. $\mathbf{N}$ tava sa dimi. Eu estava dormindo.

têvêsa [teve'sa] $v$. Atravessar.

taxi ['ta]i] prep. Atrás. Ubanku taxi moto. Banco de trás da moto.

taxin [ta' $\left.\int \tilde{1}\right] n$. Tacho pequeno.

taya ['taja] $n$. Telha.

tazadu [ta'zadu] adj. Atrasado.

tê ['te] $a d v$. Até.

te $[$ 't $\varepsilon$ ] 1. $v$. Ter. $\mathbf{N}$ te livu livu. Tenho muitos livros. 2. $n$. Terra.

tê ['te] 1. poss. Teu. 2. poss. Tua.

teela ['te:la] $n$. Estrela.

teempi ['t $\varepsilon: p i] n$. Panela de ferro.

teeta ['te:ta] $n$. Testa. M:2009:237.

têêxi ['teefi] num. Treze.

tega $\left[\mathrm{t} \varepsilon^{\prime} g a\right] v$. Entregar.

telefoni [tعl $\varepsilon^{\prime}$ foni] $n$. Telefone.

telele $\left[t \varepsilon l \varepsilon^{\prime} l \varepsilon\right] n$. Cachoeira pequena.

têlêvizan [televi'zã] $n$. Televisão.

tema [tz'ma] $v$. Teimar.

têmadu [tz'madu] adj. Teimoso.

tempa ['tẽpa] 1. $n$. Ingrediente. 2. $n$. Pimenta bolinha.

tempa [tẽ'pa] $v$. Temperar.

tempa ['tẽpa] $n$. Tempero.

tempu ['tẽpu] $n$. Tempo.

têmê [te'me] $v$. Tremer.

têmê gidigidi [te'me gidigi'di] idiom. Tremer muito.

têmê tatata [te'me tata'ta] idiom. Tirintar.

ten ['tẽ] $a d v$. Até. Maxi tendê ko nho fa ten wo sê. Mas eu não entendi nada até agora.

tendê [tẽ'de] $v$. Entender.

tenta [tẽ'ta] $v$. Tentar.

tesa fya ['tesa 'fja] $n$. Terça-feira.

têsê [te'se] $v$. Tecer.

têsêru [te'seru] num. Terceiro.

têstêmunha [teste'muja] $n$. Testemunha. 
teta ['teta] n. Mamilo.

tetu ['tetu] n. Teto.

têtuuga [te'tu:ga] $n$. Tartaruga.

tevesa [teve'sa] $v$. Atravessar.

têxi ['te $\mathrm{i}]$ num. Três.

têxora ['te'ऽra] num. Três horas.

tezadu [te'zadu] adj. Esticado.

ti ['ti] pro. Você.

tia ['tia] n. Tia.

tigu ['tigu] $n$. Trigo.

timi ['timi] n. Equipe.

tinha ['tina] $v$. Ter.

tinji $\left[\mathrm{t} \int \tilde{1}^{\prime} z^{1}\right] \nu$. Ficar roxo.

tinta ['tĩta] $n$. Tinta.

tintêw [tĩ'tew] $n$. Tinteiro.

tipu ['tipu] $n$. Tipo.

tiru ['tiru] n. Tiro.

tisa [ti'sa] v. Atiçar.

tiisa ['ti:sa] $n$. Hepatite.

tisêru [ti'seru] $n$. Terceiro.

tisidu [ti'sidu] $n$. Tecido.

to ['to] $v$. Escolher.

tô ['to] $n$. Torre.

tobya [to'bja] $v$. Trabalhar.

toka [to'ka] $v$. Tocar.

toka ganiga [to'ka gani'ga] idiom. Local onde aparece hérnias.

tokito [toki'to] onom.

tolo [to'lo] $v$. Dividir.

tomba [tõ'ba] $v$. Tombar.

tombeta [tõ'beta] $n$. Trombeta.

tomenta [tomẽ'ta] $v$. Atrapalhar.

tomentu [to'mẽtu] $n$. Tormento.

ton ['tõ] ideo. Cf. Tezadu ton. 
tôni [to'ni] n. Pássaro tôni.

tonitoni [tว̃'ni tว̃'ni] $n$. Espinha.

tônôzê d'ope [tono'ze do'pe] $n$. Tornozelo.

too ['to:] v. Gotejar.

tôôtô ['to:to] adj. Torto.

tôsan [to'sã] $n$. Tostão.

tôsê [to'se] $v$. Torcer.

tosi [to'si] v. Tossir.

toto ['tot’] n. Pênis.

totolo [totว'lo] ideo. Cf. Kitxi tololo.

totwa [to'twa] 1. v. Dobrar. 2. v. Entornar.

tôtwadu [to'twadu] adj. Torto.

tôvada [to'vada] $n$. Trovão.

toxa ['tofa] 1. $n$. Candeia. 2. $n$. Tocha.

toxi ['tofi] $n$. Tossir.

tôxê [to' $\mathrm{e}] \mathrm{v}$. Torcer.

toya ['toja] $n$. Toalha.

trezentu [tre'zẽctu] num. Trezentos.

trinta ['trĩta] num. Trinta.

tu ['tu] $v$. Descascar.

tuban [tu'bã] $n$. Tubarão.

tudu ['tudu] 1. quant. Todo. 2. quant. Tudo.

tudu pe ['tudu 'pe] quant. Tudo.

tungu [tũ'gu] $v$. Mancar.

tonera [to'nera] $n$. Torneira.

tusan [tu'sã] 1. v. Descansar. 2. v. Sentar.

tuvada [tu'vada] $1 . n$. Tempestade. 2. $n$. Trovoada.

tuvada-mangi [tu'vada 'mãgi] $n$. Mau tempo.

tuzwa [tu'zwa] $n$. Tesoura.

twa ['twa] adj. Azedo.

twatwa ['twa'twa] $n$. Malagueta toatoa.

txeketxeke $\left[\mathrm{t} \int \varepsilon^{\prime} \mathrm{k} \varepsilon \mathrm{t} \int \varepsilon^{\prime} \mathrm{k} \varepsilon\right]$ adj. Estreito.

txi $\left[{ }^{\prime} \mathrm{t} \mathrm{j} \mathrm{i}\right]$ 1. pro. Te. 2. pro. Ti. 3. n. Tio. 4. pro. Tu. 
txia ['t $\left.\int \mathrm{ia}\right] n$. Tia.

txibika [t]ibi'ka] ideo. Cf. Umwen xyadu txibika.

txilêlê [t]ile'le] adj. Atordoado.

tximatxi [t]i'mat $\left.\int i\right] n$. Tomate.

tximbi ['t $\mathrm{t} \tilde{\mathrm{b}} \mathrm{bi}]$ 1. $n$. Ódio. 2. $n$. Rancor.

txinta ['t $\mathrm{t}$ îta] $n$. Tinta.

txintêw [t $\int 1^{1}$ tew $n$. Tinteiro.

txiu ['t $f i u] n$. Tio.

txiipa ['t $\left.\int i: p a\right] n$. Tripa.

txitxo [t $\left.\int \mathrm{i}^{\prime} \mathrm{t} \int \mathrm{\jmath}\right] a d v$. Cedo.

txokolo [t〕jko'lo] adj. Pequeno.

txotxo ['t $\left.\int \jmath^{\prime} \mathrm{t} \int \mathrm{\jmath}\right] n$. Pássaro txotxo.

txubun [t $\int u^{\prime}$ bũ] onom. Ê kyê awa txubun. Ele caiu na água.

txya ['t $\mathrm{tjja} v$. Tirar.

txya bweba ['t $\int j a$ 'bweba] idiom. Barbear.

txyadô [t $\left.\int j a ' d o\right] ~ n$. Tirador.

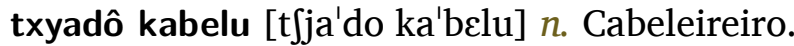

txyan [t]jã] $a d v$. Além.

txyatu ['t $\left.\int j a t u\right] n$. Teatro.

txyô ['tfjo] 1. n. Quintal. 2. n. Terreno. 3. v. Tirar.

txyonsu ['t $\left.\int j \tilde{s} s u\right] n$. Pássaro txyonsu. 
ũa ['ũa] art. Um. Zwan kopa livu ũa. João comprou um livro.

uanga [uã'ga] $v$. Espalhar.

uari [u'ari] n. Ar.

ũaũa ['ũa'ũa] $a d v$. Algum.

ubaaku [u'ba:ku] 1. n. Buraco. 2. n. Cova.

ubaaku rixi [u'ba:ku 'rifi] $n$. Narina.

ubadu [u'badu] $n$. Barril cortado ao meio.

ubaasu [uba:'su] $n$. Braço.

ubanku [u'bãku] $n$. Banco.

ubasu [u'basu] 1. n. Abraço. 2. n. Baço. 3. prep. Embaixo.

ubasu ôtô [u'basu 'oto] 1. n. Garganta. 2. n. Pescoço.

ubaaw [u'ba:w] $n$. Barro.

uben [u'bẽ] $n$. Bem. Ê gogo di fêzê uben fa. Ele não gosta de fazer o bem.

ubiku [u'biku] $n$. Bico.

ubôlu [u'bolu] $n$. Bolo.

ububu [ubu'bu] $n$. Luto.

ubudu [u'budu] $n$. Pedra.

ubuka [u'buka] $n$. Boca.

ubwê [u'bwe] $n$. Boi.

ubya [u'bja] $n$. Feitiço.

ubyadô [u'bjado] adj. Enfeitiçado.

udedu [u'dedu] $n$. Dedo.

udentu [u'dẽtu] $n$. Dentro. Udentu rôdôma. Dentro da garrafa.

udôdô [u'dodo] adj. Doido.

udumu [udu'mu] $n$. Mão de pilão.

udyabu [u'djabu] $n$. Diabo.

ufaka [u'faka] n. Faca.

ufatu [u'fatu] n. Fato (roupa).

ufew $\left[\mathrm{u}^{\prime} \mathrm{f} \varepsilon \mathrm{w}\right] n$. Ferro.

ufin kumin [u'fi ku'mĩ] $a d v$. Final.

ufisu [u'fisu] $n$. Ofício. 
ufôgu [u'fogu] $n$. Fogo.

ufu [u'fu] $n$. Espuma.

ufunda [u'fũda] $n$. Pacote.

ufundi [ufũ'di] $n$. Prato local a base de mandioca.

ufundu [u'fũdu] adj. Fundo.

ufungunu [ufũgu'nu] $n$. Hérnia.

ufya [u'fja] $n$. Folha.

ufôgu [u'fogu] n. Fogo.

uga ['uga] $n$. Rua.

ugafu [u'gafu] n. Garfo.

ugagu [u'gagu] adj. Gago.

ugalu [u'galu] n. Galo.

ugani [u'gani] $a d v$. À parte.

ugatu [u'gatu] n. Gato.

ugba [u'gba] 1. n. Andim. 2. n. Mondim.

ugba pôkô ['ugba 'poko] $n$. Chiqueiro.

ugbaga [ugba'ga] $n$. Panela de barro.

ugbami [ugba'mi] n. Queixo.

ugbôgôdô [ugbogo'do] 1. n. Grota. 2. n. Vale.

uguya [u'guja] $n$. Agulha.

ugwe $\left[u^{\prime} g w \varepsilon\right]$ 1. n. Quarto. 2. $n$. Sala de visita.

uka [u'ka] 1. n. Árvore enorme. 2. n. Feiticeiro.

ukabu [u'kabu] n. Cabo.

ukalu [u'kalu] $n$. Caldo.

ukampu [u'kãpu] n. Campo.

ukantu [u'kãtu] $n$. Canto.

ukau [u'kau] n. Carro.

ukopu [u'kopu] n. Copo.

ukpa [u'kpa] 1. n. Folhas secas. 2. n. Lampião.

ukpaka [ukpa'ka] 1. n. Casca. 2. n. Concha. 3. n. Escamas. 4. $n$. Pele.

ukpaku [u'kaku] $n$. Casco de tartaruga.

ukpaku [u'kpaku] $n$. Escova de dentes tradicional.

ukpami [ukpa'mi] $n$. Defumador. 
ukpan [u'kpã] n. Marmita.

ukpan-kabese [u'kpã ka'bese] n. Crânio.

ukperi [ukpe'ri] n. Cesta.

uku [u'ku] n. Ânus.

ukugba [uku'gba] $n$. Cinta para mulher.

ukundu [ukũ'du] 1. n. Erva medicinal. 2. $n$. Pêlo.

ukuru [uku'ru] $n$. Cru.

ukuru [u'kuru] n. Escuro.

ukutu [u'kutu] n. Pedaço.

ukwatu [u'kwatu] n. Quarto.

ukyebu [u'kjebu] n. Quiabo.

uladu [u'ladu] $n$. Lado.

ulalu [u'lalu] $n$. Doença de pele.

ulasu [u'lasu] n. Laço.

ulatu [u'latu] n. Caminho.

ulensu [u'lẽsu] $n$. Lenço.

uman [u'mã] $n$. Mão.

umatu [u'matu] n. Mato.

umayu [u'maju] $n$. Vara.

umundu [u'mũdu] $n$. Mundo.

umunha [u'muna] $n$. Unha.

umwe $\left[u^{\prime} \mathrm{mw}\right]$ n. Mar.

unfenu [ũ'fenu] $n$. Inferno.

umpan [ũpã] $n$. Pão.

untuen [un'tuẽ] $n$. Fruto silvestre.

unu [u'nu] $n . \mathrm{Nu}$.

unwa [u'nwa] n. Lua.

unôtxi [u'not $\left.\int i\right] n$. Noite.

unvuluku [ũvu'luku] 1. n. Ataque. 2. $n$. Rebuliço. verbupa[u'pa]n.Pau.

upa-bana [u'pa ba'na] $n$. Bananeira.

upane [upa'ne] $n$. Nuvem de chuva.

upanu [u'panu] n. Pano.

upe $\left[\mathrm{u}^{\prime} \mathrm{p} \varepsilon\right] n$. Pé. 
upuru [upu'ru] interj.

upusu-uman [u'pusu u'mã] $n$. Pulso.

upêtu [u'petu] n. Peito.

urabu [u'rabu] n. Rabo.

uramu [u'ramu] $n$. Ramo.

uratu [u'ratu] n. Rato.

uremu [u'remu] $n$. Remo.

uriw [u'riw] n. Rio.

urôpa [u'ropa] $n$. Roupa.

urosu [u'rosu] $n$. Arroz.

uruba $\left[u^{\prime}\right.$ ruba] 1. $v$. Ferver. 2. $n$. Furúnculo.

urumu [u'rumu] $n$. Safu.

ururu [u'ruru] $n$. Cordão umbilical.

urya [u'rja] $n$. Orelha.

usaku [u'saku] 1. n. Bolsa. 2. n. Saco.

usalu [u'salu] $n$. Sal.

usaan [u'sã:] $n$. Sobras.

usan [u'sã] $n$. Chão.

usolu [u'solu] $n$. Sol.

usuda [usu'da] 1. n. Pimenta. 2. n. Pimenta selvagem.

usuda-malaka [usu'da ma'laka] 1. $n$. Malagueta. 2. $n$. Pimenta importada.

usuva [u'suva] $n$. Chuva.

utabu [u'tabu] $n$. Tábua.

utasu [u'tasu] $n$. Tacho.

utximu ['utximu] $n$. Último.

utêru ['uteru] $n$. Útero.

uu $\left[u^{\prime} u\right] n$. Linha.

uventu [u'vẽtu] $n$. Vento.

uvôdô [u'vodo] n. Festa.

uvungu [u'vũgu] $n$. Dança.

uwê ['we] n. Olho.

uzulu [u'zulu] adj. Azul. 
va ['va] $n$. Chicote.

vaa ['va:] 1. v. Cortar. 2. v. Passar.

vaan ['vã:] adj. Varão.

vaanda ['vã:da] $n$. Varanda.

vabu [va'bu] interj. $\hat{\mathbf{E}}$ tama vabu. Ele pegou de repente.

vedadêw [veda'dew] adj. Verdadeiro.

vadiw [va'diw] adj. Vadio.

valô [va'lo] $n$. Valor.

valê [va'le] $v$. Ajudar.

vampwe [vã'pwe] adj. Enorme.

vamu ['vamu] v. Vamos. Bamu ôbôgôdô Ie paxya kêtê. Vamos à ilha do Príncipe passear um pouco.

vangana [vãga'na] v. Cambalear.

vani [va'ni] $v$. Sacudir.

vansa [vã'sa] v. Avançar.

vantagi [vã'tagi] $n$. Vantagem.

vapô [va'po] 1. n. Navio. 2. $n$. Vapor.

varentu [va'rẽtu] adj. Avarento.

varya [va'rja] $n$. Avaria.

ve ['ve] adj. Velho.

vê ['ve] 1. v. Ver. 2. $a d v$. Vez.

vedadi [vع'dadi] adj. Verdade.

vêdê ['vede] adj. Verde.

vela ['vela] $n$. Vela.

vêmê [ve'me] adj. Vermelho.

vêmê bababa [ve'me baba'ba] idiom. Vermelhíssimo.

vendê [vẽ'de] $v$. Vender.

vendêdô [vẽde'do] adj. Vendedor.

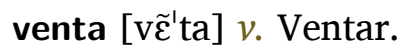

ventenha [vẽt $\varepsilon^{\prime}$ ja] $n$. Ventania.

ventu ['vẽtu] $n$. Vento.

ventenha [vẽ'tena] $n$. Gravana. 
ventuyan [vẽ'tujã] $n$. Ventilador.

venenu [ve'nenu] $n$. Veneno.

vêsê ['vese] $a d v$. Vez.

vêvê [ve've] $v$. Viver.

vêyaku ['vejaku] adj. Malandro.

viantêw [viã'tew] $n$. Vinhateiro.

vida ['vida] $n$. Vida.

vidu ['vidu] $n$. Vidro.

vijan [vi'zã] $n$. Vizinha.

viji ['vizi] $n$. Virgem.

vijin [vi' $3 \tilde{1}] n$. Vizinho.

vijita [vi'zita] $n$. Visita.

vijya [vi'zja] v. Vigiar.

vijyamentu [vizja'mẽtu] $n$. Festa de oitavo dia de nascimento.

vika [vi'ka] v. Aproximar-se.

vin ['vĩ] $n$. Vinho.

vinagi [vi'nagi] $n$. Vinagre.

vindô [vĩ'do] 1. $n$. Estrangeiro. 2. $n$. Imigrante.

vinhu ['viju] $n$. Vinho.

vinten [vĩ'tẽ] $n$. Vintém.

vintxi ['vĩt]i] num. Vinte.

vintxi ũa [vĩtfi' ũa] num. Vinte e um.

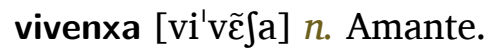

vivu ['vivu] adj. Vivo. Cf. Vêvê.

vivê [vi've] $v$. Viver.

viza [vi'za] $v_{\text {. Avisar. }}$

vizanda [vi'zãda] $a d v$. Desta vez

vizita [vizi'ta] v. Visitar. Cf. Uvôdô.

vôdô ['vodo] n. Festa.

voga $\left[\mathrm{v} \jmath^{\prime}\right.$ ga] $v$. Significar.

vôgyan [vo'gjã] $n$. Vergonha.

vôlô [vo'lo] v. Insultar.

vômita [vomi'ta] $v$. Vomitar. 
vontadi [võ'tadi] $n$. Vontade.

vota [v'ta] $v$. Volta.

voota [vo:'ta] $v$. Voltar.

vovo [vว'vo] $v_{\text {. Derramar. }}$

vovu ['vovu] $n$. Coração.

vozu ['vozu] $n$. Voz.

vuguvugu ['vugu'vugu] $n$. Pedaço de madeira usado para pegar frutas.

vulantxi [vu'lãtfi] $n$. Volante.

vunga ['vũga] $n$. Balanço. Cf. Uvungu.

vungu ['vũgu] $n$. Canção.

vunvu [vũ'vu] $n$. Abelha.

vutu ['vutu] $n$. Vulto.

vwa ['vwa] $v$. Voar.

vwadô [vwa'do] adj. Peixe voador.

vwê ['vwe] $v$. Varrer.

vya ['vja] 1. $v$. Fazer de novo. 2. $v$. Virar. 3. $v$. Voltar.

vyaji ['vjazi] $n$. Viagem.

vyantêw [vjã'tew] $n$. Vinhateiro.

vya we ['vja 'we] idiom. Virar.

vyola ['vjəla] $n$. Viola.

vyolan [vjə'lã] $n$. Violão.

vyuva ['vjuva] $n$. Viúva.

vyôlinu [vjo'linu] $n$. Violino.

vyuvu ['vjuvu] $n$. Viúvo. 
wada ['wada] $v$. Esperar.

wanga [wã'ga] v. Espalhar.

we $\left[{ }^{\prime} \mathrm{w} \varepsilon\right] \nu_{\text {. Ir. }}$

wê ['we] $n$. Olho.

wêtenta [we'tẽta] num. Oitenta.

wêtu ['wetu] num. Oito.

wêtusentu ['wetu'sẽtu] num. Oitocentos.

wetxi ['wet]i] $n$. Oeste.

winiwini [wi'niwi'ni] 1. ideo. Cf. Kêba winiwini. 2. ideo. Cf. Kêtêkêtê.

wo ['wว] $a d v$. Agora.

wô ['wo] $v$. Crescer.

wodu ['wodu] adj. Maduro.

wo sê ['wo 'se] $a d v$. Agora.

wowo ['wo'wว] $v$. Chuviscar. 
xa [']a] adj. Cheio.

xadu ['Jadu] adj. Cheio.

xarutu [Ja'rutu] $n$. Charuto.

xatyadu [Ja'tjadu] 1. adj. Aborrecido. 2. adj. Chateado.

xê ['Se] $v$. Ir.

xefi [']cfi] $n$. Chefe.

xeli ['SEli] $n$. Chale.

xerere $\left[\int \varepsilon r \varepsilon^{\prime} r \varepsilon\right] n$. Cupim.

xêrni ['Serni] $n$. Cherne.

xêru ['Seru] n. Cheiro.

xi ['Ji] 1. conj. Se. 2. prep. Sem. Ôzê umwe sa susêgadu xi zonda. Hoje o mar está calmo e sem onda. xiba ['Siba] n. Lula.

xibi [ $\left[\mathrm{j}^{\prime} b i\right] n$. Pássaro $x i b i$.

xidentxi [ $\left[\mathrm{i}^{\prime} \operatorname{dẽt} \int \mathrm{i}\right] n$. Acidente.

xifi ['Jifi] $n$. Chifre.

xiga [ $\left.{ }^{\prime} i^{\prime} g a\right] v$. Chegar.

xigaru [ji'garu] $n$. Cigarro.

xigi [Si'gi] $v$. Seguir.

xikindi [ji'kĩdi] 1. n. Apreensão. 2. adj. Repugnância.

xikitori []iki'tori] $n$. Escritório.

xikôlati [jiko'lati] $n$. Chocolote.

xikotxi [ $\left.\int^{\prime}{ }^{\prime} k \jmath t \int i\right] n$. Chicote.

xila [Si'la] dem. Aquele. Livu xila karu muntu. Aquele livro é muito caro.

xilorya [ji'lorja] $n$. Ceroulas.

xima ['Sima] 1. $a d v$. Cima. Jaru kyê xima meze ê keba. A jarra caiu de cima da mesa e quebrou. 2. adv. Em cima.

ximentxi [كi'mẽt $\left.\int i\right]$ 1. $n$. Muito. Ximentxi kwa na meze pa no da li ukabu. Muita coisa na mesa para nós acabarmos. 2. $n$. Semente.

ximi ['Simi] $n$. Um inseto.

ximitew $\left[\int \mathrm{imi} i^{\prime} \mathrm{t} \varepsilon \mathrm{w}\right] n$. Cemitério.

ximya $\left[\int i ' m j a\right] \nu$. Semear.

$\operatorname{xin}\left[' \int \tilde{1}\right] \nu$. Expremer. 
xina $\left[\mathrm{ji}^{\prime}\right.$ na] $n$. Aprender.

xinali $\left[\int i\right.$ 'nali $] n$. Sinal.

xinela [ji'ncla] $n$. Chinelo.

xinku ['Jîku] num. Cinco.

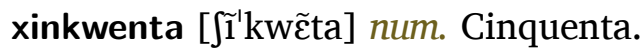

xinora [ $\left[i^{\prime}\right.$ nora $n$. Cenoura.

xinta kadya ['xĩta ka'dja] $n$. Cinta.

xintu [' $\left.\int \tilde{t} t u\right] n$. Cinto.

xintxi $\left[\int \tilde{1}^{1} t \int \mathrm{i}\right] \nu$. Sentir.

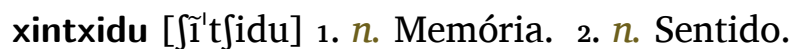

xintxinela [ [ٓît $\left.\int i^{\prime} n \varepsilon l a\right] n$. Sentinela.

xinu ['Sinu] $n$. Sino.

xinxan [ $\left.\tilde{1}^{\prime} \int \tilde{a}\right] a d v$. Rápido.

xinzêw $\left[\int \tilde{I}^{1} z e w\right] n$. Cinzeiro.

xipiga $\left[\int \mathrm{ji}^{\prime}\right.$ piga $n$. Espiga.

xipitali [Sipi'tali] $n$. Hospital.

xisti [ $\left.\int \mathrm{is}^{\prime} \mathrm{t} \int \mathrm{i}\right] \mathrm{v}$. Assistir.

xitamagu [ ${ }^{\prime} i^{\prime}$ tamagu] $n$. Estômago.

xitikadu [Siti'kadu] adj. Esticado.

xitu ['Situ] $n$. Sítio.

xitwasan [ [itwa'sã] $n$. Situação.

xivi [ [i'vi] $\nu$. Servir.

xividô [Sivi'do] $n$. Trabalhador.

xivisali []ivi'sali] $n$. Serviçal.

xivisu [ [i'visu] $n$. Serviço.

xixi $\left[\int i^{\prime} \int \mathrm{i}\right] \nu$. Urinar.

xizê ['Size] $n$. Cinza.

xkada ['Skada] $n$. Escada.

xkapa ['Skapa] v. Escapar.

xkeda ['Jkeda] $n$. Esquerda.

xkola ['Jksla] $n$. Escola.

xkravidan [Skravi'dã] $n$. Escravidão.

xkêvê [Ske've] $v$. 
xoferi [ $\int^{\prime}$ feri] $n$. Motorista.

xpitali $\left[\int p i '\right.$ tali $] n$. Hospital.

xpêransa [Jpe'rãsa] $n$. Esperança.

xtangêw [ [tã'gew] $n$. Estrangeiro.

xtrinki ['Strîki] ideo. Cf. Novu xtrinki.

xtuda $\left[\int t u^{\prime} d a\right] v$. Estudar.

xya ['Jja] 1. $a d v$. Além. 2. adj. Cheio. 3. v. Inchar.

xyadu ['Sjadu] adj. Cheio.

xyê ['Sje] $v$. Sair.

xyê mi ['Sje 'mi] idiom. Sumir.

xyota [']j’ta] $n$. Sótão. 
yeta ['jeta] 1. $n$. Canto. 2. $n$. Espaço entre objetos.

yêlê [je'le] interj.

yew $[$ 'jew] $n$. Ilheu.

yogo [jJ'gว] 1. v. Curar-se. 2. v. Melhorar.

yôlô [jo'lo] 1. $v$. Despir. 2. $v$. Tirar.

yoyo [j’'js] n. Habitantes de São Tomé. 


\section{$\mathbf{Z}$}

za ['za] adv. Já. N xiga za. Eu já cheguei.

zagwa [za'gwa] $n$. Azagoa (prato local).

zalima ['zalima] $n$. Alma.

zanta [zã'ta] v. Jantar.

zantêw [zã'tew] n. Fresco.

zanêw [za'new] $n$. Janeiro.

zapasê [zapa'se] $v$. Desaparecer.

zê ['ze] 1. v. Apanhar porção. 2. v. Buscar (água).

zeda $\left[z \varepsilon^{\prime}\right.$ da] $v$. Azedar.

zedu ['zedu] adj. Azedo.

zeeta [ze:'ta] v. Rejeitar.

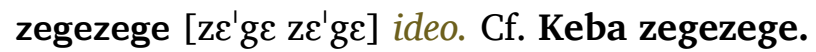

zeme $\left[\mathrm{z} \varepsilon^{\prime} \mathrm{m} \varepsilon\right]$ v. Gemer.

zentxi ['zẽtsi] $n$. Gente. Cf. Jentxi.

zêtu [zetu] n. Jeito.

zêtôna [ze'tona] n. Azeitona.

zôga [zo'ga] v. Jogar.

zôgu ['zogu] n. Jogo.

zona ['zona] $n$. Zona.

zonda ['zõda] $n$. Onda.

zoxi ['zoSi] $a d v$. Sempre.

zubyan [zu'bjã] $n$. Bolso.

zuda [zu'da] v. Ajudar.

zudê [zu'de] $n$. Judeu.

zuga [zu'ga] $v$. Jogar.

zujya [zu'zja] v. Caçoar.

zujyan [zu'zjã] 1. $n$. Varanda. 2. $n$. Fofoca.

zulu ['zulu] $n$. Azul.

zunta [zũ'ta] $v$. Juntar.

zuntu ['zũtu] 1. $a d v$. 2. n. Cotovelo.

zuzu [zu'zu] $n$. Jejum.

zuzuzu [zuzu'zu] ideo. Cf. Kintxi zuzuzu.

zwa ['zwa] v. Jurar.

zwixi ['zwi $[$ i] $n$. Juíz. 